NBER WORKING PAPER SERIES

\title{
RACIAL BIAS AND IN-GROUP BIAS IN JUDICIAL DECISIONS: EVIDENCE FROM VIRTUAL REALITY COURTROOMS
}

\author{
Samantha Bielen \\ Wim Marneffe \\ Naci H. Mocan \\ Working Paper 25355 \\ http://www.nber.org/papers/w25355 \\ NATIONAL BUREAU OF ECONOMIC RESEARCH \\ 1050 Massachusetts Avenue \\ Cambridge, MA 02138 \\ December 2018, Revised May 2019
}

We thank Christine Jolls, Ozkan Eren, Shawn Kantor, Carl Kitchens, Marc Isaac, Bulent Unel, Stefan Voigt, Barton Willage, Richard Boylan and participants of seminars at the University of Iowa, Florida State University, the European Law and Economics Association Meetings in Milan, Italy, and the Economic Consequences of Legal Development Workshop at UCLouvain for helpful comments. Funding from the Faculty of Business Economics of Hasselt University is gratefully acknowledged. We thank Johan Ackaert and Sofie Hennau for allowing us to engage their law students in the study, and to the Office of the District Attorney of Limburg, Belgium and in particular the District Attorney, Guido Vermeiren for sharing their expertise and for allowing us to use their main courtroom. We also thank prosecutors Bruno Coppin and Pieter Strauven, and attorneys Sophia Lycops, Tom Van Overbeke and Mieke Denissen for participating in the trials. We are grateful to Jeff Luyten and Michel Séquaris from Uncanny Virtual Experiences for making this project possible by providing technical support in creating the VR videos and to Sem Metten for creating the website that communicated with the VR videos and that enabled the participants to register their decisions. Bielen acknowledges financial support from Research Foundation Flanders, grant number 12S3117N. The views expressed herein are those of the authors and do not necessarily reflect the views of the National Bureau of Economic Research.

NBER working papers are circulated for discussion and comment purposes. They have not been peer-reviewed or been subject to the review by the NBER Board of Directors that accompanies official NBER publications.

(C) 2018 by Samantha Bielen, Wim Marneffe, and Naci H. Mocan. All rights reserved. Short sections of text, not to exceed two paragraphs, may be quoted without explicit permission provided that full credit, including $(\odot$ notice, is given to the source. 
Racial Bias and In-group Bias in Judicial Decisions: Evidence from Virtual Reality Courtrooms Samantha Bielen, Wim Marneffe, and Naci H. Mocan

NBER Working Paper No. 25355

December 2018, Revised May 2019

JEL No. K4,Z1

\section{ABSTRACT}

We shot videos of criminal trials using 3D Virtual Reality (VR) technology, prosecuted by actual prosecutors and defended by actual defense attorneys in an actual courtroom. This is the first paper that utilizes VR technology in a non-computer animated setting, which allows us to replace white defendants in the courtroom with individuals who have Middle Eastern or North African descent in a real-life environment. We alter only the race of the defendants in these trials, holding all activity in the courtroom constant, creating arguably perfect counterfactuals (http:// proficient.ninja/splitscreen/). Law students, economics students, practicing lawyers and judges are randomly assigned to watch with VR headsets, the trials that differed only in defendants' race. Background information obtained from the evaluators allowed us to identify their cultural heritage. Evaluators made decisions on guilt/innocence in these burglary and assault cases, as well as prison sentence length and fine in accordance with the guidelines provided by the relevant law. There is evidence that evaluators are harsher towards defendants of their own race during the guilt-innocence decision. In the sentencing phase, we find in-group bias in the opposite direction: evaluators are more lenient towards defendants of their own race. This is the first paper that identifies such opposing effects of bias within the same decision sequence. Regarding overall racial bias, we document that minorities are more likely to get convicted, and that they are given stiffer punishment, conditional on conviction. We find only scant evidence that the concerns of the evaluators about terrorism, about immigration, or their trust in the judiciary or the police have an impact on their judicial decisions, suggesting that the source of the bias may be deep-rooted. Merging a small sample of judges and prosecutors with the sample of lawyers provides results that are very similar to those obtained from the analysis of lawyers.

Samantha Bielen

Hasselt University

Agoralaan 30, Building D

3590 Diepenbeek, Belgium

samantha.bielen@uhasselt.be

Wim Marneffe

Hasselt University

Agoralaan 30, Building D

3590 Diepenbeek, Belgium

wim.marneffe@uhasselt.be
Naci H. Mocan

Department of Economics

Louisiana State University

2439 BEC

Baton Rouge, LA 70803-6306

and NBER

mocan@1su.edu 


\section{Racial Bias and In-group Bias in Judicial Decisions:}

Evidence from Virtual Reality Courtrooms

\section{$\underline{\text { I. Introduction }}$}

The investigation of racial bias in decision-making is important for both scientific inquiry and for public policy. A particularly important decision is the judgment passed on others with consequential outcomes. For example, although judicial decisions are expected to be made blindly, whether such impartiality exists in practice has long been debated, and a great deal of research has focused on the investigation of whether conviction, sentencing and clemency decisions made by judges, juries or state governors are biased against minorities (Alesina and La Ferrara 2014, Rehavi and Starr 2014, Abrams, Bertrand and Mullainathan 2012, Argys and Mocan 2004, Glaeser and Sacerdote 2003, Mustard 2001). These findings are important because judicial decisions are made with deliberation, as opposed to quickly, and they are high-stakes decisions with serious consequences.

A related, and more nuanced line of research has recently emerged to investigate the existence of in-group bias (decision-maker's preferential treatment of the members of his/her own group). Anwar, Bayer and Hjalmarsson (2012) analyzed the impact of racial composition of juries in Florida, and found that all-white juries are more likely to convict black defendants. Shayo and Zussman (2011) analyzed data from Israeli small claims courts and reported that a claim was more likely to be accepted by the judge if he/she is of the same ethnicity as the plaintiff, and that this effect was strongly associated with terrorism intensity in the area surrounding the court during the year preceding the judicial decision. Gazal-Ayal and Sulitzeanu-Kenan (2010) found in-group bias in Jewish and Arab judges’ decisions on criminal cases in Israel. Grossman et al. (2015) reported that Arab defendants received more lenient punishment in the appellate court when the panel of judges included at least one Arab judge. Depew, Eren and Mocan (2017) reported negative in-group bias in judicial decisions in Louisiana juvenile courts. 
Analysis of judicial decisions is complicated by a number of inherent selection problems. Although recent research exploited random assignment of defendants to judges to alleviate some of these problems (Eren and Mocan 2018, Shayo and Zussman 2017, Depew, Eren and Mocan 2017, Abrams, Bertrand and Mullainathan 2012, Shayo and Zussman 2011), random assignment does not resolve all selection issues. Even if the defendants are randomly assigned to judges, there are a number of intervening steps before the defendants appear in front of the judge, and the events during this process may confound the inference obtained from the analysis of judicial decisions. ${ }^{1}$ Similarly, the composition of cases that come in front of a judge can also change because of the strategic behavior of defense attorneys. ${ }^{2}$

The impression of judicial racial bias may also emerge as an artifact of the behavior of the individuals in the courtroom. For example, if prosecutors are more diligent and aggressive towards a certain type of defendants in comparison to others, this differential effort in the courtroom can have a systematic effect on judge decisions. The effort and effectiveness of the defense attorneys may also systematically differ between groups of defendants. For instance, minority defendants may not be able to afford high-quality attorneys if their income and wealth levels are lower, and ineffective defense provided by low quality attorneys will translate into worse outcomes for minorities such as higher conviction probabilities and longer sentences (Anderson and Heaton 2012). Part of the negative outcomes associated with court-assigned

\footnotetext{
${ }^{1}$ For instance, after cases are (randomly) assigned to judges, prosecutors enter the process and they have the discretion to determine the charges levied against the defendants. The attitude of the prosecutor regarding charging a particular defendant more or less aggressively has an impact on the eventual outcome of the case. For example, as described in Boylan (2012), a prosecutor can charge a defendant with possessing a gun when selling drugs in addition to a drug-trafficking offense, while deciding not to file a gun charge for another drug seller. If prosecutors are more lenient towards a group of defendants on the margin, the conviction and sentencing decisions of judges will resemble favoritism towards that group of defendants even if judges themselves are completely unbiased. Furthermore, the willingness of the prosecutor to offer a plea bargain arrangement to the defendant and his/her discretion in setting the terms of the offer have an impact on which defendants and what types of cases end up being adjudicated.

${ }^{2}$ For example, after the case is assigned to a judge the defense attorney may be more or less open to plea bargaining based on the attributes of the judge, such as the race and the reputation of the judge.
} 
attorneys to low-income defendants is attributable to attorney effort, motivated by the compensation structure of these attorneys (Agan et al. 2018). Thus, racial differences in judicial decisions could be driven by attorney quality and effort, not by the racial bias of judges. ${ }^{3}$

Finally, each particular case that is brought to trial has its own set of mitigating and aggravating circumstances, its own features about the background and the criminal history of the defendant, and the circumstances of the victim (if the crime involves a victim). Researchers try to account for such differences by controlling for the type of crime that is allegedly committed by the defendant (e.g. burglary, assault and so on). Such broad classification of crime commission may be sufficient if the number of cases handled by each judge is large, but this may not always be the case in practice, or in a particular data set analyzed. ${ }^{4}$ These pre-trial decisions and the selection problems they create, as well as the actions of various parties in the courtroom (ranging from the intensity of the language used by both the defense and the prosecutor, to the body language), are nearly impossible to control for.

In this paper we provide a solution to the biases caused by these confounders. Using Virtual Reality (VR) technology we record trials in a real courtroom, with actual prosecutors and actual defense attorneys. This is the first paper that utilizes 3D Virtual Reality technology that uses actual people in these videos, rather than computer-animated scenes. ${ }^{5}$ The details are provided

\footnotetext{
${ }^{3}$ Chen, Halberstam and Yu (2018) show that voice-based snap judgements of the evaluators (who made assessments about the masculinity of the voices) by listening to lawyers' identical short opening remarks in front of the U.S. Supreme Court, predict the outcomes in the Court.

${ }^{4}$ Other, more subtle, complications may also emerge in the investigation of in-group bias. For example, assume that within a crime category minority defendants are more likely to have A-type circumstances (e.g. stealing a car and getting involved in an accident using that car) and that white defendants are more likely to have B-type circumstances (e.g. stealing a car and committing a robbery using that car). Assume that judges are not racially biased, but minority judges are more strict against B-type circumstance and that white judges are more strict against A-type circumstance. In this scenario, if judges have discretion in sentencing, white (minority) judges will be harsher against minority (white) defendants, not because of racial bias but because of differential attitudes of judges towards different offenses.
}

${ }^{5}$ Schulman et al. (1999) shot 2D videos of actors who portrayed patients displaying various symptoms of cardiac problems. These videos were shown to physicians and physicians' estimates of the probability of coronary artery disease and their recommendations about cardiac catheterization are recorded to analyze differences in recommended treatment by race, sex, and age of the patient. Although this is a creative and important study, the 144 treatments ( 2 races, 2 sexes, 2 age groups, 2 coronary risk levels, 3 types of chest 
in Sections II and III. The VR technology allows us to replace the defendants in the 3D VR videos of the trials, holding constant every spoken word and every action in the court, enabling us to create arguably perfect counterfactuals. A glimpse of one of the trials with two different defendants can be seen at http://proficient.ninja/splitscreen/.

Two-hundred and one evaluators, who are either Master's level law students, undergraduate economics students, practicing criminal attorneys, prosecutors or judges, made decisions on conviction as well as on prison sentence length and fine (on those defendants who are found guilty) in accordance with the guidelines provided by the relevant penal code. By design, the race of the defendant is uncorrelated with the characteristics of both the prosecutors and the defense attorneys and with all courtroom activity. Defendant race is also uncorrelated with evaluator attributes. This feature of the design allowed us to decompose the in-group bias in decision making; i.e. it enables us to investigate whether the bias is driven by white or minority (or both) evaluators. This decomposition, which could not be implemented by previous research due to data limitations, provides new insights into the source of the bias.

By design, we hold the prosecutor, the defense attorney and their actions in the courtroom constant, and we do not reveal the names of the defendants to the evaluators. The defendants speak only three times during the trial to answer three questions posed by the judge. These answers are: "Yes,” “Not guilty”, and "No”. All actor-defendants are born in Belgium and they speak Dutch fluently with no accent. This implies that "foreignness" or minority status of the defendants can only be inferred from their darker skin complexion, but not from their names or accents. ${ }^{6}$ As explained in Section III, a separate group of 89 students, who are not involved in

\footnotetext{
pain, 3 types of exercise test results) are embedded in 8 videos of 8 patients, and each physician evaluated one of these 8 patients.

${ }^{6}$ The body language was also similar between the defendants, as we discuss later in the paper.
} 
the experiment, confirmed that the defendants are easily identified as being white or minority by the pictures of their faces.

The results point to negative in-group bias in the conviction decision (evaluators being harsher on defendants of their own race). The effects are equally strong for both minority evaluator-minority defendant matches, and white evaluator-white defendant matches, although they are not statistically significant. In contrast, we find significant in-group favoritism in the sentencing phase (assigned prison sentences and fines). Decomposition analyses reveal that while in-group favoritism is equally strong for both white and minority evaluators in assigning prison sentences, in-group favoritism in fines is dominated by white evaluators. These findings reveal a previously undocumented asymmetric pattern: evaluators are harsher against defendants of their own race during the conviction phase, but they are more lenient towards defendants of their own race when imposing punishment, given conviction.

When we analyze overall racial bias, we find statistically and economically significant racial bias against minorities at all stages: conviction, prison sentence, and fine, which is partially the reflection of the fact that the majority of the evaluators are white.

We also analyze whether disparate treatment of defendants is impacted by evaluators' trust in the judiciary, by their trust in police, and by their concerns about terrorism and immigration. We find limited evidence that such concerns influence racial biases in these judicial decisions, suggesting that the source of the bias may be deep-rooted.

The analysis of lawyers' decisions reveals the same pattern of racial bias we find in the sample of economics students and law students. ${ }^{7}$ We also have a small sample of judges and prosecutors $^{8}$ who made conviction and sentencing decisions on these cases. Although the decisions of judges and prosecutors cannot be analyzed separately because of their small sample

\footnotetext{
${ }^{7}$ In-group bias cannot be analyzed in the lawyer sample because of the lack of minority lawyers.

${ }^{8}$ Who have not participated in the shooting of the VR trials.
} 
size, when we add judges and prosecutors to the sample of lawyers we obtain the same results as those obtained from the sample of lawyers, suggesting that judges and prosecutors do not adjudicate substantially differently in comparison to lawyers.

Section II describes the general idea and the contribution of the paper. Section III provides the details of the experimental design and the data. Section IV presents the descriptive statistics, Section V includes the econometric framework specifications and Section VI presents the results. Sections VII includes extension and robustness checks. Section VIII presents the analysis of attorneys' decisions. Section IX analyzes the question of whether the conviction and sentencing decisions of the evaluators are impacted by the extent to which the evaluator believes that immigration is a problem, terrorism is a problem, or whether the police or the judicial system can be trusted. Section $\mathrm{X}$ is the conclusion.

\section{General Idea and the Contribution of the Paper}

Imagine we are watching a trial. The district attorney presents his case the way he sees appropriate. The defense attorney defends her client with the knowledge and the skill she possesses. The facts of the case are presented and debated by both parties. The defendant, who is sitting in front of the judge, is listening to the arguments and counter-arguments made by the prosecutor and by his defense attorney. The defendant is a white man. At the end of the trial the judge makes a decision based on the arguments presented. She renders a verdict about conviction/acquittal; and if she finds the defendant guilty, she assigns a prison sentence and/or a fine.

Now imagine we go back in time and watch the same exact trial. The same prosecutor, the same defense attorney, the very same arguments, the same words, the same body language. Everything that took place in the courtroom is precisely the same, with one difference: the defendant is someone else. He is not a white man, but he has dark skin. Would the decision of the judge about the verdict, the prison sentence length and the fine be different? Are these judicial decisions influenced by whether or not the judge and the defendant have similar racial/ethnic backgrounds? If so, are these influences stronger for white judges or minority judges? If there 
are race-driven effects on these decisions, are they impacted by whether the judge believes that immigration is a problem, terrorism is a problem, or whether the police or the judicial system can be trusted? These are the questions we try to answer in this paper.

Of course, if the judge were to watch the same trial the second time (the only difference between the two versions being the defendant's race), she would immediately recognize that this was the same case she adjudicated before. Therefore, while the first judge watches the trial with the white defendant, we ask another judge to watch the same trial with the defendant who has dark skin. To be exact, we have a total of 201 observers who watch six different criminal trials from the view point of the judge in the courtroom (from the bench of the judge). Each of these six trials has a different defendant who faces a different criminal charge with different circumstances. Each of these six trials has two versions. The only difference between the two versions is that while the defendant in Version 1 of each trial is a young white man, the defendant in Version 2 of the same trial is a young man with darker skin color. We mix these trials and then randomly assign them to these 201 evaluators, who act as judges, making sure that everyone watches all six trials in random order, and that everyone watches three trials with white defendants and three other trials with dark-skin defendants. Half of the evaluators watch Version 1, while the other half watched Version 2 of each VR video.

As explained in detail in Section III, the VR technology allows us to video-record the courtroom activity in 3D. It also allows us to replace an individual in this VR video (the defendant) with another individual who is video-recorded separately. In the end, this production generates two identical VR videos with one difference: version 1 contains the white defendant, and version 2 contains the minority defendant with dark skin color. ${ }^{9}$

Figure 1 displays a side-by-side image of version 1 and version 2 of a particular scene from one of the trials. The version in the top frame involves a white defendant and the version in the

\footnotetext{
${ }^{9}$ 3D Virtual Reality videos offer advantages compared to regular 2D videos. Once the participants put on the headsets they experience "immersion" into the actual environment, meaning that they feel part of the environment in which they are being placed, and they no longer get sensorial stimuli from their actual physical location. Also, the participants can look around in the 3D Virtual Reality videos in a 360 degrees environment instead of viewing the setting from a fixed focal point in a 2D video. Furthermore, the participants also experience "presence", meaning that they actually feel like being present in the environment because the sense of reality is increased significantly compared to 2D videos (Sadowski and Stanney 2001, Slater and Wilbur, 1997).
} 
bottom frame involves a minority defendant. In each frame, the person on the right is the prosecutor who is presenting his case. The defendant is sitting in the middle; and the person on the left, behind the defendant, is the defense attorney. This picture depicts how the judge (the evaluator) observes the trial, although watching the Virtual Reality videos using 3D headsets produces a much more realistic image of the actions and sounds of the courtroom.

Two short segments of this trial (shown in Figure 1) titled "Split screen Comparison of Version 1 and Version 2 of Video No 4" are at the link: http://proficient.ninja/splitscreen/. This particular clip presents a 40-second segment of the fourth trial shown (Video No 4), but it displays two versions of the same trial simultaneously on the split screen. The top segment of the screen displays the trial with the white defendant and the bottom segment displays the same trial with the minority defendant. Every detail in both videos is identical with the exception of the defendants. The second video at this link presents the full version of the same trial with the minority defendant (Video No 4, Version 1), and the clip below (Video No 4, Version 2) displays the same trial with the white defendant.

Another short video-clip at the link http://proficient.ninja/uhasselt/ provides a glimpse of a different trial (note that the prosecutor and the defense attorney as well as the defendant are different). This video is titled "Video No 1, Version 1" to indicate the first trial (Video No 1) with the white defendant (Version 1). Two short segments are included in the clip. The first segment shows a section from prosecutor's opening remarks; and the second part shows a segment in which the defense attorney speaks. Pictures from other trials can be found at this link by scrolling down. ${ }^{10}$

The prosecutors and the defense attorneys in all videos are actual prosecutors and actual defense attorneys who practice criminal law in the province of Limburg, Belgium. We used a real courtroom in Hasselt, Limburg to shoot the VR videos of the trials. The VR videos are shot

\footnotetext{
${ }^{10}$ Previous experimental research that investigated the impact of defendant characteristics such as race and mental illness on trial verdicts provided mock trial transcripts to be read by the evaluators. The race of the victim or defendant is manipulated using photographs and names (Mossiere, Maeder and Pica 2018; Maeder, Mossiere and Cheung 2012), or evaluators were given vignettes that described the offender and the circumstances of the case (Mercado, Bornstein and Schopp 2006). Some studies showed videos of mock trials where the trial conditions, such as eyewitness evidence, has been manipulated by the experimenters (Jones et al. 2017).
} 
from the bench of the judge so that the evaluators can observe the trial from the vantage point of the judge.

At the conclusion of each trial, each evaluator renders a verdict on guilt vs. innocence and assigns a sentence if s/he finds the defendant guilty. We compare the verdicts and the prison sentence lengths and fines between the evaluators who watched the same exact trial but faced a different defendant. This design enables us to identify the impact of the race of the defendant on judicial decisions, holding constant everything else that can influence the decisions. Furthermore, because we have information on the evaluators who made judgments on the defendants, we investigate whether the evaluators hand down more or less severe verdicts and sentences if they themselves are a minority in the society. ${ }^{11}$

\section{External Validity}

The first group of evaluators, who watch the VR videos and make decisions as a judge, are a mixture of undergraduate and master's economics students, and masters' law students from Hasselt University in Belgium. It can be argued that the decisions of undergraduate and master's economics students and even those made by master's level law students, although informative, do not correspond to the decisions made by actual judges. It is important to underline that in Belgium a law graduate is integrated into the judicial system very quickly. Specifically, a law graduate can begin his/her career path towards becoming a judge with a judicial internship, provided that s/he has one year of experience in the field (which can consist of an internship at the Bar or any other legal function). During the judicial internship, the intern is active in at least one bench of a first instance court, where s/he has the assignment to support the judges, participate in judicial deliberations and draft verdicts. Thus, law graduates in Belgium can start a judicial internship as early as one year after graduation, and during this internship they are

\footnotetext{
11 This component could not be done in the second group of evaluators because this group consisted of attorneys and there was no minority among them. The same is true for judges and prosecutors who evaluated these cases.
} 
expected to make judicial decisions in court cases. After three years of internship (i.e. four years after graduation) law graduates can become full-fledged judges.

Nevertheless, to address the question of whether students' decisions are different from those who are actively involved in the judicial system, we repeated the experiment with 36 practicing Belgian attorneys who specialize in criminal law, and obtained similar results. Finally, we repeated the experiment with a small number of judges and prosecutors (8 judges and 4 prosecutors). This small sample does not allow us to analyze them separately but adding judges and prosecutors to the sample of lawyers did not alter the results, suggesting that judge and prosecutor decisions are not substantially different from those made by the lawyers. The details of data and the procedures are provided in the next section and in Appendix 1. As with any analysis, however, the answer to the question of whether the results would carry over to other settings, requires further research.

\section{The Design of the Study and the Data}

We are granted permission by the district attorney of Limburg, Belgium to use actual criminal cases as well as actual prosecutors and an actual courtroom. Upon discussions with two prosecutors we decided to focus on burglary and assault cases because such cases provide substantial discretion to the judge about sentencing, and no special background or additional expert information is needed to deliver a verdict (which would be the situation in cases such as medical liability). Three actual burglary and three actual assault cases are selected from the court archives or from the docket. ${ }^{12}$

\footnotetext{
12 Although we did not change any details of the cases, we altered the names of the actual victims and witnesses to guarantee anonymity of the real cases. As explained in the paper, synopses of actual case files are provided to the evaluators before the beginning of the experiment so that they could assess the background of each case, the forensic evidence, the background of the defendant, and so on, as the judge would do. We did not provide the names of the defendants to evaluators in these case files to avoid any signaling about the race of the defendants. In the videos, the defendant is always referred to as 'my client' (by the lawyer) or as 'the defendant' (by the prosecutor). For burglary cases we changed the location of the event to eliminate the possibility of an evaluator being familiar with a particular burglary incident in a particular neighborhood. Given that the actual defendants were in some cases older than our actor-
} 
Two prosecutors who specialize in burglary and assault cases volunteered to participate. We contacted a number of law firms that specialize in criminal cases to be part of the experiment. After interviews, we selected three lawyers (two female and one male) who have experience in both burglary and assault cases. The lawyers and the prosecutors were given the case files one week before the shooting of the videos and were asked to prepare the cases similar to an actual court trial. The lawyers did not talk to the prosecutors before the shooting to keep the trial environment as realistic as possible. Both the prosecutors and lawyers tried and defended the cases the way they would normally do in real-life trials. There was no script to follow. They presented their case with no instructions from anyone.

In Belgium the judge is in control of the court hearing although his/her actual role is limited. The judge talks very little during the trial; he/she speaks just to direct the proceedings. The judge first asks the defendant if he understands the charges against him/her and whether the defendant pleads guilty or not guilty. In each of our videos, the defendants indicate that they understand the charges and that they plead not guilty. The judge then allows the prosecutor to start with his statement. Once the prosecutor is finished, the defense attorney can launch his/her pleading. In an actual hearing, the judge sets the time frame for her verdict (normally four weeks after the conclusion of the hearing) and she could potentially ask the defendant some questions during the trial. Our set up (the evaluators watching the VR videos with headsets) does not allow the evaluators to interrogate the defendant. It is, however, not uncommon in Belgian criminal proceedings for the judge not to ask any questions to the defendant.

For the sake of realism in our videos, we needed an actual judge to control the flow of proceedings. We selected a retired judge from the region of Hasselt to be in control of the cases, as he would normally do. The VR camera was located before the judge's bench. Thus, the

defendants, we changed the age of the defendant in the case files that are provided to the evaluators to match the age of the defendant-actors in our courtrooms. 
evaluators who watched the videos could only hear his voice in the VR video, but could not see him. This way the setting remained realistic and the evaluators viewed the cases from the perspective of the judge. The evaluators were not primed in any way.

We employed three white defendants (each would act as the defendants in two trials) and three non-white defendants (each would take part in two trials) for our six cases. ${ }^{13}$ We limited the number of cases to six because a trial took 12 minutes on average, which implied that watching the six VR videos and making decisions on these six trials lasted two hours. Asking the evaluators to watch trials for more than two hours was infeasible for a number of reasons. The pictures of these actors are provided in Figure 2. ${ }^{14}$ Snapshots of them during the trials can be found by scrolling down at the link http://proficient.ninja/uhasselt/.

We involved 153 students from the faculties of Economics and Law of Hasselt University to act as judges in these trials. The Economics students were a mix of juniors and masters' students that were enrolled in the Policy Evaluation course. The Economics group consisted of 86 students. They were randomly subdivided into four groups (because we had 25 headsets to watch the VR videos) to participate in the experiment. All four groups watched the videos on the same day, and we made sure there was no interaction between any of the four groups of students. To avoid interaction between the groups, we put them in separate rooms and let them watch a movie (or be lectured by an instructor) while one of the other groups was involved in the

\footnotetext{
${ }^{13}$ We selected male actors who lived outside of the region where the evaluators reside in order to avoid the possibility of an evaluator recognizing one of the actors. We also made sure that all actors were about the same age, and we gave them instructions on wardrobe so that the clothing worn by the pairs of actors was similar.

${ }^{14}$ A professional Virtual Reality production firm was hired, and a cameraman and a technician were in charge to ensure the technical quality of the video and the audio. A static 360 camera (OZO) was used to shoot the cases. The camera was positioned before the bench of the judge and was on the same height as the judge, which allowed the participant in the experiment to observe the court room from the exact same angle as the actual judge. All videos are shot in one court room in the main court building in Hasselt, Belgium.
} 
experiment. They were also instructed not to inform each other via mail or phone. A professor was always supervising the group of students who were not in the lab.

Law students are enrolled in Master's degree program at Hasselt University. They participated in the experiment as part of a course on Research Methods, which is mandatory class for all law students. There were 67 law students enrolled in this course, and they all took the experiment the day after the Economics students. Law students were randomly divided into three groups and again we made sure they could not interact with the other groups as the experiment was ongoing for one of the groups.

The evaluators were told that they were participating in an experiment which was an exercise in the adjudication of criminal acts. We organized a random lottery (with 20 movie tickets) for evaluators who participated in both the experiment and the follow up survey. ${ }^{15}$

The follow up survey, which is completed by the evaluators over the internet, is used to gather background information on the evaluators. We decided to collect this information not on the same day of the experiment but nine days after it to minimize concerns about incorrect information being provided. ${ }^{16}$ The survey contained 40 questions, and the key questions were sprinkled throughout. For example, we asked innocuous questions about concerns regarding unemployment, importance of family, and so on, before asking whether they think terrorism is a major problem in Belgium.

We recruited practicing attorneys from the Flanders Bar Association. By email and by phone we contacted 250 lawyers who were listed under the category of "criminal law" on the web site of the Association. Thirty-six lawyers agreed to participate. The lawyers received the same

\footnotetext{
${ }^{15}$ The experiment took place in November 2017. There was no unusual news or events in Belgium during this period related to immigration, terrorism or asylum seekers.

${ }^{16}$ If we had asked the evaluators questions about their cultural background, about their concern regarding crime and the judicial system etc. immediately after they completed the experiment, they might have been cognizant about the purpose of the survey, and may have provided untruthful responses.
} 
information as the student participants and the flow of the proceedings was identical. ${ }^{17}$ Because the overwhelming majority of the lawyers are white we could not investigate in-group bias in their decisions, but we were able to analyze the existence of racial bias in lawyers' decisions.

We also tried to recruit judges and prosecutors, with limited success. We asked the court presidents of multiple courts and the head of one District Attorney's office for permission to conduct the experiment. ${ }^{18}$ The courts and District Attorney's office sent an email to all a judges and prosecutors and asked them if they wanted to take part in a study on criminal trials that uses virtual reality technology. Only eight judges and four prosecutors agreed to participate. The VR experiment with judges and prosecutors was conducted partly in the court buildings, and partly at Hasselt University for those who weren't available on the dates the VR equipment was set in the court buildings. Participating judges and prosecutors are guaranteed anonymity.

Although the decisions of judges and prosecutors cannot be analyzed as a separate group because of the small sample size, as a robustness exercise we added judges and prosecutors to the sample of lawyers. We obtained results that were very similar to those obtained from the sample of lawyers, suggesting that the decisions of judges and prosecutors are not significantly different from those of lawyers.

The evaluators watched the VR videos using VR headsets (Oculus Rift headsets) on powerful computers with high quality graphics cards. The lab hosted 25 students at one time (See Figure 3). The evaluators were granted anonymity during the experiment and in the follow-up survey (see Appendix 1 for details). ${ }^{19}$

\footnotetext{
${ }^{17}$ The lawyers took the experiment individually during a ten-day period in July 2018.

${ }^{18}$ Obviously, the prosecutors who participated in the VR trials did not take part in the evaluations.

${ }^{19}$ For the purpose of the experiment we developed a website that would guide the participants through the experiment. The website contained instructions for the evaluators on what to do (when to put on the headsets, when to take them off, when to read a case folder, etc.). The website also communicated with the headset so that the videos would play automatically in the correct order, and provided a platform which allowed the evaluators to submit their decisions in each case (conviction/acquittal and sentences in case of conviction). As a real judge would do, the evaluators had to first read the case folder pertaining to that particular case. The case folders were color-coded to avoid confusion. That is, each of the six cases
} 
After reading the case folder, evaluators could click on a button on the screen to start the VR video. They had 30 seconds to put on the headsets to watch the VR video. After watching the video, they took off the headsets, and clicked on a button on the screen to go to the deliberation phase. First, they were asked to decide on conviction or acquittal. If they decided to convict, they had to assign the sentence (prison sentence and/or fine). As is the case with real judicial decision, they also had to make a decision on whether and how much to suspend the prison sentence and the fine. All of these decisions were made by clicking and typing on the screen.

The experiment lasted for two hours, with a five-minute break (interactions with other participants were not allowed) after watching the first three videos and making judgments on these first three cases. As mentioned earlier, we limited the number of cases to be watched and evaluated, to six. This is because increasing the experiment beyond two hours (reading the case files, watching the VR videos with headsets, delivering decisions) would have reduced the quality of the decisions, and also it was not feasible for logistical reasons.

After watching and rendering decisions on all six cases, participants were presented with an overview of their decisions for all the six cases and they could alter any decisions they made (conviction, prison term and fine) on any of the six cases before they were finished with the experiment. In the analyses we use the final decisions made on each case. ${ }^{20}$

If the defendants in the VR videos are not recognizable as being a member of a minority or majority group in Belgium, then our design will provide null results. ${ }^{21}$ Put differently, if the

were assigned a different color folder. The case folders contained the relevant background information about the cases, including the summary of the police report, and the criminal history of the defendant (See Appendix 1 for the details of each of the six cases, the way presented to the subjects).

${ }^{20}$ To investigate if the evaluators took their task seriously, we conducted a number of tests such as the analysis of the decisions by the speed of the decisions made by the evaluators, by the order in which the decisions were made, and so on. These are detailed in Section VII.

${ }^{21}$ Ethnicity refers to common ancestry, a perception of common history and culture. Race typically refers to a group of people defined by physical characteristics. Race classifications are not established by a set of natural or biological factors but they are human constructs where skin color, eye shape, 
evaluators cannot infer correctly the racial background of our defendant-actors by looking at them, then the evaluators would not assign differential verdicts or sentences even if the evaluators had racial biases. To put bluntly, the question is whether the evaluators can tell the difference between a Belgian person of European heritage and another individual who is a racial/ethnic minority with dark skin (e.g. a Belgian with Moroccan or Turkish origin)? Or, would the evaluators think that the latter person is a white European, but happens to have sun tan? The pictures of the defendants are provided in Figure 2.

To analyze whether the defendants can be identified as white or minority, we used a different group of 89 students who were shown pictures of the defendants. The students identified the defendants’ race correctly with 99 percent accuracy. The details are provided in the Appendix.

Because we have six different cases (three burglaries and three assaults) and two versions of each case (one with a white defendant and one with a non-white defendant) we have a total of 12 videos in the experiment, and each defendant-actor participated in two videos. We made six sets with different sequences of the videos and three different combinations to make sure that each evaluator would see each defendant only once. The sets are listed in Table 1 . The details are discussed in the footnote to Table 1.

height, hair type are used as markers to define races (Omi and Winant 1994). The European Court of Human Rights states that "Whereas the notion of race is rooted in the idea of biological classification of human beings into subspecies on the basis of morphological features such as skin colour or facial characteristics, ethnicity has its origin in the idea of societal groups marked in particular by common nationality, religious faith, shared language, or cultural and traditional origins and backgrounds."

Race and ethnicity often overlap, and groups of people may move between categories. For example, as explained by Omi and Winant (1994), for the British, Irish were considered as a different race, although they had similar physical attributes as the British. In the U.S. Irish used to be treated as similar to the Black race. Now they are considered "white" but they constitute an ethic group. U.S. Census Bureau listed five races in 1870: White, Colored (Blacks), Colored (Mulattoes), Chinese, Indian. In 1950 there were three race classifications: White, Black, Other. In 1990 the classifications became White, Black, Asian or Pacific Islander, American Indian or Alaska Native, and in 2010 they consisted of White, Black, Asian, Hawaiian or Pacific Islander, American Indian or Alaska Native. The Census Bureau contemplated using Arab as a new racial category for the 2020 census, although the idea was not implemented. 


\section{$\underline{\text { IV. Descriptive Statistics }}$}

Table 2 presents the descriptive statistics related to student evaluator attributes. Minority Evaluator takes the value of one if either the mother or the father of the evaluator was born outside of Belgium, and if that country is outside of the European Union (EU). ${ }^{22}$ Thus, minority evaluators are first- or second-generation immigrants whose ancestral origins are in Turkey (10 evaluators), Morocco (4 evaluators), and one evaluator each from Iraq, Zimbabwe, and Armenia. Alternatively, we determined if the evaluator was a minority in Belgium based on the answers to the following question. "Do you or anyone in your household speak a language other than Dutch?”23 In this alternative definition, we coded the evaluator as a minority if he/she indicated that either Arabic, Armenian, Turkish or Shona is spoken at home. ${ }^{24}$

Using the same survey that was registered nine days after the experiment, we also measured evaluators' beliefs and attitudes on a number of social issues. The dummy variable Trust in the Legal System takes the value of 1 if the individual assigned a value of 7 or higher to the question "On a score of 0-10, how much would you say you personally trust the legal system? 0 means you do not trust the legal system at all, and 10 means you have complete trust.” A similar question is used to gauge trust in police. "On a score of $0-10$, how much would you say you personally trust the police? 0 means you do not trust the police at all, and 10 means you have complete trust." Trust in Police takes the value of 1 if the person gave a rating of 7 or higher to this question.

Using a scale from 0 to 10 , the evaluators could also reveal attitudes towards immigration in response to the question "Is Belgium made a worse or better place to live by people coming to

\footnotetext{
${ }^{22}$ If the parent was born in a country which is part of the EU, such as Germany or France, the evaluator is not considered as a minority in Belgium. There was on evaluator with parent(s) from Japan, one evaluator with parent(s) from South Korea, and another one from India. These three individuals of Asian heritage are excluded from the analysis, but considering them as minorities did not alter the results.

${ }^{23}$ Hasselt University is located in Flanders, the Dutch-speaking part of Belgium.

${ }^{24}$ We did not consider evaluators as a minority in Belgium when for example French, Polish or Italian is spoken at home.
} 
live here from other countries?” Those who chose $0-5$ are considered to be those who believe that Belgium is worse off because of migration (58 percent of the evaluators). ${ }^{25}$

The evaluators were also given the question "To what extent do you think it is important that Belgian society pays attention to terrorism?” and were asked to reveal their beliefs about this statement as (1=very unimportant, $7=$ =very important). If the person chose 6 or 7 , we identified him/her as agreeing that terrorism is a major problem in Belgium. Later in the paper we investigate the sensitivity of the results to the variation in these cutoff values.

Table 3 presents the descriptive statistics of the decisions made by evaluators. Row (1) displays information about the conviction decision by the race of the defendant [Columns (1) and (2)], as well as by race-matching between the defendant and the evaluator [Columns (3) to (6)]. For example, columns (1) and (2) reveal that the conviction rate among minority defendants is 12 percentage points higher in comparison to the conviction rate of white defendants ( 0.79 vs. 0.67) and that the difference is statistically different from zero. Columns (5) and (6) reveal that when minority defendants are matched with white evaluators they are less likely to get convicted in comparison to their match with minority evaluators (0.78 in column 6 vs. 0.82 in column 5). The same detrimental impact of race-matching is observed for white defendants who have a slightly higher likelihood of getting convicted if they are matched with evaluators of their own race (0.68 in column 4 vs. 0.65 in column 3), although these differences are not statistically significant.

\footnotetext{
${ }^{25}$ The three questions on the trust in the legal system, trust in the police and the extent to which immigration is a problem in Belgium were asked in the same way and using the same scale as in the European Social Survey (ESS). Using the ESS survey years of 2016 we found that in the overall population of Belgium 36 percent trust the legal system, 58 percent trust the police, and 75 percent believe that Belgium is made a worse place to live because of immigration. The rates of trust in the legal system and trust in the police are similar between the overall Belgium population (ESS survey data) and those observed among our evaluators, reported in Table 2. The percentage of those who believe that immigration made Belgium a worse place to live is lower among our student evaluators in comparison to the overall population (59 percent vs. 75 percent).
} 
Row (2) of Table 3 displays the average prison sentence imposed on defendants if they were found guilty. Part of the prisons sentence can be suspended at the discretion of the evaluator. Row (3) presents the average suspended prison sentence among various groups. The difference between the initial prison sentence and the suspended sentence is the actual, effective prison term faced by the convicted defendants, displayed in row (4). For example, column (1) shows that convicted minority defendants receive an average of 10.2 months prison time (row 2), and that 5.8 months of this initial sentence is suspended (row 3). Thus, row (4) and column (1) show that the effective prison term among minority defendants is 4.3 months, on average.

Columns (5) and (6) and row (4) show that minority defendants receive effective prison sentences that are 1.7 months shorter if they face a minority evaluator instead of a white evaluator. Columns (3) and (4) of row (4) show that white defendants receive 1.9 months shorter sentences (3.6 months vs. 5.5 months) if they face a white evaluator as opposed to a minority evaluator. This suggests that evaluators provide preferential treatment in assigning prison sentences to defendants who are of the same race, which reflects positive in-group bias in effective prison term.

Rows (5) to (7) of Table 3 display information on the assessment of fines. Columns (5) and (6) indicate there is no sizable in-group bias related to fines received by minority defendants. On the other hand, white defendants' average fines are considerably lower when they are matched with white evaluators (columns 3 and 4), although the difference is not significantly different from zero. The details of this picture will be revealed in the empirical analysis section.

An interesting aspect of Table 3 is that average effective prison terms is not significantly different between white and minority defendants (row 4, columns 1 and 2). The same is true for average effective fines (row 7, columns 1 and 2). This statistical insignificance is misleading because racial bias in the conviction decisions generates a selected sample of defendants who are sentenced. Note in Table 3 that while 361 minority defendants are convicted and sentenced, there 
are only 309 white defendants who are sentenced. These 42 “excess” minority defendants end up in the sentencing phase because of the 12 percentage point difference in the conviction rates between the races $(0.79$ vs. 0.67$){ }^{26}$ Thus, we present the empirical results both ways:

i) that account for this selection bias and ii) that ignore the selection bias.

\section{$\underline{\text { V. Econometric Analysis }}$}

\section{In-group bias}

To test for the existence of in-group bias we make use of information obtained from the evaluators regarding their cultural heritage. This information allows us to estimate Equation (1).

(1) $\mathrm{Y}_{c j}=\alpha_{1}+\beta_{1}$ Minority Defendant $_{\mathrm{c}}+\gamma_{1}$ Minority Evaluator $_{\mathrm{j}}$ $+\delta_{1}$ Minority Defendant ${ }_{c}{ }^{*}$ Minority Evaluator ${ }_{j}+\mathbf{X}_{j} \Theta+\mu_{c}+\omega_{c j}$

where $\mathrm{Y}_{\mathrm{cj}}$ stands for the outcomes related to case $c$, judged by the evaluator $j$. The first outcome is an indicator to represent whether the defendant is convicted by evaluator $(j)$. The second and third outcomes are the prison term and the amount of monetary fine imposed on the defendant if he is found guilty. Minority Defendant is a dummy variable which takes the value of one if the defendant in case $c$ (in the VR video of case $c$ ) is a racial Minority. Recall that a particular case is identical across all evaluators who watch the VR video of that case, with the exception of the race of the defendant. ${ }^{27}$

In Equation (1) Minority Evaluator takes the value of 1 if the evaluator, who makes the conviction and sentencing decisions, is a minority him/herself in Belgium. Six courtroom

\footnotetext{
${ }^{26}$ The same point is made by Depew et al. (2017). Because the sequential decision of conviction and sentencing of the defendants by the same judges generates sample selection in the sentencing phase, the authors analyzed the sentencing outcomes of those defendants who pled guilty (as opposed to those who are convicted and then sentenced by the same judge).

${ }^{27}$ In other words, all evaluators watch the same video of a particular trial (indexed by $c$ ), except that some evaluators are randomly chosen to watch the version with the white defendant, while other subjects are randomly assigned to the version that includes the minority defendant.
} 
hearings ( $c=1,2, \ldots 6)$ are watched and judged by each evaluator $(j)$. Three of these cases involve burglary, and the other three are assault cases. In some specifications we include case fixed effects $\left(\mu_{c}\right)$, in others we control for the type of crime on which the trial was based (assault vs. burglary). Vector $\mathrm{X}$ includes attributes of the evaluators such as their sex and whether they are law students or economics students. Although all evaluators watch the same cases, the order in which these cases are watched is different by design. ${ }^{28}$

In Equation (1) $\gamma_{1}$ captures the difference in outcomes between white defendant-minority evaluator pairs and white defendant-white evaluator pairs, and $\gamma_{1}+\delta_{1}$ captures the differential impact on sanctions assigned on minority defendants by minority versus white evaluators. Thus, $\delta_{1}$ is the difference-in-difference estimate, which signifies the differential decisions of minority evaluators versus white evaluators in their treatment of minority defendants over white defendants. Put differently, if $\delta_{1}$ is different from zero, this is evidence for in-group bias.

Inclusion of evaluator fixed effects to specification (1) could be important in the analysis of data from actual trials because judges who preside over those hearings may embody unobserved (to the analysts) attributes that may confound the results. For example, as explained in Depew, Eren and Mocan (2017) if judges are assigned to jurisdictions non-randomly (e.g. by an election, voted by local residents of the jurisdiction) and if judge race is correlated with judge leniency in sentencing, judge fixed effects are important to control for. This is not a concern in our paper because, by design, there is no correlation between evaluator race and the attributes of the cases. Similarly, defendant's race is orthogonal to case and evaluator characteristics by design. Nevertheless, we also estimate (1) by adding evaluator fixed effects.

\footnotetext{
${ }^{28}$ As Table 1 demonstrates, evaluators who were randomly assigned to Set 1 or Set 2 watched these six cases in a particular sequence (Sequence 1), while those who were randomly assigned to Sets 3 or 4 watched the same videos in a different order (Sequence 2); and Sequence 3 is the third sequence in which the videos are watched by evaluators. Vector X contains Sequence1 and Sequence2 which are two dummy variables that control for the sequence in which the videos are watched.
} 
While specification (1) is important in the investigation of in-group bias, it cannot determine the source of the bias. For example, assume that the difference-in-difference coefficient $\delta_{1}$ in Equation (1) is negative. This indicates that evaluators are more lenient towards defendants of their own race, but this does not specify whether this impact is driven by white or non-white evaluators. In-group bias $\left(\delta_{1}<0\right)$ could emerge when i) white evaluators treat both types of defendants with equal severity, but minority defendants treat minority defendants more leniently, ii) white evaluators treat minority defendants more harshly than white defendants, but minority evaluators treat minority defendants (much) more leniently in comparison to white defendants, iii) both minority and white evaluators treat minority defendants more leniently, and so on.

One of the contributions of this paper is our ability to decompose the in-group bias effect, in order to determine the source of the bias. Because the race of the defendant is, by design, uncorrelated with all courtroom attributes and with all case characteristics, and because it is also uncorrelated with the race of the evaluator, we can run the regressions below, conditional on defendant race, to investigate the source of the in-group bias.

(2A) $\mathrm{Y}_{c j}=\alpha_{2}+\gamma_{2}$ Minority Evaluator $+\mathbf{X}_{j} \Theta+\mathbf{C}_{c} \boldsymbol{\Lambda}+\mu_{\mathrm{c}}+\mathrm{u}_{c j}$ in the sample of Minority defendants

(2B) $\mathrm{Y}_{c j}=\alpha_{3}+\gamma_{3}$ White Evaluator $+\mathbf{X}_{\mathbf{j}} \Pi+\mathbf{C}_{c} \boldsymbol{\Xi}+\theta_{\mathrm{c}}+\tau_{c j}$ in the sample of White defendants.

The in-group bias coefficient of $\delta_{1}$ in Equation (1) is equal to $\left(\gamma_{2}+\gamma_{3}\right)$ in Equations (2A) and (2B). For example, if Y stands for the probability of conviction and if $\delta_{1}<0$ in Equation (1), this implies positive in group bias. That is, evaluators are less likely to convict the defendants who are of the same race. Equations (2A) and (2B), however, provide further information. For example, if $\gamma_{2}<0$ and $\gamma_{3}=0$, this implies that the in-group bias identified in the data (by Equation 1) is driven by the behavior of minority evaluators. Alternatively, if $\gamma_{3}<0$ and $\gamma_{2}=0$, this indicates 
that the in-group is due to the behavior of white evaluators. It could also be the case that $\gamma_{2}<0$ and $\gamma_{3}<0$, indicating that both groups are biased in favor of their own race. ${ }^{29}$

\section{Overall Racial Bias}

To investigate the existence of overall racial bias in conviction and sentencing decisions we run regressions of the following type:

(3) $\mathrm{Y}_{c j}=\alpha_{4}+\beta_{4}$ Minority Defendant ${ }_{c j}+\mathbf{X}_{\mathrm{j}} \Phi+\mathrm{v}_{\mathrm{c}}+\varepsilon_{c j}$

The estimated coefficient $\beta_{4}$ identifies whether minority defendants are treated differently in comparison to their white counterparts in conviction in sentencing decisions. For completeness, we also estimate Equation (3) incusing evaluator fixed effects.

Note that in Equation (1), which analyzes in-group bias, $\left(\alpha_{1}+\beta_{1}\right)$ represents the impact of white judges on minority defendants, and $\alpha_{1}$ stands for the impact of white judges on white defendants. Thus, $\beta_{1}$ represents the differential treatment of minority defendants vis-à-vis white defendants by white judges. Similarly, $\left(\beta_{1}+\delta_{1}\right)$ stands for the differential treatment of minority defendants by minority judges. If $p$ stands for the proportion of white judges in the sample, then the overall differential treatment of minority defendants by all judges is equal to $\left[\beta_{1}+(1-p) * \delta_{1}\right]$, which should be equivalent to the estimated coefficient of Minority Defendant $\beta_{4}$ in Equation (3).

\section{$\underline{\text { VI. Results }}$}

\section{In-group Bias in Conviction Decisions}

Table 4A presents the estimation results of Equation (1). These specifications investigate the existence of in-group bias in conviction decisions, which is identified by the coefficient of the interaction term (Minority Defendant x Minority Evaluator). There are 153 evaluators in the

\footnotetext{
${ }^{29}$ For a more detailed explanation of this process, see Equations (4) to (6) on page 25 in the Appendix of Lusher, Campbell and Carrell (2015).
} 
group of law students and economics students, who made decisions on conviction vs. acquittal on each of the six cases they watched in virtual reality videos, generating a sample of 918 decisions. The analyses of lawyer decisions (and those of lawyers, prosecutors and judges) are reported later in the paper. In column (1) of Table 4A we control for whether the case was an assault or burglary, as well as whether the decision on the case was made during the first half of the experiment or in the second half (Early Trial). Column (2) presents the results from another specification which includes trial fixed-effects. Column (3) adds the sex of the evaluators and whether the decision was made during the first half of the experiment. Column (4) controls for the Sequence type (the order in which videos are watched), in addition to trial fixed effects.

The coefficient of the interaction term (Minority Defendant x Minority Evaluator) represents the impact of in-group bias in the conviction decision. The point estimate is about 0.085 , although it is not statistically significant at conventional levels. This provides suggestive evidence for negative in-group bias: defendants are 8.5 percentage points (about 12 percent from the mean conviction rate) more likely to get convicted if they face an evaluator who is of the same race. Estimating the model by including evaluator fixed effects provided results (presented in the Appendix 2 Table A2-1) that are consistent with those reported in Table 4A.

Although preferential treatment of in-group members is intuitive, and there is evidence of such behavior (Chen and Li 2009, Shayo and Zussman 2011), negative in-group bias has been reported recently in naturally-occurring data by Depew, Eren and Mocan (2017), who found that Louisiana juvenile court judges assign longer sentences to defendants who are of the same race as them. This could be because judges are elected in Louisiana and therefore they may be avoiding giving the impression to the voters of favoring their own race, and thus they may go overboard. This is, of course, not the case in our paper because our evaluators do not have such a concern. 
Another explanation could be that an evaluator, who belongs to a minority or majority group, might consider a defendant of the same group as a representative of the group. In that case, the evaluator might be harsher towards the defendant for badly representing the group for just being put in front of the judge, and this sentiment can translate into convicting the defendant even if the case against him in the court hearing may not have been very strong. ${ }^{30}$ Negative in-group bias that can be attributed to this effect has been detected in lab experiments where in-group members have violated a social norm (Mendoza et al. 2014, Goette et al. 2006).

A subtle explanation of the negative in-group bias, suggested by Table 4A, could be that evaluators are unbiased against their own race but that they are more lenient towards the other race. Although this hypothesis cannot be reliably tested using data that are obtained from court cases, ${ }^{31}$ it can be tested in our data because, by construction, the race of the judge is orthogonal to other variables. This analysis, which is reported in Table $4 \mathrm{~B}$, displays the results based on Equations (2A) and (2B). These models help identify the source of the in-group bias (i.e. whether in-group bias is driven by white or minority evaluators). The first column of Table 4B presents the results of the regression that uses the sample of white defendants, and column (2) is based on the sample of minority defendants. As shown in column (1) of Table 4B, the coefficient of White Evaluator is 0.049 (albeit statistically insignificant), indicating that white defendants are treated more harshly by white evaluators. Specifically, white defendants are about 5 percentage points

\footnotetext{
${ }^{30}$ In a different context, Corell et al. (2002) and Correll et al. (2007) used subjects such as police officers and college students in videogame-like simulations, where the subjects viewed a series of images of black or white individuals, sometimes holding guns or other objects. Subjects' decisions to shoot or not to shoot these targets revealed racial biases in the speed with which the decision are made, and both white and black subjects displayed the same shooter bias against black targets. Subjects were faster when shooting an armed black man in comparison to an armed white man; they were more careful in not shooting an unarmed white man in comparison to an unarmed black man. List and Price (2009) reported that minority donors are less likely to make a contribution for a charity during a door-to-door fundraising drive if the solicitor is also a minority, and that the size of the gift is lower, conditional on the decision to give, suggesting lack of trust.

${ }^{31}$ This is because the regression need to include judge fixed-effects, which makes it impossible to include the judge race indicator.
} 
more likely to get convicted by white evaluators. Column (2) of Table 4B indicates that minority defendants are 5.6 percentage points more likely to get convicted if they face a minority evaluator, although the coefficient is not statistically significant. ${ }^{32}$ This, with the proviso that the effects are not estimated with precision, Tables $4 \mathrm{~A}$ and $4 \mathrm{~B}$ indicate the existence of negative in-group bias in conviction decisions, with effects in equal magnitude in case of white and minority evaluators. Put differently, evaluators are harsher against defendants of their own race in conviction decisions, and that this effect is driven equally by white and minority evaluators.

\section{Overall Racial Bias in Conviction Decisions}

Table 4C presents the results of estimating Equation (3) that investigates the overall racial bias in conviction decisions, where the outcome is the probability of conviction and the key explanatory variable is the race of the defendant. The results show that minority defendants are about 12 percentage points more likely to get convicted in comparison to white defendants, which is consistent with the result of in-group bias regressions (Table $4 \mathrm{~A}$ ). ${ }^{33}$ This indicates that two defendants, whose cases are identical in every respect except for their race, receive different resolutions. Specifically, the defendants face the same exact criminal charge with the same exact mitigating and aggravating circumstances. They are charged by the same prosecutor and are defended by the same attorney in the same exact way (same spoken language and same body language in the courtroom). Nevertheless, minority defendants are 12 percentage points (about 16 percent) more likely to get convicted in comparison to the white defendant, all else being the same. Furthermore, this differential outcome emerges regardless of whether the decision-maker is a minority or whether he/she is a member of the white majority in the population.

\footnotetext{
32 Not surprisingly, this finding is consistent with the mean conviction rates reported in Table 3. The conviction rate of white defendant-white evaluator matches is 0.68 , whereas the rate is 0.65 for white defendant-minority evaluator matches (Row 1, columns 3 and 4). The conviction rate of minority defendant-minority evaluator matches is 0.82 , while the rate is 0.78 for minority defendant-white evaluator matches (Row 1, columns 5 and 6).

${ }^{33}$ The version of this model with evaluator fixed effects, which provides the same inference, is presented in Table A2-2.
} 


\section{Sentencing Decisions: Prison Term and Fine}

Those defendants who are found guilty are sentenced to a prison term and/or fine. Because there is overall racial bias in the conviction decision (Table 4C) this bias contaminates the sample of defendants who are sentenced. More specifically, the existence of racial bias in convictions implies that some minority defendants, who should not have been convicted, are nevertheless found guilty because of their race. If these individuals represent borderline cases in the conviction-acquittal decision, they may receive lenient punishment in the sentencing phase. In this case, OLS estimates of racial bias in sentence length and fine would be biased downwards. To account for such selection, we follow Hoffman and Oreopoulos (2009) and Angrist et al. (2006) and trim the sample of those who are found guilty. This procedure assumes that evaluators use a higher standard to determine guilt in case of white defendants, which implies that the marginal convicted minority defendant is "less guilty" than marginal convicted white defendant. Therefore, we trim out "excess" minority defendants (with lowest levels of punishment) to obtain equal-size groups by race at the sentencing phase. ${ }^{34}$ We, however, also report the results based on the entire sample of convicted defendants, without trimming the sample.

In Table 5 we display the conviction rates of white and minority defendants by the race of the evaluator they faced. White evaluators made 408 decisions on minority defendants and they made another 408 decision on white defendants. These white evaluators convicted minority defendants 78 percent of the time, while they convicted white defendants with 68 percent probability. This generated 319 convicted and sentenced minority defendants, but only 276 white defendants who are found guilty and then sentenced. Put differently, the 10 percentage point difference in the conviction rates between white and minority defendants (0.78 vs. 0.68 ), which

\footnotetext{
${ }^{34}$ In the robustness section we use an alternative method of correction sample selection. We assign zero punishment (zero months of prison term and zero fine) to all defendants who are found not guilty. We then use all defendants, regardless of whether or not they were convicted, in the sentencing regressions.
} 
is due to racial bias of white evaluators, generated 43 excess minority defendants to be sentenced by white evaluators (319-276=43).

As shown in Tables 4A-4C, and as Table 5 also demonstrates, minority evaluators too are biased against minority defendants in their conviction decisions (conviction rates of 0.82 vs. 0.65 as shown in columns (3) and (4) of Table 5). This has created 9 excess minority defendants (4233=9) sentenced by minority judges. The trimming procedure allows us to determine these marginal defendants and drop them from the sample. This is achieved by analyzing the sentence distribution of all 319 minority defendants who are convicted by white evaluators and by dropping 43 of these who received the lowest sentences from these white evaluators. Among the 319 minority defendants who are found guilty by white evaluators, there are exactly 43 defendants for whom both the effective prison sentence is zero and the effective fine is zero. That is, white judges assigned prison terms and fines, and then suspended all of the prison term and the entire fine in these 43 cases. We applied the same procedure to drop the 9 minority defendants (to bring down the number of sentenced minority defendants to the number of sentenced white defendants: from 42 to 33) who were convicted and then sentenced by minority evaluators: those who are at the far left tail of the sentence distribution. ${ }^{35}$ We report the results based both on the trimmed sample as well as those based on the untrimmed sample (the entire group of convicted defendants).

Table 6A presents the estimation results of the in-group bias analysis (Equation 1) where the outcome is the effective prison sentence. Recall that effective prison sentence is the actual prison sentence imposed on the defendant, which is the difference between the initial sentence handed down by the evaluator and the suspended sentence (see Table 3). This sample includes those

\footnotetext{
${ }^{35}$ Six minority defendants who are convicted by minority evaluators had zero effective prison time and zero effective fine assigned to them. These are the minority defendants with no effective sentences, and they are dropped. Among the remaining convicted minority defendants, we dropped those who had zero effective prison time coupled with lowest effective fines (which were 100 and 300 Euros).
} 
defendants who are found guilty. Panel A of Table 6A presents the results that employ the trimmed sample, and Panel B displays the results that are based on the whole sample (the entire group of convicted defendants). The results reveal existence of positive in-group bias in prison sentencing. The estimated coefficient of the interaction term Minority defendant * Minority Evaluator is negative and significantly different from zero in every specification in Table 6A.

The magnitude of the coefficients in Table 6A indicate that if the defendants are sentenced by an evaluator of their own race, they receive prison sentences that are almost 4 months shorter, on average. This is a big impact as the average sentence length is 4 months. Regressions that included evaluator fixed effects provided the same conclusion (Appendix 2, Table A2-3).

Table 6B presents the results of the analyses that investigate the source of the in-group bias in prison sentence. Here, effective sentence lengths are regressed on the race of the evaluator, conditional on the race of the defendant (see Equations 2A and 2B). Columns (1) and (2) employ the sample of white defendants and columns (3) and (4) use the sample of minority defendants. Within each group, the first column reports the results based on the trimmed sample (columns 1 and 3), whereas the second column (columns 2 and 4) use the entire (untrimmed) sample of convicted defendants. Note that he sample sizes are the same between these two samples of white defendants (columns 1 and 2), and therefore the results in these columns are identical. This is due to the fact that in case of white defendants, trimmed and untrimmed samples are one and the same because the sample is trimmed by eliminating “excess” minority defendants who were convicted because of their race by both white and minority evaluators. Columns (3) and (4) of Table 6B show that in the sample of minority defendants, if the evaluator is also a minority, the prison term is about to 1.7 months shorter. Columns (1) and (2) display the results of the same analysis in the sample of white defendants who were found guilty. Convicted white defendants receive sentences that are about 2 months shorter if they face an evaluator who is also white, although the impact is not statistically different from zero. The equality of the coefficients of the 
evaluator race between columns (1) and (3) and between columns (2) and (4) cannot be rejected. These results indicate positive the in-group bias in the assignment of prison sentence. Convicted defendants receive shorter sentences if their race is matched with the race of the judge, and that this bias is driven equally by white and minority evaluators.

Table 6C presents the estimation results of the overall racial bias in the assigned effective prison term. Trimming the sample of convicted defendants is expected to eliminate the marginal minority defendants who should not have been found guilty in the absence of racial bias in convictions. Thus, trimming should eliminate the downward bias in the estimated effect of the defendant's race on prison sentence. As expected, the coefficient of Minority Defendant is larger when the regressions use the trimmed sample in Panel A of Table 6C. The results indicate that minority defendants receive about 0.7 months longer prison terms when the racial selection bias in conviction is not adjusted for (panel B of Table 6C), but that minority defendants receive 1.3 months longer sentences (about 32\% from the mean) if selection is accounted for. ${ }^{36}$ Models with evaluator fixed effects provided the same inference (Appendix 2, Table A2-4).

In the assault and burglary cases the Belgian criminal code provides the option for the judge to assign a fine in addition to a prison sentence, or in certain circumstances just a fine without a prison sentence. Thus, evaluators can assign a fine to the convicted defendants in addition to a prison term if the evaluators find it appropriate. Table 7A presents the results of in-group bias analyses pertaining to imposing a fine. The dependent variable is the logarithm of the fine imposed on the defendant. ${ }^{37}$ The coefficient of the interaction term (Minority Defendant $\mathrm{x}$ Minority Evaluator) is negative in all specification and the point estimate is around -0.6,

\footnotetext{
${ }^{36}$ As discussed earlier, the coefficient of interest (Minority Defendant) in Table 6C is also recoverable from the two coefficients obtained from the in-group bias regressions of Table 6A: (Minority Defendant) and (Minority Defendant x Minority Evaluator). For example, using column 4 of the trimmed sample of Table 6A, 1.684-(3.766)*0.11 is equal to 1.269 (where 0.11 is the proportion of minority evaluators in the sample). The coefficient of Minority Defendant in column (4) of the trimmed sample in Table 6C is 1.285 .

${ }^{37}$ Because there are some zeros in effective fines, we added one Euro to effective fines assigned by the evaluators.
} 
indicating that defendants who have the same race as the evaluator receive fines that are 46 percent lower. ${ }^{38}$

Models reported in Table 7B reveal that this in-group bias effect is driven by white evaluators. Convicted white defendants receive fines that are 75 percent lower if they are evaluated by a white person (the coefficient of White Evaluator is -1.19), but the impact of the evaluator's race on fine is not significantly different from zero in the sample of minority defendants. The equality of the estimated evaluator coefficients in columns (1) and (2) and in columns (3) and (4) are rejected at the 1 percent and 2 percent level of significance, respectively. ${ }^{39}$ This result reveals positive in-group bias in the assignment of fines, indicating that convicted defendants are assigned lower fines when the person who assigns the fine is of the same race as the defendant, and that this effect is driven by white evaluators.

Table 7C displays the regression results that investigate the existence of overall racial bias in fines. The results in Panel B, that are based on the entire sample, indicate that minority defendants receive fines that are 44 percent higher than those assigned to white defendants who are identical in all respects other than race. Panel A, which reports the results based on the trimmed sample, reveal that correcting the sample selection (stemming from the bias in conviction decision), increases the coefficient of interest to 1.07 , which implies that minority defendants receive fines that are 185 percent higher. ${ }^{40}$

In summary, the results of Tables 6A-7C reveal positive in-group bias in prison sentence and fine that are assigned to convicted defendants: evaluators treat defendants of their own race more leniently during the punishment phase. Because the majority of the evaluators in the sample are

\footnotetext{
${ }^{38}$ The impact is calculated as $\exp \{\beta-0.5 \operatorname{Variance}(\beta)\}-1$, where $\beta$ is the estimated coefficient, and $\operatorname{Var}(\beta)$ is its variance (Kennedy 1981).

${ }^{39}$ Models with evaluator fixed effects can be found in Appendix 2, Table A2-3.

${ }^{40}$ Models with evaluator fixed effects can be found in Appendix 2, Table A2-4.
} 
white $^{41}$, the in-group bias in prison time and fines translates into overall racial bias against minorities in sentencing. ${ }^{42}$

Recall that we find negative in-group bias in the convictions decisions (Tables 4A and 4B, although the effect is not statistically significant) but that the in-group bias in the sentencing phase is positive. This means that evaluators are harsher towards defendants of their own race during the guilt-innocence decision, but that they favor same-race defendants during sentencing phase. This is the first paper that identifies such opposing effects within the same decision sequence.

\section{$\underline{\text { VII. Extensions and Robustness }}$}

We used an alternative measure to determine the cultural background of the evaluators. Instead of making use of information on parents' country of origin, we determined whether the evaluator is a minority in Belgium by using information on the language used in the household (see the Data Section on details). Using this alternative indicator of minority status provided very similar point estimates.

The unconditional mean of the prison sentence and the fine assigned by the evaluators are smaller than their respective variances and the distributions are left-skewed. Therefore, we estimated the prison term and fine regressions using negative binomial models, which provided the same inference. ${ }^{43}$

\footnotetext{
${ }^{41}$ Eighty-nine percent of the evaluators are white (see Table 2).

${ }^{42}$ Recall that, as described at the end of section $\mathrm{V}$, the racial bias coefficient $\beta_{4}$ (the coefficient of Minority Defendant in Equation (3) is equal to $\beta_{1}+\mathrm{p} \delta_{1}$, where $\beta_{1}$ and $\delta_{1}$ are the relevant coefficients from the ingroup bias regression (1), and $p$ is the proportion of white evaluators.

${ }^{43}$ For example, Table 6C shows that minority defendants receive prison sentences that are 1.3 months longer, which is about a 32 percent increase from the mean sentence length. Negative binomial models provided an estimate of this racial bias of 31 percent. Similarly, Panel A of Table 7C shows that minorities receive fines that are 185 percent higher than their white counterparts (implied by the coefficient of 1.071). The negative binomial model reveals a smaller, 28 percent effect of the race of the defendant on the amount of the fine assessed.
} 
During the experiment the evaluators had the option (as the actual judicial procedure allows for) to reflect and to revise their original decisions on conviction, prison sentence and fine. There are 153 evaluators who made 2,258 decisions (918 decisions on whether to convict, and 670 decisions on prison sentence and fine on those who are found guilty). We divided the sample into two groups: those evaluators who never altered their first decisions (88 evaluators) and those who made at least one change in their decisions (65 evaluators). Changing a decision may indicate that the evaluator contemplated more carefully about the case and therefore felt the need to revise his/her original decision. Alternatively, if an evaluator was very deliberate in watching the presentations of the prosecutor and the defense attorney and if the evaluator read the case file carefully, he/she did not have the need to go back and revise the original decisions about conviction and/or sentencing. It is also possible that changing a decision at the end of the experiment may indicate that the evaluator has realized the purpose of the experiment, and as a result he/she went back to revise at least one of the decisions he/she made during the experiment. In this case, any statistically significant effect of racial bias would disappear or would be smaller in the sample of evaluators who changed at least one of their decisions. In any case, it is interesting to investigate whether the results are different between these two groups of evaluators.

To investigate whether the evaluators took their task seriously, we analyzed the time they spent in making their decisions. Figure 4 displays the distribution of total time spent on 6 trials by evaluators for decision-making. For example, 500 seconds means that that the evaluator took on average 1 minute and 23 seconds to decide on a case after he/she completed watching the VR video of the case. ${ }^{44}$ Recall that the evaluators read the case files prior to watching the VR videos of the case. The case file contains information about the case (police report, etc., as well as the sentencing guidelines for that particular crime. See Appendix 1). A quick decision after reading the case files and after watching the trial may imply that the evaluator watched the trial

\footnotetext{
44 This is total time spent to make the decision on guilt/innocence, and on prison sentence and fine.
} 
carefully and formed an opinion during the trial, and did not have to think long about the verdict and punishment. Alternatively, a quick decision may indicate that the evaluator did not pay attention to the case and made a quick and haphazard decision. To investigate the sensitivity of the results to decision time, we dropped from the sample the 25 percent of fastest evaluators and the 25 percent of the slowest evaluators and re-estimated the models. We repeated the exercise by dropping the slowest and fastest 30 percent, 20 percent, and 15 percent of the distribution of cases, and obtained very similar results.

Similarly, the evaluators may have gotten fatigued during the experiment and they may have lost their concentration towards the end. If this is the case, the decisions made later during the experiment should be less careful and more noisy. Alternatively, they may have realized the purpose of the experiment, and may have made their decisions accordingly. To investigate this point, we analyzed the first three decisions and the last three decisions made by the evaluators to analyze any differences in the results between the groups. Finally, we re-estimated the models using the sample of male or female evaluators and using only law students or only economics students.

Table 8 summarizes the results obtained from these analyses. Overall Bias indicates the estimated coefficient of Minority Defendant in the relevant regression. In-group bias pertains to the coefficient of Minority Defendant x Minority Evaluator. Column (1) replicates the estimates obtained from the entire sample as presented in Tables 4A-7C. Columns (2) and (3) report the results based on the first three and last three decisions, respectively, of each evaluator. Column (4) presents the estimates related to cases in which the evaluators have modified at least one of their initial decisions. Column (5) pertains to the sample of cases where the initial decisions are not modified. Finally, columns (6) and (7) present the estimates where slowest 25 percent and fastest 25 percent of evaluators are dropped from the estimation sample. As Table 8 reveals, the estimates are highly consistent across various sub-samples, which indicates that fastness or 
slowness of decision-making, altering or not altering the initial decisions, or decisions made earlier or later during these six trials have no significant impact on the results. Similarly, there is no appreciable difference between law students and economics students (columns 10 and 11) and between male and female evaluators (columns 8 and 9), with one difference: racial in-group bias is not significantly different from zero in case of female evaluators. ${ }^{45}$

Punishment decisions (prison sentence and fine) are made on those who are convicted. Recall that the results reveal racial bias in the conviction decisions against minorities (Table 4C). This means that the sample of convicted defendants include some minority defendants who are found guilty because of their race. Thus, in the analyses pertaining to prison term and fine we also reported the results obtained from the trimmed samples which drop marginally innocent minority defendants. Alternatively, instead of trimming the sample to eliminate marginally not guilty defendants, we used all defendants regardless of their conviction status, but assigned a prison sentence of zero and a fine of zero to those who were found not guilty. We then used the entire sample to run prison sentence and fine regressions. The results, presented in Appendix Tables A2-7 to A2-10, are consisted with those reported in 6A to 7C. The estimated impacts are smaller in magnitude but they are sizable and statistically significant.

\section{Is it race or something else?}

Could these findings be an artifact of some other attribute of the defendants? For example, could it be the case that the body language of the defendants is influenced by their race and that it is the body language, rather than the race of the defendants, that triggers the response of the evaluators? There are a number of answers to this question. First, in our six trials and 2 versions of each trial (generating 12 versions with six white and six minority defendants), body language

\footnotetext{
${ }^{45}$ There are 9 female minority evaluators and 8 male minority evaluators.
} 
is very similar between white and minority defendants (see the pictures of the trials with white and minority defendants by scrolling down at http://proficient.ninja/uhasselt/). This is because after shooting a particular trial with the white defendant, that video was shown to the minority defendant (who would replace the white defendant in that particular video) so that he could mimic the body language of the white defendant.

The body language of the defendants did not project any disrespect towards the judge or the prosecutor either. ${ }^{46}$ The only possible difference was the white defendant in trial 1 , who occasionally crossed his legs, while other defendants never crossed their legs. If crossing legs while sitting in front of the judge is considered as disrespectful behavior, which should be punished, this would imply that this white defendant received harsher punishment than what was appropriate, and it indicates that our results are potentially an underestimate of the racial bias we detect against minorities.

One can argue that minorities would be more timid and nervous during a trial because of cultural reasons, while white defendants would be more self-confident. Self-confidence could signal innocence, while being timid and nervous could suggest the acceptance of guilt, and this could be the reason why the evaluators were biased against minorities. This argument has no validity because, as discussed above, minority defendants were told to mimic the body language of the white defendants. Second, recall that minority defendants are more likely to get convicted by both white and minority evaluators. Given that minority evaluators would not fall into such a trap of cultural misunderstanding of the body language of their own in-group, this result cannot be attributed to possible differences in body language.

\footnotetext{
${ }^{46}$ The spoken language did not differ between the defendants. They did not speak during the trial with the exception of their statements regarding their understanding of the charges, their statement about a "not guilty" plea and their statement about not adding anything else to their attorney's defense. These statements were: "Yes," "Not guilty” and "No."
} 


\section{The Analysis of Attorney Decisions}

As described in the data section, 36 attorneys also participated in the experiment. Tables 9 and 10 present the descriptive statistics of the attorney sample. It is interesting to note that only 28 percent of lawyers revealed that they had trust in the legal system, when the rate was 44 percent among law and economics students, and 36 percent in the Belgian population (see footnote 25). The rate of trust in police is identical between attorneys and students (42 percent), while it is 58 percent in the overall population. The proportion of attorneys who believe that Belgium became a worse place to live because of immigration is 67 percent ( 59 percent among students, and 75 percent in the population), and 75 percent of the attorneys believe that terrorism is an important problem in Belgium (48 percent among students).

Table 10 displays the summary statistics related to the conviction and sentencing decisions made by attorneys. Attorneys convict at a lower rate in comparison to students, but consistent with the behavior of students, attorneys too convict minority defendants at a higher rate (69 percent conviction rate among minority defendants vs 55 percent conviction rate among white defendants). Average effective prison sentence is similar between attorneys and students, and the average fine assigned by attorneys is only slightly lower (420 Euros vs. 468 Euros). ${ }^{47}$

Because there is no racial variation within lawyers (they are all white), in-group bias in lawyer decisions cannot be analyzed. Instead, we focus on estimation of Equations (3) which investigates the existence of racial bias. Table 11A displays the results obtained from the lawyer sample regarding racial bias in conviction decision, and shows that minority defendants are about 14 percentage points more likely to be found guilty by practicing lawyers, holding constant everything else about the attributes of the case and trial environment. Estimating Equation (3) that includes lawyer fixed effects provided identical coefficient for the Minority Defendant

\footnotetext{
${ }^{47}$ These are weighted averages of fines assigned to minority and white defendants shown in row (7) of tables 3 and 10.
} 
dummy. It is interesting to note that the size of the racial bias coefficient estimated in the sample of attorneys (14 percentage points as shown in Table 11A) is almost the same as the one estimated among the sample of law students (14.6 percentage points as shown in Table 8, column 10).

Tables $11 \mathrm{~B}$ and $11 \mathrm{C}$ present the regression results that analyze the impact of defendant race on prison sentence and fine assigned by attorneys. ${ }^{48}$ While Table $11 \mathrm{~B}$ indicates that minority defendants receive sentence lengths that are on average 0.7 month longer, this effect is not statistically different from zero. On the other hand, Table $11 \mathrm{C}$ reveals that attorneys assign 131 percent larger fines to convicted minority defendants (implied by the coefficient of 0.927). Thus, the analysis of attorneys' decisions reveal a pattern that is similar to those observed in the behavior of law students and economics students. Minority defendants are more likely to get convicted for the same exact crime, based on the same arguments made by the prosecutors and for the same defense by their attorney, and they are more likely to receive stiffer punishment upon conviction.

Because there are only 36 attorneys in the sample, it is not feasible to divide them into groups (slow vs. fast decision makers, first three decisions vs. last three decisions, and so on) in order to analyze whether the decisions differ between groups. Instead, we added the attorneys to the student sample, and re-ran the various models reported in Table 8. In these models we included an indicator for attorneys and interacted it with the Minority Defendant dummy to analyze whether attorney decisions differ from those of the students in various sub-groups. The results are summarized in Table 12. The entries are the coefficients (standard errors) of the Minority

\footnotetext{
${ }^{48}$ Each of the 36 lawyers evaluated each of the six cases, yielding to 216 decisions on conviction versus acquittal (108 cases of white defendants and 108 cases of minority defendants). Fifty-nine of the white defendants are convicted (55 percent), while conviction rate among minority defendants was 69 percent (74 minority defendants are convicted). This implies the existence of 15 "excess" convicted minority defendants. Ranking of the 74 convicted minorities by sentence length and fine showed that 12 defendants received zero effective prison term and zero effective fine, despite their conviction. These are the marginal convicted defendants, who are arguably not guilty despite being convicted. Of the remaining convicted defendants with effective prison terms of zero months, we dropped three people who are sentenced to zero months effective prison term and the lowest initial fines assigned as punishment (two people with 100 Euro fines, and one person with 104 Euros).
} 
Defendant dummy in each regression. The coefficient of the interaction term between Minority Defendant dummy and the Attorney dummy was never different from zero in any of the regressions. The results displayed in Table 12 are very similar to those shown in Table 8, indicating that analyzing attorneys and students as one group yields the same results as those obtained from the analysis of students, implying no significant differences in behavior between these two groups of evaluators.

\section{Judges and Prosecutors}

The attorneys in our analyses are criminal trial lawyers and therefore they have experience with real-life trials. Nevertheless, one can argue that attorneys do not make decisions like judges do, and therefore attorney decisions, although one step closer to the real world in comparison to economics students and law students, may not represent the decisions of judges. We tried to recruit judges and prosecutors for them to evaluate the cases in the same exact way our other evaluators did. As explained in the data section, only eight judges and four prosecutors agreed to participate in the VR evaluations of these trials. Therefore, their decisions cannot be analyzed separately. We, however, merged the judge/prosecutor sample with the attorney sample and reran the racial bias regressions, including indicators for being a judge and a prosecutor. ${ }^{49}$ The results are reported in Tables 13A to 13C. The estimated coefficient of the Minority Defendant in Table 13A indicates that minorities are 10 percentage points more likely to get convicted in this sample (the impact was 14 percentage points in the sample of lawyers in Table 11A). Table 13B shows that, as in the case of lawyer results (Table 11B), the impact of minority defendant is positive but not different from zero in the prison sentencing models. The coefficient of minority dummy is 0.86 in the fine regressions of Table 13C (it was 0.93 in Table $11 \mathrm{C}$ of the lawyer sample), indicating that minorities are assigned fines that are 136 percent larger in comparison

\footnotetext{
${ }^{49}$ Because all lawyers, judges and prosecutors are white, in-group bias cannot be investigated.
} 
to white defendants. Thus, adding eight judges and four prosecutors to the sample of 36 attorneys increases the sample size of attorneys by one third, and the results obtained from this combined sample of attorneys, judges and prosecutors are similar to those obtained from the sample of attorneys, suggesting that judge and prosecutor decisions on these trials are not substantially different from those of the attorneys.

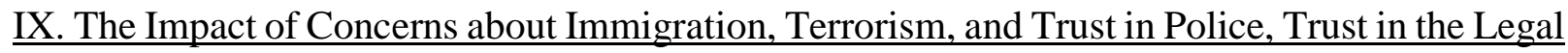
System

We also analyzed the question of whether the conviction and sentencing decisions of the evaluators get impacted by their trust in the judiciary, or by their trust in police. Similarly, we analyzed whether evaluators' beliefs that terrorism is a major problem in Belgium and whether Belgium is made worse off because of immigration has an impact on the results. In each case we created dichotomous indicators to represent the lack of trust or the concern about terrorism and migration as described in the data section. Each of these variables is added to model (3) and interacted with Minority Defendant. These regressions showed that the coefficients of the interaction term were almost always statistically insignificant, indicating that evaluators' trust in the judiciary and trust in police, or their concerns about terrorism or migration had no impact on the conviction or sentencing decisions they made with the following exceptions. In the sample of law students and economics students, the concern about immigration increased the racial bias in prison sentencing. Specifically, if the evaluators believe that Belgium is made a worse place to live by people coming to live here from other countries, they assign sentence lengths to minority defendants that are 1.6 months longer in comparison to those who do not believe that immigration has made Belgium a worse place to live. Similarly, those attorneys who do not trust 
police are about 20 percentage points more likely to convict a minority defendant in comparison to attorneys who have trust in police. ${ }^{50}$

Evaluators' concerns about immigration, terrorism and their trust in the judicial system and the police are measured by their responses to four questions (see Section IV and Table 2). For example, Trust in the Legal System takes the value of 1 if on a scale from 0 (no trust) to 10 (complete trust) the evaluator chose a value of 7 or higher. Measurement error in these variables can have an impact on the results, and unlike classical measurement error in explanatory variables of econometric analyses, the direction of the bias might be unclear in experimental studies (Yariv, Gillen and Snowberg 2018). Therefore, to investigate the sensitivity of the results to the manner in which evaluators' concerns about immigration, terrorism and their trust in the judiciary and police are measured, we used different cutoffs for classification. For example, we classified evaluators as trusting the legal system if they chose 6 or higher on the scale from 0 to 10 . This provided a sample mean of 60 percent of evaluators having trust in the legal system. Alternatively, we classified evaluators as having trust in the legal system if they chose 8 , 9, or 10, which generated a sample mean of 0.20 for trusting the legal system. Similarly, we altered the cutoffs of questions about trust in police, and about concerns for immigration and for terrorism. $^{51}$ Estimating the models based on these alternative measures did not alter the inference. Specifically, the belief that immigration made Belgium a worse place to live prompts student evaluators to assign 1.4 to 2.5 month longer prison sentences to minority defendants. In the lawyer sample the results of these alternative estimations showed that having no trust in the

\footnotetext{
${ }^{50}$ We repeated the same exercise using Equation (1) to investigate the impact of the concerns about immigration, terrorism and the trust in police or the judiciary on in-group bias by interacting these variables with Minority Evaluator, Minority Defendant, and Minority Defendant x Minority Evaluator. No pattern of the coefficient of the triple-interaction term (Minority Defendant x Minority Evaluator $x Z$, where $Z$ represents the variable about immigration, terrorism, trust in the judiciary or trust in police) was detected in these analyses, which is likely because of very low sample variation in this variable. The sample means of these variables range from 0.01 to 0.04 .

${ }^{51}$ These alternative cutoffs provided the following sample means: 0.10 and 0.60 for trust in police, 0.10 and 0.60 for believing that terrorism is an important problem, and 0.3 and 0.7 for believing that Belgium is made a worse place to live because of immigration.
} 
judiciary prompts lawyers to assign prison sentences on minorities that are 3.6 to 5.5 month longer in comparison to lawyers who have trust in the judicial system.

\section{$\underline{X . ~ S u m m a r y ~ a n d ~ C o n c l u s i o n ~}$}

In this paper we investigate whether the decision about guilt vs. innocence of an individual, who is being accused of a crime, is impacted by his race. We also ask whether the extent of the punishment he receives (prison sentence and fine) depends on his race. Do these judicial decisions depend on whether or not the defendant and the judge are of the same race; i.e. is there in-group bias in judicial decisions? If so, are these influences stronger in case of white judges or minority judges? If there exist race effects on these decisions, are they impacted by whether the judge believes that immigration is a problem, that terrorism is a problem, or whether the judicial system or police can be trusted?

Some of these are old questions, and all of them are important for both scientific inquiry and public policy. These questions, however, have been difficult to answer because of a number of inherent endogeneity issues that emerge in the analysis of data. For instance, even if defendants (some of whom are white and some of whom are minority) are randomly assigned to judges (who also vary in their race), the composition and the attributes of the cases adjudicated by judges are influenced by actors other than the judge and the defendant. As an example, if prosecutors are more lenient and generous towards a particular group of defendants during the plea-bargaining stage, or if prosecutors are less diligent and less aggressive towards a group of individuals during the trial, the conviction and sentencing decisions of judges will resemble favoritism towards that group even if judges themselves are unbiased. Similarly, the quality of the defense attorney may be correlated with the race of the defendants. For instance, if minorities are less likely to afford high quality defense attorneys, it will be more likely for minorities to get convicted in a trial. As detailed in Section II, there are other, more subtle, issues that complicate the analyses of judicial decisions and their interplay with race. 
At the heart of the issue lies the near impossibility to create a 'counterfactual scenario' to a trial, which involves the defense attorney, the prosecutor, and the defendant. In this paper we create a design which holds constant everything that takes place during a trial, with the exception of the race of the defendant.

We shot Virtual Reality videos of six criminal trials in Belgium, prosecuted by actual prosecutors and defended by actual defense attorneys in an actual courtroom. Only the defendants in the courtroom are actors. The prosecutors and the defense attorneys are given the case files one week before the shooting of the trials so that they could do the background work and prepare their case and their defense. Similarly, the prosecutors and the defense attorneys presented their cases orally in the court room, as they would normally do. The Virtual Reality technology enabled us to replace white defendants in the courtroom with individuals who have Middle Eastern or North African descent. This allowed us to alter only the race of the defendants in these trials, holding all activity in the courtroom constant, including every word spoken by the prosecutor and the defense attorney, and all the body language in the courtroom. A short clip of two videos can be seen here http://proficient.ninja/splitscreen/. This paper is the first one that utilizes 3D Virtual Reality technology that uses actual people, rather than computer-animated scenes.

Scrolling down at the link http://proficient.ninja/uhasselt/ allows one to observe scenes from all six trials. Full versions of one of these trials can be also be watched (in 2D) at this link. Two versions of this particular trial are titled Video No 4 - Full Version 1 (with the minority defendant), and Video No 4, Full Version 2 (with the white defendant).

This design allows us to bypass the identification challenges faced by previous empirical research, and it enables us to create arguably perfect counterfactuals. In our case, the race of the defendant in each trial is uncorrelated with the characteristics of the prosecutors, with the characteristics of defense attorneys, and with any activity in the courtroom. Defendant race is 
also uncorrelated with evaluator attributes. This feature of the design not only permits us to investigate the existence of in-group bias, but for the first time in this literature, it also allows us to decompose the bias to determine its source.

The only variation in a given trial is obtained from the raceof the defendants. We hold all actions (body language, spoken words, and so on) of the prosecutor and the defense attorney in the courtroom constant. Evaluators, who watched the two versions of a particular trial, observed identical courtroom activity with only one difference: half of the evaluators saw a white defendant, the other half saw a minority defendant. The evaluators don't know the names of the defendants; thus names cannot be used as signals of minority status (Bertrand and Mullainathan 2004). The defendants barely spoke during the trial: they spoke only three times during the trial to answer three questions of the judge about whether they understand the charges against them (they answered “Yes”); whether they plead guilty or not guilty (they answered "Not guilty”), and whether they had anything else to add to what their lawyer said during the trial (they answered “No”). All actor-defendants are born in Belgium and they speak fluent Dutch. Because they had no accent and because they spoke only a few words during the trial their minority status could not be inferred from the way they spoke. Finally, all actor-defendants were instructed to wear similar clothes. Thus, the differentiation between white and minority defendants is obtained from the variation in their skin color. This point is verified by providing pictures of the defendants to another group of 89 freshmen students of Hasselt University. These students identified the race of each defendants correctly with 99 percent accuracy.

A total of 153 Master's degree law students and undergraduate and Master's degree economics students are randomly assigned to watch, from the view point of the judge, the VR videos of these identical criminal trials that differed only in defendants' skin color (See Figures 1 and 2). Background information obtained from the evaluators enabled us to identify their 
cultural heritage. Evaluators made decisions on guilt/innocence as well as prison sentence and fine in accordance with the guidelines provided by the relevant law.

The results provide suggestive evidence of negative in-group bias during the conviction phase. Evaluators are 8.5 percentage points more likely to convict a defendant if he is of the same race as the evaluator, although this effect is not significant at conventional levels. Decomposition of this negative in-group bias shows that the bias is equally strong for both white and minority evaluators. Analyzing overall discrimination in convictions, we find that minority defendants are 12 percentage points more likely to get convicted in comparison to white defendants even though they are tried for the same exact case and even though everything that went on during the trial is the same.

According to the relevant criminal law, convicted defendants can be assigned a prison sentence and/or a fine. In this sentencing stage, we find in-group favoritism. Convicted defendants receive prison sentences that are about 4 months shorter if the evaluator is of the same race. We show that this positive in-group bias in prison sentences is driven equally by white and minority evaluators. Because most evaluators are white, this behavior translates into racial bias in prison sentencing with minority defendants being sentenced on average 1.3 months longer prison terms, which corresponds to a 32 percent increase in prison time. Positive in-group bias also exists in the assignment of fines, but this in-group bias is driven by white evaluators. White defendants who face white evaluators received fines that are 75 percent lower. This behavior translates into racial bias in fines where minority defendants receive fines that are 185 percent higher than their white counterparts.

We repeated the same experiment with a group of 36 practicing attorneys, most of whom specialize in criminal law. Because all of these attorney are white, we could not investigate ingroup bias in their decisions but analyzed the existence of racial bias. The results were similar to those obtained from law students and economics students, both qualitatively and in magnitude. 
A small group of judges and prosecutors, who were not involved in the experiment, also participated as evaluators of these VR trials. Their small sample size (eight judges and four prosecutors) did not permit us to analyze their decisions separately, but when we merged the sample of judges and prosecutors with the sample of lawyers, the analyses provided very similar results to those obtained from the lawyer sample, suggesting that judge/prosecutor decisions are not substantially different from those of the lawyers.

A large number of additional analyses confirm the robustness of the results. For example, the speed with which the evaluators made their decisions, or whether the evaluators altered their original conviction or sentencing decisions have no impact on the results. Similarly, the decisions made during the first half of the experiment (the first three trials) are no different from those made in the second half, and the decisions of men and women are similar.

It is important to underline that the in-group bias in the conviction phase is negative (although not statistically significant) but that the in-group bias in the sentencing phase is positive. In other words, evaluators are harsher towards defendants of their own race when it comes to the guiltinnocence decision, but they favor same-race defendants during the sentencing phase. This finding is important because it reveals a changing pattern of bias (negative-then-positive in-group bias) in the same decision sequence by the same group of evaluators.

We also analyzed whether disparate treatment of defendants is impacted by evaluators' trust in the judiciary, by their trust in police, and by their concerns about terrorism and immigration. We find that with two exceptions ${ }^{52}$ evaluators' trust in the judiciary and their trust in police, or their concerns about terrorism or migration had no impact on their conviction or sentencing decisions, suggesting that the source of the racial bias may be deep-rooted.

\footnotetext{
${ }^{52}$ Law and economics students' concern about immigration lead to longer prison terms for minorities, and lawyers' lack of trust in police lead to higher probability of conviction of minorities.
} 
Figure 1

A Snapshot of the Virtual Reality Videos of the same Trial

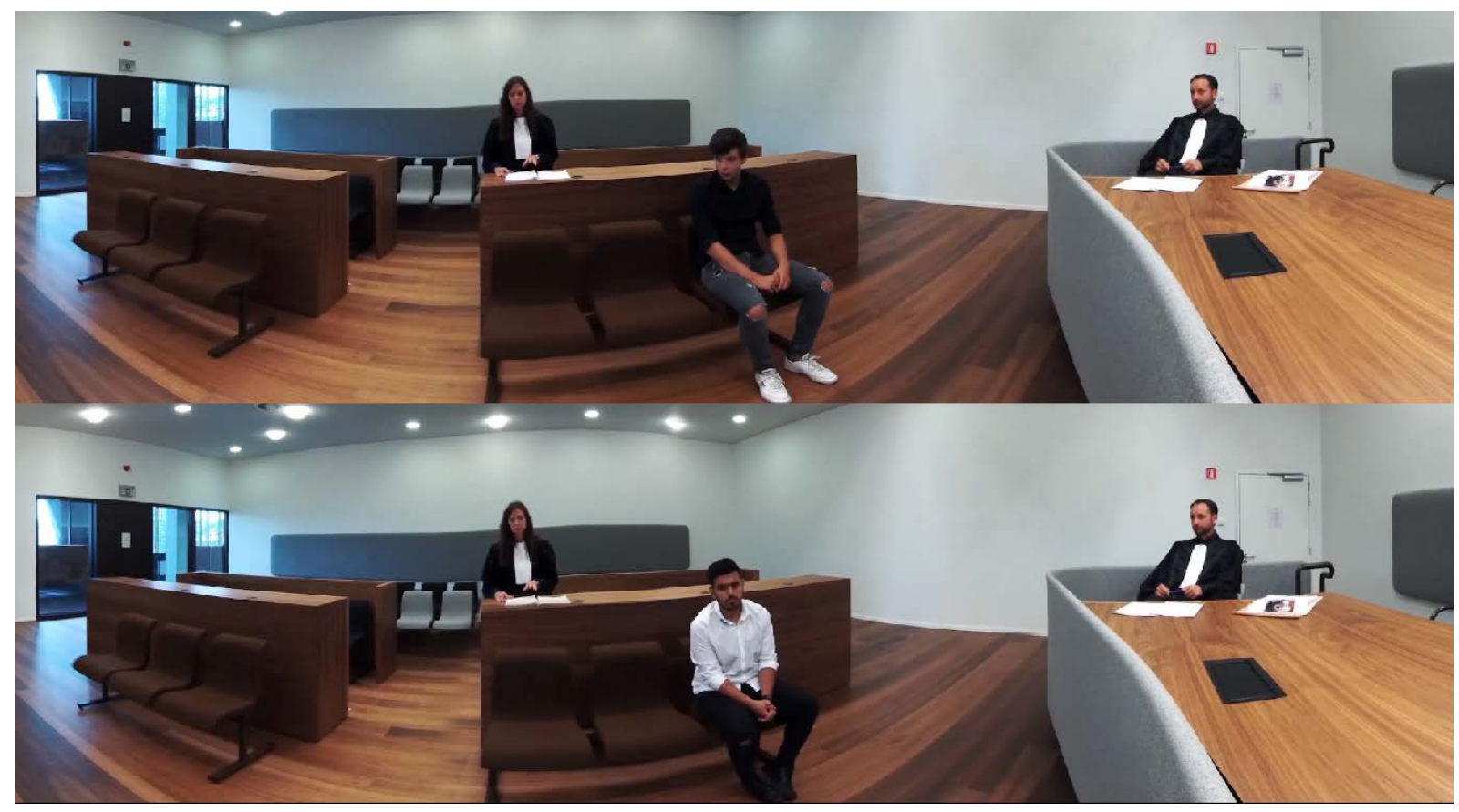

This scene can be watched at http://proficient.ninja/splitscreen/ 
Figure 2

Six Defendants in Six Trials

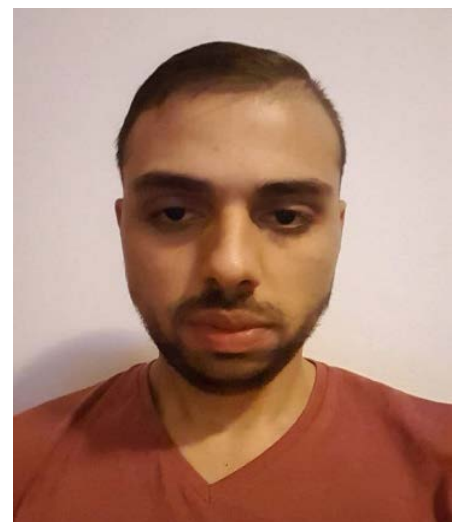

Minority Defendant-1 (M1)

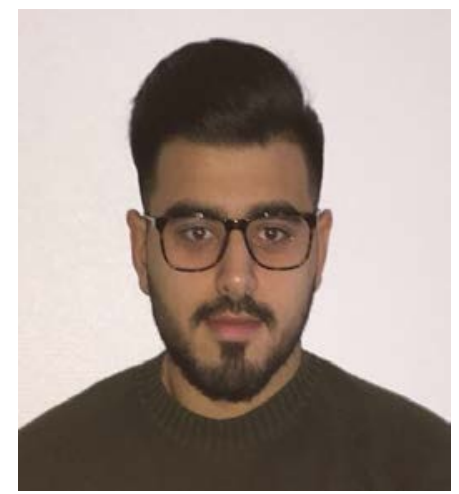

Minority Defendant-2 (M2)

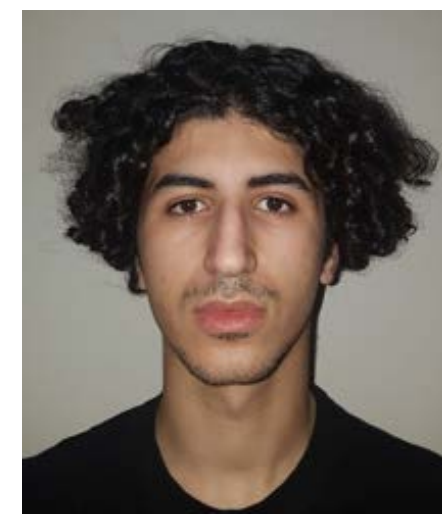

Minority Defendant-3 (M3)

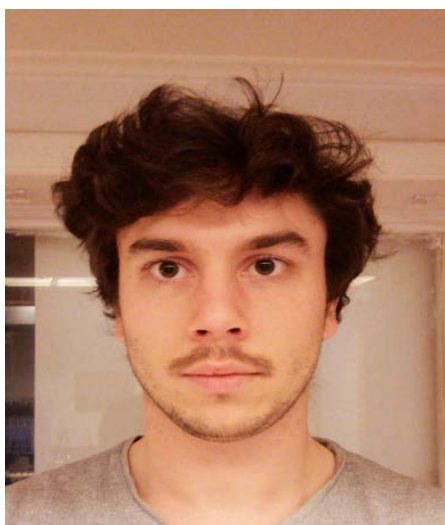

White Defendant-1 (WH1)

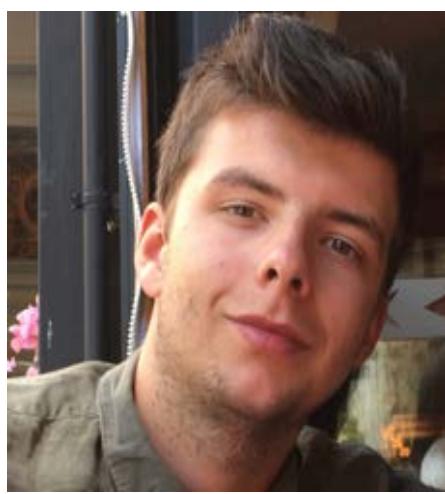

White Defendant-2 (WH2)

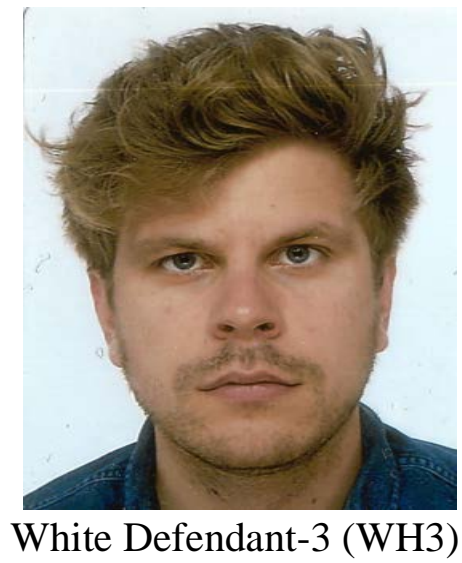


Figure 3

Evaluators Watching the VR Videos of the Trials

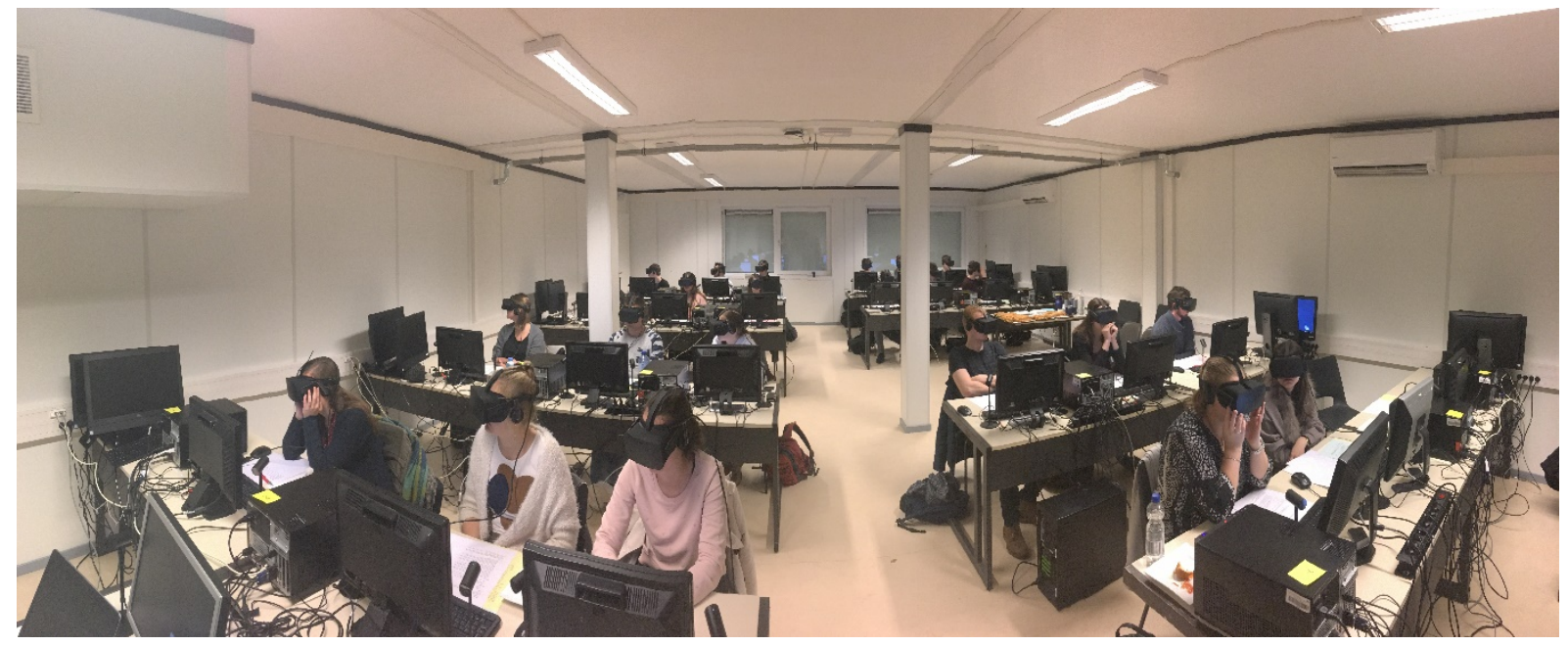

Figure 4

Distribution of Time Taken to Make Decisions (in Seconds)

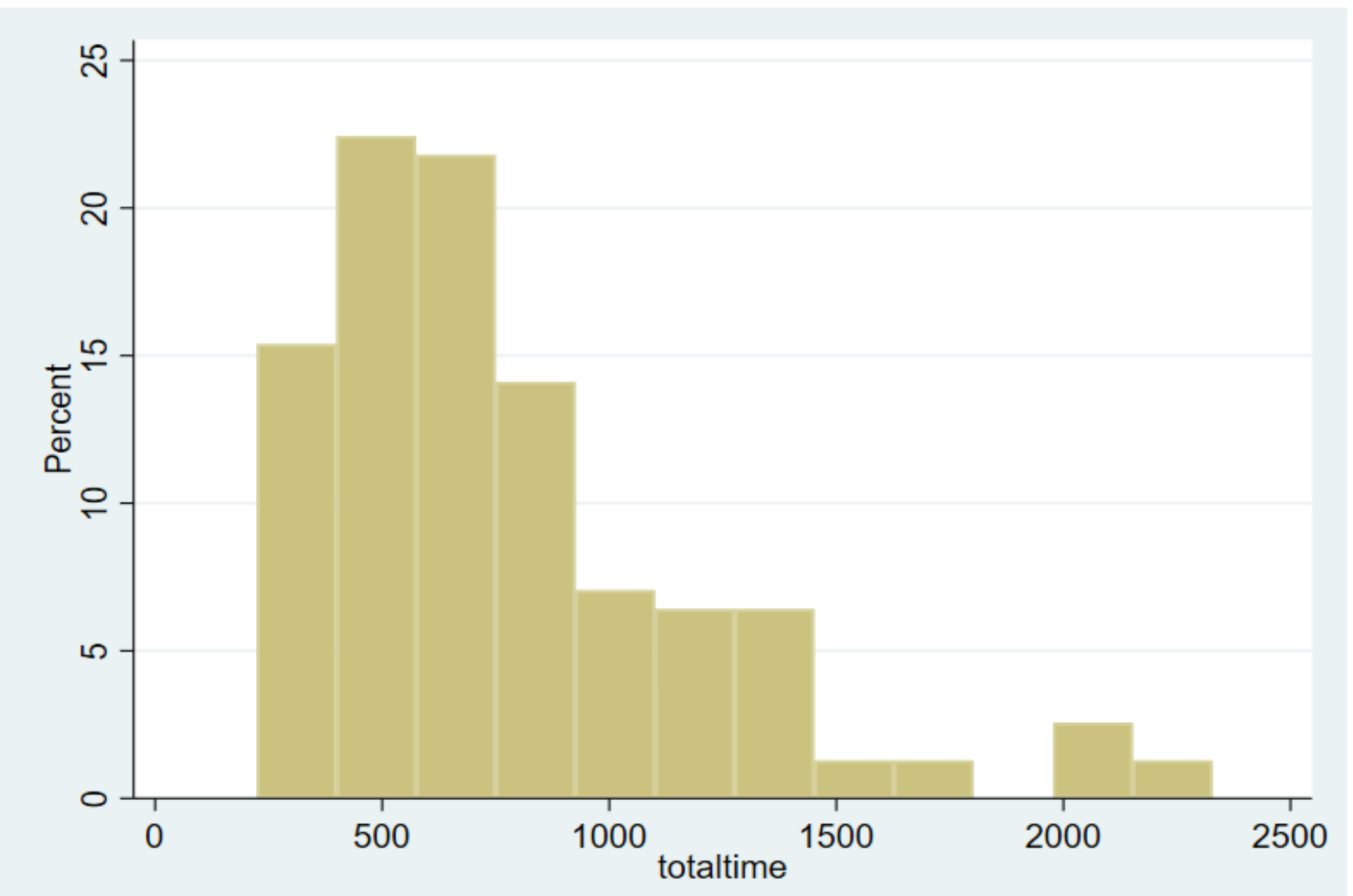


Table 1

The Sequence of Trials Watched by Evaluators, and the Identity of Defendants, Prosecutors and Defense Attorneys in Each Trial

\begin{tabular}{|c|c|c|c|c|c|}
\hline $\begin{array}{c}\text { Set } 1 \\
\text { (Sequence1, } \\
\text { Version 1) }\end{array}$ & $\begin{array}{c}\text { Set } 2 \\
\text { (Sequence1, } \\
\text { Version 2) }\end{array}$ & $\begin{array}{c}\text { Set } 3 \\
\text { (Sequence2, } \\
\text { Version 1) }\end{array}$ & $\begin{array}{c}\text { Set } 4 \\
\text { (Sequence2, } \\
\text { Version 2) }\end{array}$ & $\begin{array}{c}\text { Set } 5 \\
\text { (Sequence3, } \\
\text { Version 1) }\end{array}$ & $\begin{array}{c}\text { Set } 6 \\
\text { (Sequence3, } \\
\text { Version 2) }\end{array}$ \\
\hline${ }_{\mathrm{SO}}^{\mathrm{WH} 1} \mathrm{BUR}_{\mathrm{B}}^{1}$ & ${ }_{\mathrm{SO}}^{\mathrm{M} 1} \mathrm{BUR}_{\mathrm{B}}^{1}$ & ${ }_{\mathrm{TO}}^{\mathrm{M} 2} \mathrm{AS}_{\mathrm{P}}^{3}$ & ${ }_{\mathrm{TO}}^{\mathrm{WH} 2} \mathrm{AS}_{\mathrm{P}}^{3}$ & ${ }_{\mathrm{TO}}^{\mathrm{WH} 2} \mathrm{BUR}_{\mathrm{B}}^{3}$ & ${ }_{\mathrm{TO}}^{\mathrm{M} 2} \mathrm{BUR}_{\mathrm{B}}^{3}$ \\
\hline${ }_{\mathrm{SO}}^{\mathrm{M} 1} \mathrm{BUR}_{\mathrm{B}}^{2}$ & ${ }_{\mathrm{SO}}^{\mathrm{WH}} \mathrm{BUR}_{\mathrm{B}}^{2}$ & ${ }_{\mathrm{M}}^{\mathrm{WH}} \mathrm{AS}_{\mathrm{P}}^{2}$ & ${ }_{\mathrm{M}}^{\mathrm{M} 3} \mathrm{AS}_{\mathrm{P}}^{2}$ & ${ }_{\mathrm{M}}^{\mathrm{M} 3} \mathrm{AS}_{\mathrm{P}}^{1}$ & ${ }_{{ }_{M}}^{\mathrm{WH}^{3}} \mathrm{AS}_{\mathrm{P}}^{1}$ \\
\hline${ }_{\mathrm{TO}} \mathrm{BUR}_{\mathrm{B}}^{3}$ & ${ }_{\mathrm{TO}}^{\mathrm{M} 2} \mathrm{BUR}_{\mathrm{B}}^{3}$ & ${ }_{\mathrm{M}}^{\mathrm{M}} \mathrm{AS}_{\mathrm{P}}^{1}$ & ${ }_{\mathrm{M}} \mathrm{AS}_{\mathrm{P}}^{1}$ & ${ }_{\mathrm{SO}}^{\mathrm{M} 1} \mathrm{BUR}_{\mathrm{B}}^{2}$ & $\mathrm{BUR}_{\mathrm{B}}^{2}$ \\
\hline${ }_{\mathrm{M}}^{\mathrm{M}} \mathrm{AS}_{\mathrm{P}}^{1}$ & ${ }_{\mathrm{M}}^{\mathrm{WH}} \mathrm{AS}_{\mathrm{P}}^{1}$ & ${ }_{\mathrm{TO}}^{\mathrm{WH} 2} \mathrm{BUR}_{\mathrm{B}}^{3}$ & ${ }_{\mathrm{TO}}^{\mathrm{M} 2} \mathrm{BUR}_{\mathrm{B}}^{3}$ & ${ }_{\mathrm{M}}^{\mathrm{WH}} \mathrm{AS}_{\mathrm{P}}^{2}$ & ${ }_{\mathrm{M}}^{\mathrm{M}} \mathrm{AS}_{\mathrm{P}}^{2}$ \\
\hline${ }_{\mathrm{M}}^{\mathrm{WH}} \mathrm{AS}_{\mathrm{P}}^{2}$ & ${ }_{\mathrm{M}}^{\mathrm{M} 3} \mathrm{AS}_{\mathrm{P}}^{2}$ & $\begin{array}{l}\mathrm{M} 1 \\
{ }_{\text {SO }} B_{B}\end{array}$ & ${ }_{\text {SO }}^{\text {WH1 }}$ BUR $_{B}^{2}$ & ${ }_{\mathrm{SO}}^{\mathrm{WH} 1} \mathrm{BUR}_{\mathrm{B}}^{1}$ & ${ }_{\mathrm{SO}}^{\mathrm{M} 1} \mathrm{BUR}_{\mathrm{B}}^{1}$ \\
\hline${ }_{\mathrm{TO}}^{\mathrm{M} 2} \mathrm{AS}_{\mathrm{P}}^{3}$ & ${ }_{\mathrm{TO}}^{\mathrm{W} 2} \mathrm{AS}_{\mathrm{P}}^{3}$ & ${ }_{\mathrm{SO}}^{\mathrm{WH} 1} \mathrm{BUR}_{\mathrm{B}}^{1}$ & ${ }_{\text {SO }}^{\mathrm{M} 1} \mathrm{BUR}_{\mathrm{B}}^{1}$ & ${ }_{\mathrm{TO}}^{\mathrm{M} 2} \mathrm{AS}_{\mathrm{P}}^{3}$ & $\mathrm{WH}_{\mathrm{TO}} \mathrm{AS}_{\mathrm{P}}^{3}$ \\
\hline
\end{tabular}

Each evaluator was randomly assigned to one of these six sets. Each set includes six cases (trials),

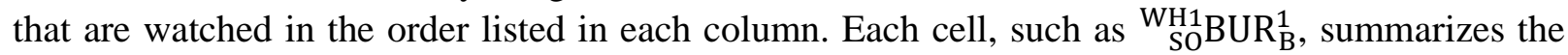
characteristics of that particular trial. BUR and AS stand for a burglary case, and an assault case, respectively. BUR ${ }^{1}$ means the first burglary case, $\mathrm{BUR}^{2}$ means the second burglary case, $\mathrm{AS}^{3}$ stands for the third assault case, and so on.

A subscript to the right identifies the prosecutor: $\mathrm{TH}_{\mathrm{B}}^{1}$ means that the first burglary case is prosecuted by Bruno (B). There are two prosecutors in the experiment: Bruno (B) and Pieter (P). The subscript to the left identifies the defense attorney. There are three defense attorneys: TO, SO and M.

The superscript to the left identifies the defendant. There are three minority defendants: M1, M2, and M3; and there are three white defendants: WH1, WH2 and WH3. See Figure 2 for the pictures of all six defendants.

The entry ${ }_{\text {SO }}^{\mathrm{WH} 1} \mathrm{BUR}{ }_{\mathrm{B}}^{1}$ represents the first burglary case $\left(\mathrm{BUR}^{1}\right)$, where the defendant was WH1. The case was prosecuted by $\mathrm{B}$, and the defense attorney was SO.

The first VR video of Set 1 is ${ }_{\mathrm{SO}}^{\mathrm{WH}} \mathrm{BUR} \mathrm{B}_{\mathrm{B}}^{1}$ and the first video of Set 2 is ${ }_{\mathrm{SO}}^{\mathrm{M} 1} \mathrm{BUR} \mathrm{B}_{\mathrm{B}}^{1}$. These two videos are identical in all respects but one: the race of the defendant (WH1 vs. M1); See Figure 1.

Each evaluator watched one of the six sets depicted in Table 1. Thus, each one of the three burglary cases $\left(\mathrm{BUR}^{1}, \mathrm{BUR}^{2}, \mathrm{BUR}^{3}\right)$ as well as each of the three assault cases $\left(\mathrm{AS}^{1}, \mathrm{AS}^{2}, \mathrm{AS}^{3}\right)$ is watched by each evaluator. 
Table 2

Descriptive Statistics of Evaluator Characteristics

\begin{tabular}{lc}
\hline & Evaluator Attributes \\
\cline { 2 - 2 } Minority Evaluator & 0.11 \\
& $(0.32)$ \\
Male Evaluator & 0.47 \\
& $(0.50)$ \\
Law Student & 0.44 \\
& $(0.50)$ \\
\hline $\mathrm{N}$ & 153 \\
\hline & Evaluator Beliefs \\
Trust in the Legal System & 0.44 \\
$\mathrm{~N}$ & $(0.50)$ \\
\hline \multirow{2}{*}{ Trust in Police } & 151 \\
\hline Terrorism is an Important & 0.42 \\
Problem in Belgium & $(0.50)$ \\
\hline $\mathrm{N}$ & 0.48 \\
\hline Belgium is made a worse place & $(0.50)$ \\
to live by people coming to live & 153 \\
here from other countries & 0.59 \\
\hline $\mathrm{N}$ & $(0.49)$ \\
\hline \hline
\end{tabular}


Table 3

Descriptive Statistics of Conviction Decision, Sentence Length and Fine Imposed by Evaluators

\begin{tabular}{|c|c|c|c|c|c|c|}
\hline & \multirow[b]{2}{*}{$\begin{array}{l}\text { Minority } \\
\text { defendant } \\
\text { (1) }\end{array}$} & \multirow[b]{2}{*}{$\begin{array}{l}\text { White } \\
\text { defendant } \\
\text { (2) }\end{array}$} & \multicolumn{2}{|c|}{ White Defendant } & \multicolumn{2}{|c|}{ Minority Defendant } \\
\hline & & & $\begin{array}{c}\text { Minority } \\
\text { Evaluator } \\
(3)\end{array}$ & $\begin{array}{c}\text { White } \\
\text { Evaluator } \\
(4)\end{array}$ & $\begin{array}{l}\text { Minority } \\
\text { Evaluator } \\
(5)\end{array}$ & $\begin{array}{c}\text { White } \\
\text { Evaluator } \\
\text { (6) }\end{array}$ \\
\hline $\begin{array}{l}\text { (1) Conviction } \\
\text { Rate }\end{array}$ & $\begin{array}{c}0.79 * * * \\
(0.41)\end{array}$ & $\begin{array}{c}0.67 * * * \\
(0.47)\end{array}$ & $\begin{array}{c}0.65 \\
(0.48)\end{array}$ & $\begin{array}{c}0.68 \\
(0.47)\end{array}$ & $\begin{array}{c}0.82 \\
(0.39)\end{array}$ & $\begin{array}{c}0.78 \\
(0.41)\end{array}$ \\
\hline $\mathrm{N}$ & 459 & 459 & 51 & 408 & 51 & 408 \\
\hline $\begin{array}{l}\text { (2) Initial Prison } \\
\text { Sentence (months) }\end{array}$ & $\begin{array}{l}10.2 \\
(8.6)\end{array}$ & $\begin{array}{c}9.6 \\
(7.6)\end{array}$ & $\begin{array}{c}9.8 \\
(8.9)\end{array}$ & $\begin{array}{c}9.5 \\
(7.4)\end{array}$ & $\begin{array}{l}7.7^{* *} \\
(6.2)\end{array}$ & $\begin{array}{c}10.5^{* *} \\
(8.9)\end{array}$ \\
\hline $\mathrm{N}$ & 361 & 309 & 33 & 276 & 42 & 319 \\
\hline $\begin{array}{l}\text { (3) Suspended Prison } \\
\text { Sentence (months) }\end{array}$ & $\begin{array}{c}5.8 \\
(5.2)\end{array}$ & $\begin{array}{c}5.7 \\
(5.6) \\
\end{array}$ & $\begin{array}{c}4.3 \\
(4.9)\end{array}$ & $\begin{array}{c}5.9 \\
(5.6)\end{array}$ & $\begin{array}{c}4.9 \\
(4.7)\end{array}$ & $\begin{array}{c}5.9 \\
(5.3)\end{array}$ \\
\hline $\mathrm{N}$ & 361 & 309 & 33 & 276 & 42 & 319 \\
\hline $\begin{array}{l}\text { (4) Effective Prison } \\
\text { Sentence (months) }\end{array}$ & $\begin{array}{c}4.3 \\
(6.7)\end{array}$ & $\begin{array}{c}3.8 \\
(5.1)\end{array}$ & $\begin{array}{l}5.5^{* *} \\
(6.3)\end{array}$ & $\begin{array}{l}3.6 * * \\
(4.9)\end{array}$ & $\begin{array}{c}2.8 \\
(3.5)\end{array}$ & $\begin{array}{c}4.5 \\
(7.0)\end{array}$ \\
\hline $\mathrm{N}$ & 361 & 309 & 33 & 276 & 42 & 319 \\
\hline $\begin{array}{l}\text { (5) Initial Fine } \\
\text { (Euros) }\end{array}$ & $\begin{array}{c}783 \\
(1,193)\end{array}$ & $\begin{array}{c}697 \\
(1,089)\end{array}$ & $\begin{array}{c}788 \\
(985)\end{array}$ & $\begin{array}{c}686 \\
(1,101)\end{array}$ & $\begin{array}{c}828 \\
(990)\end{array}$ & $\begin{array}{c}777 \\
(1,218)\end{array}$ \\
\hline $\mathrm{N}$ & 361 & 309 & 33 & 276 & 42 & 319 \\
\hline $\begin{array}{l}\text { (6) Suspended Fine } \\
\text { (Euros) }\end{array}$ & $\begin{array}{c}291 \\
(560) \\
\end{array}$ & $\begin{array}{c}278 \\
(520) \\
\end{array}$ & $\begin{array}{c}321 \\
(446) \\
\end{array}$ & $\begin{array}{c}273 \\
(528) \\
\end{array}$ & $\begin{array}{c}311 \\
(585) \\
\end{array}$ & $\begin{array}{r}288 \\
(557) \\
\end{array}$ \\
\hline $\mathrm{N}$ & 361 & 309 & 33 & 276 & 42 & 319 \\
\hline $\begin{array}{l}\text { (7) Effective Fine } \\
\text { (Euros) }\end{array}$ & $\begin{array}{c}492 \\
(1,000)\end{array}$ & $\begin{array}{c}419 \\
(889)\end{array}$ & $\begin{array}{c}467 \\
(738)\end{array}$ & $\begin{array}{c}413 \\
(907)\end{array}$ & $\begin{array}{c}518 \\
(765)\end{array}$ & $\begin{array}{c}488 \\
(1,028)\end{array}$ \\
\hline $\mathrm{N}$ & 361 & 309 & 33 & 276 & 42 & 319 \\
\hline
\end{tabular}

* signifies difference in the means between groups at the $10 \%$ level. ** indicates significant difference at the $5 \%$ level, and $* * *$ represents difference at the $1 \%$ level or better. 
Table 4A

In-group Bias in Conviction Decisions

\begin{tabular}{|c|c|c|c|c|}
\hline & $(1)$ & $(2)$ & (3) & (4) \\
\hline Minority Defendant & $\begin{array}{l}0.103^{* * *} \\
(0.029)\end{array}$ & $\begin{array}{c}0.110^{* * *} \\
(0.026)\end{array}$ & $\begin{array}{l}0.110^{* * *} \\
(0.026)\end{array}$ & $\begin{array}{l}0.110^{* * *} \\
(0.026)\end{array}$ \\
\hline Minority Evaluator & $\begin{array}{l}-0.025 \\
(0.083)\end{array}$ & $\begin{array}{l}-0.033 \\
(0.077)\end{array}$ & $\begin{array}{l}-0.041 \\
(0.076)\end{array}$ & $\begin{array}{l}-0.039 \\
(0.076)\end{array}$ \\
\hline $\begin{array}{l}\text { Minority Defendant x } \\
\text { Minority Evaluator }\end{array}$ & $\begin{array}{c}0.070 \\
(0.102)\end{array}$ & $\begin{array}{c}0.085 \\
(0.084)\end{array}$ & $\begin{array}{c}0.089 \\
(0.087)\end{array}$ & $\begin{array}{c}0.085 \\
(0.084)\end{array}$ \\
\hline Law Student & $\begin{array}{c}0.017 \\
(0.029)\end{array}$ & $\begin{array}{c}0.017 \\
(0.029)\end{array}$ & $\begin{array}{l}-0.011 \\
(0.029)\end{array}$ & $\begin{array}{l}-0.012 \\
(0.029)\end{array}$ \\
\hline Male Evaluator & & & $\begin{array}{c}-0.088^{* * *} \\
(0.029)\end{array}$ & $\begin{array}{c}-0.095 * * * \\
(0.029)\end{array}$ \\
\hline Early Trial & $\begin{array}{c}-0.127 * * * \\
(0.028)\end{array}$ & & $\begin{array}{c}-0.101 * * * \\
(0.030)\end{array}$ & \\
\hline Sequence 1 & & & & $\begin{array}{c}-0.073 * * \\
(0.034)\end{array}$ \\
\hline Sequence 2 & & & & $\begin{array}{l}-0.036 \\
(0.031)\end{array}$ \\
\hline Assault Case & $\begin{array}{c}-0.105^{* * *} \\
(0.029) \\
\end{array}$ & & & \\
\hline Observations & 918 & 918 & 918 & 918 \\
\hline Trial FE & No & Yes & Yes & Yes \\
\hline
\end{tabular}

Early Trial dummy $=1$ if the trial is one of the first three trials watched by that evaluator. Sequence 1 and Sequence 2 are dichotomous indicators of the order in which the videos are watched. Standard errors are clustered at the evaluator level. ${ }^{* * *} \mathrm{p}<0.01$, ${ }^{* *} \mathrm{p}<0.05,{ }^{*} \mathrm{p}<0.1$

Table 4B

Decomposing In-group Bias in Conviction Decisions: Conviction Regressions Conditional on Defendant Race

\begin{tabular}{lcc}
\hline \hline & $(1)$ & $(2)$ \\
White Evaluator & White Defendants & $\begin{array}{c}\text { Minority } \\
\text { Defendants }\end{array}$ \\
\cline { 2 - 3 } Minority Evaluator & 0.049 & \\
& $(0.076)$ & 0.056 \\
Law Student & & $(0.059)$ \\
& -0.044 & 0.023 \\
Male Evaluator & $(0.044)$ & $(0.036)$ \\
& $-0.103^{* *}$ & $-0.074^{*}$ \\
Early Trial & $(0.043)$ & $(0.038)$ \\
\hline Observations & $-0.094^{* *}$ & $-0.110^{* * *}$ \\
Trial FE & $(0.046)$ & $(0.041)$ \\
\hline \hline
\end{tabular}

Early Trial dummy $=1$ if the trial is one of the first three trials watched by that evaluator. Standard errors are clustered at the evaluator level. ${ }^{* * *} \mathrm{p}<0.01,{ }^{* *} \mathrm{p}<0.05,{ }^{*} \mathrm{p}<0.1$ 
Table 4C

Overall Racial Bias in Conviction Decisions

\begin{tabular}{lcccc}
\hline \hline & $(1)$ & $(2)$ & $(3)$ & $(4)$ \\
\cline { 2 - 5 } Minority Defendant & $0.111^{* * *}$ & $0.120^{* * *}$ & $0.120^{* * *}$ & $0.120^{* * *}$ \\
& $(0.028)$ & $(0.024)$ & $(0.025)$ & $(0.024)$ \\
Law Student & 0.016 & 0.016 & -0.011 & -0.012 \\
& $(0.028)$ & $(0.028)$ & $(0.028)$ & $(0.028)$ \\
Male Evaluator & & & $-0.088^{* * *}$ & $-0.095^{* * *}$ \\
& & & $(0.028)$ & $(0.029)$ \\
Early Trial & $-0.127^{* * *}$ & & $-0.101^{* * *}$ & \\
Sequence 1 & $(0.028)$ & & $(0.030)$ & \\
& & & & $-0.073^{* *}$ \\
Sequence 2 & & & & $(0.034)$ \\
& & & & -0.037 \\
Assault Case & $-0.105^{* * *}$ & & & $(0.031)$ \\
& $(0.029)$ & & & \\
Observations & 918 & 918 & 918 & 918 \\
\hline Trial FE & No & Yes & Yes & Yes \\
\hline \hline
\end{tabular}

Early Trial dummy = 1 if the trial is one of the first three trials watched by that evaluator. Sequence 1 and Sequence 2 are dichotomous indicators of the order in which the videos are watched. Standard errors are clustered at the evaluator level. ${ }^{* * *} \mathrm{p}<0.01,{ }^{* *} \mathrm{p}<0.05$, $* \mathrm{p}<0.1$

Table 5

The Conviction Rate and the Length of Effective Prison Sentence by Defendant and Evaluator Race

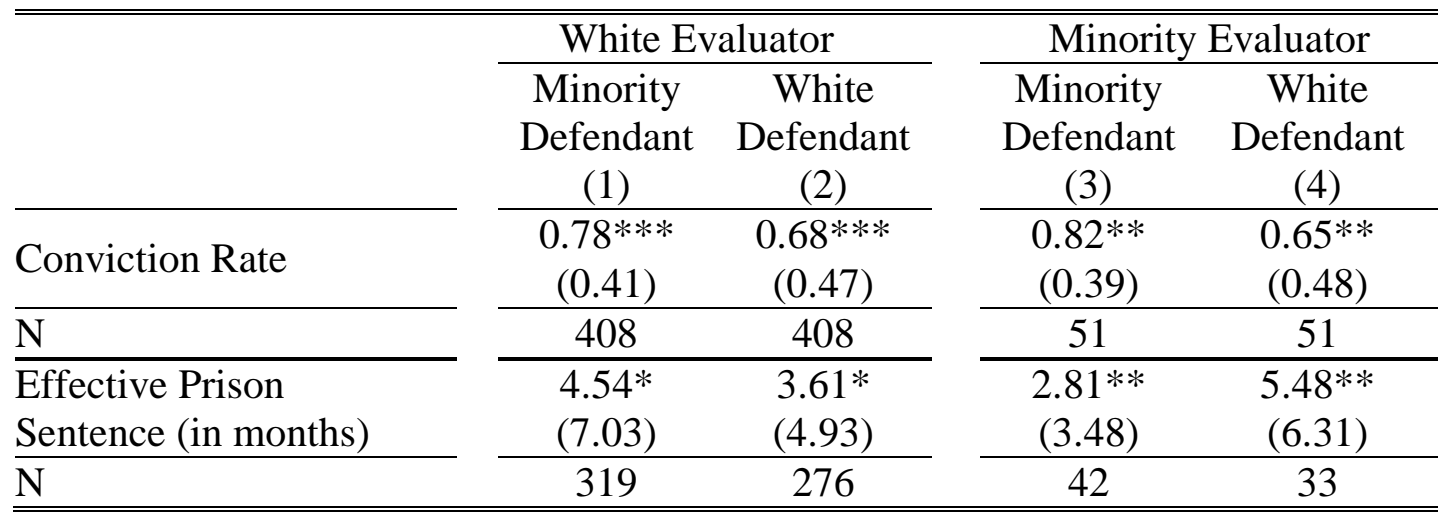

White Evaluators made 408 conviction decisions on minority defendants and 408 conviction decisions on white defendants (columns 1 and 2). Minority Evaluators made 51 conviction decisions on each group (columns 3 and 4). Effective prison sentence is assigned by the evaluators on those who are convicted (found guilty). Mean-comparison test: *** $\mathrm{p}<0.01$, ** $\mathrm{p}<0.05$, * $\mathrm{p}<0.1$ 
Table 6A

In-group Bias in Prison Sentencing

Dependent Variable: Effective Prison Sentence (months)

\begin{tabular}{|c|c|c|c|c|}
\hline \multicolumn{5}{|c|}{ A: Regressions using trimmed sample } \\
\hline & $(1)$ & $(2)$ & $(3)$ & (4) \\
\hline Minority Defendant & $\begin{array}{l}1.634^{* * *} \\
(0.556)\end{array}$ & $\begin{array}{c}1.690^{* * *} \\
(0.550)\end{array}$ & $\begin{array}{c}1.689 * * * \\
(0.545)\end{array}$ & $\begin{array}{c}1.684^{* * *} \\
(0.556)\end{array}$ \\
\hline Minority Evaluator & $\begin{array}{c}1.914 \\
(1.266)\end{array}$ & $\begin{array}{l}1.920 \\
(1.257)\end{array}$ & $\begin{array}{l}2.103^{*} \\
(1.205)\end{array}$ & $\begin{array}{l}2.080^{*} \\
(1.226)\end{array}$ \\
\hline $\begin{array}{l}\text { Minority Defendant } \\
\text { x Minority Evaluator }\end{array}$ & $\begin{array}{c}-3.544 * * * \\
(1.136)\end{array}$ & $\begin{array}{c}-3.662 * * * \\
(1.194)\end{array}$ & $\begin{array}{c}-3.671 * * * \\
(1.211)\end{array}$ & $\begin{array}{c}-3.766 * * * \\
(1.240)\end{array}$ \\
\hline Law Student & $\begin{array}{l}-0.844 \\
(0.663)\end{array}$ & $\begin{array}{l}-0.897 \\
(0.659)\end{array}$ & $\begin{array}{l}-0.336 \\
(0.672)\end{array}$ & $\begin{array}{l}-0.327 \\
(0.678)\end{array}$ \\
\hline Observations & 618 & 618 & 618 & 618 \\
\hline Trial FE & No & Yes & Yes & Yes \\
\hline \multicolumn{5}{|c|}{ B: Regressions using untrimmed sample } \\
\hline & $(5)$ & $(6)$ & $(7)$ & $(8)$ \\
\hline Minority Defendant & $\begin{array}{l}1.011^{* *} \\
(0.508)\end{array}$ & $\begin{array}{l}1.119 * * \\
(0.495)\end{array}$ & $\begin{array}{l}1.117 * * \\
(0.493)\end{array}$ & $\begin{array}{l}1.114^{* *} \\
(0.495)\end{array}$ \\
\hline Minority Evaluator & $\begin{array}{c}1.911 \\
(1.265)\end{array}$ & $\begin{array}{c}1.909 \\
(1.253)\end{array}$ & $\begin{array}{l}2.085^{*} \\
(1.202)\end{array}$ & $\begin{array}{l}2.077^{*} \\
(1.219)\end{array}$ \\
\hline $\begin{array}{l}\text { Minority Defendant } \\
\text { x Minority Evaluator }\end{array}$ & $\begin{array}{c}-3.638 * * * \\
(1.155)\end{array}$ & $\begin{array}{c}-3.739 * * * \\
(1.194)\end{array}$ & $\begin{array}{c}-3.720 * * * \\
(1.202)\end{array}$ & $\begin{array}{c}-3.832 * * * \\
(1.237)\end{array}$ \\
\hline Law Student & $\begin{array}{l}-0.846 \\
(0.627)\end{array}$ & $\begin{array}{l}-0.851 \\
(0.626)\end{array}$ & $\begin{array}{l}-0.323 \\
(0.636)\end{array}$ & $\begin{array}{l}-0.297 \\
(0.642)\end{array}$ \\
\hline Observations & 670 & 670 & 670 & 670 \\
\hline Trial FE & No & Yes & Yes & Yes \\
\hline
\end{tabular}

Effective Prison Sentence is equal to initial prison sentence minus suspended sentence. Models in column (1) include Early Trial and Assault Case dummies. Models in column (2) include Trial Fixed Effects. Models in column (3) include Trial Fixed Effects, Male Evaluator and Early Trial. Models in column (4) include Trial Fixed Effects, Male Evaluator and Sequence dummies. Standard errors are clustered at the evaluator level. ${ }^{* * *} \mathrm{p}<0.01,{ }^{* *} \mathrm{p}<0.05,{ }^{*} \mathrm{p}<0.1$ 
Table 6B

Decomposing In-group Bias in Prison Sentencing

Effective Prison Sentence Regressions Conditional on Defendant Race

\begin{tabular}{lcccc}
\hline \hline & $\begin{array}{c}(1) \\
\text { White } \\
\text { Defendants }\end{array}$ & $\begin{array}{c}(2) \\
\text { White } \\
\text { Defendants }\end{array}$ & $\begin{array}{c}\text { Minority } \\
\text { Defendants }\end{array}$ & $\begin{array}{c}\text { Minority } \\
\text { Defendants }\end{array}$ \\
\cline { 2 - 5 } White Evaluator & -1.984 & -1.984 & & \\
Minority & $(1.209)$ & $(1.209)$ & & \\
Evaluator & & & $-1.675^{*}$ & $-1.723^{* *}$ \\
Law Student & -0.237 & -0.237 & -0.554 & $(0.839)$ \\
& $(0.706)$ & $(0.706)$ & $(0.939)$ & $(0.817)$ \\
Male Evaluator & 1.037 & 1.037 & $2.087^{* *}$ & $1.962^{* *}$ \\
& $(0.691)$ & $(0.691)$ & $(0.983)$ & $(0.878)$ \\
Early Trial & $-1.204^{* *}$ & $-1.204^{* *}$ & -0.849 & -0.873 \\
& $(0.565)$ & $(0.565)$ & $(1.045)$ & $(0.865)$ \\
\hline Observations & 309 & 309 & 309 & 361 \\
Trial FE & Yes & Yes & Yes & Yes \\
Trimmed Sample & Yes & No & Yes & No \\
\hline \hline
\end{tabular}

Early Trial dummy $=1$ if the trial is one of the first three trials watched by that evaluator. Standard errors are clustered at the evaluator level. ${ }^{* * *} \mathrm{p}<0.01,{ }^{* *} \mathrm{p}<0.05,{ }^{*} \mathrm{p}<0.1$

Table 6C

Overall Racial Bias in Prison Sentencing Dependent Variable: Effective Prison Sentence (months)

\begin{tabular}{lcccc}
\hline \hline \multicolumn{5}{c}{ A: Regressions using trimmed sample } \\
\hline \multirow{4}{*}{ Minority Defendant } & $(1)$ & $(2)$ & $(3)$ & $(4)$ \\
\cline { 2 - 5 } & $1.256^{* *}$ & $1.301^{* *}$ & $1.300^{* * *}$ & $1.285^{* *}$ \\
Law Student & $(0.514)$ & $(0.506)$ & $(0.498)$ & $(0.511)$ \\
& -0.874 & -0.924 & -0.387 & -0.372 \\
Male Evaluator & $(0.654)$ & $(0.651)$ & $(0.666)$ & $(0.670)$ \\
& & & $1.666^{* *}$ & $1.751^{* *}$ \\
& & & $(0.716)$ & $(0.754)$ \\
\hline Observations & 618 & 618 & 618 & 618 \\
\hline \multicolumn{4}{c}{ B: Regressions using untrimmed sample } \\
\hline \multirow{4}{*}{ Minority Defendant } & $(5)$ & $(6)$ & $(7)$ & $(8)$ \\
\cline { 2 - 5 } Law Student & 0.605 & 0.706 & 0.708 & 0.692 \\
& $(0.470)$ & $(0.455)$ & $(0.451)$ & $(0.454)$ \\
Male Evaluator & -0.848 & -0.849 & -0.345 & -0.312 \\
& $(0.617)$ & $(0.618)$ & $(0.630)$ & $(0.634)$ \\
& & & $1.607^{* *}$ & $1.655^{* *}$ \\
Observations & 670 & 670 & $6.680)$ & $(0.712)$ \\
\hline \hline
\end{tabular}

Models in column (1) include Early Trial and Assault Case dummies. Models in column (2) include Trial Fixed Effects. Models in column (3) include Trial Fixed Effects and Early Trial. Models in column (4) include Trial Fixed Effects and Sequence dummies. Standard errors are clustered at the evaluator level. *** $\mathrm{p}<0.01,{ }^{* *} \mathrm{p}<0.05, * \mathrm{p}<0.1$ 
Table 7A

In-group Bias in Fines

Dependent Variable: Effective Fine (log Euros)

\begin{tabular}{lcccc}
\hline \hline \multicolumn{4}{c}{ A: Regressions using trimmed sample } \\
\hline & $(1)$ & $(2)$ & $(3)$ & $(4)$ \\
\cline { 2 - 5 } Minority Defendant & $1.151^{* * *}$ & $1.134^{* * *}$ & $1.131^{* * *}$ & $1.135^{* * *}$ \\
& $(0.211)$ & $(0.208)$ & $(0.206)$ & $(0.209)$ \\
Minority Evaluator & $1.138^{*}$ & $1.205^{* *}$ & $1.213^{* *}$ & $1.216^{* *}$ \\
Minority Defendant & $(0.599)$ & $(0.570)$ & $(0.577)$ & $(0.568)$ \\
X Minority Evaluator & -0.655 & -0.616 & -0.664 & -0.616 \\
Law Student & $(0.571)$ & $(0.577)$ & $(0.585)$ & $(0.576)$ \\
& $-0.674^{* *}$ & $-0.631^{* *}$ & $-0.599^{* *}$ & $-0.604^{* *}$ \\
\hline Observations & $(0.275)$ & $(0.266)$ & $(0.288)$ & $(0.286)$ \\
Trial FE & 618 & 618 & 618 & 618 \\
\hline \multicolumn{5}{c}{ B: Regressions using untrimmed sample } \\
\hline \\
Minority Defendant & $(5)$ & $(6)$ & $(7)$ & $(8)$ \\
& $0.550^{* *}$ & $0.521^{* *}$ & $0.523^{* *}$ & $0.522^{* *}$ \\
Minority Evaluator & $(0.212)$ & $(0.210)$ & $(0.210)$ & $(0.211)$ \\
Minority Defendant & $1.152^{*}$ & $1.208^{* *}$ & $1.220^{* *}$ & $1.237^{* *}$ \\
X Minority & $(0.600)$ & $(0.571)$ & $(0.576)$ & $(0.576)$ \\
Evaluator & -0.872 & -0.788 & -0.854 & -0.781 \\
Law Student & $(0.606)$ & $(0.605)$ & $(0.617)$ & $(0.605)$ \\
& & & & \\
Observations & $-0.661^{* *}$ & $-0.652^{* *}$ & $-0.599^{*}$ & $-0.612^{*}$ \\
Trial FE & $(0.299)$ & $(0.293)$ & $(0.313)$ & $(0.311)$ \\
\hline \hline
\end{tabular}

Models in column (1) include Early Trial and Assault Case dummies. Models in column (2) include Trial Fixed Effects. Models in column (3) include Trial Fixed Effects, Male Evaluator and Early Trial. Models in column (4) include Trial Fixed Effects, Male Evaluator and Sequence dummies. Standard errors are clustered at the evaluator level. ${ }^{* * *} \mathrm{p}<0.01,{ }^{* *} \mathrm{p}<0.05,{ }^{*} \mathrm{p}<0.1$ 
Table 7B

Decomposing In-group Bias in Fines

Effective Fine Regressions Conditional on Defendant Race Dependent variable: Log (Euros)

\begin{tabular}{lcccc}
\hline \hline & $\begin{array}{c}(1) \\
\text { White } \\
\text { Defendants }\end{array}$ & $\begin{array}{c}(2) \\
\text { White } \\
\text { Defendants }\end{array}$ & $\begin{array}{c}\text { Minority } \\
\text { Defendants }\end{array}$ & $\begin{array}{c}(4) \\
\text { Minority } \\
\text { Defendants }\end{array}$ \\
\cline { 2 - 5 } White Evaluator & $-1.192^{* *}$ & $-1.192^{* *}$ & & \\
Minority & $(0.569)$ & $(0.569)$ & & \\
Evaluator & & & 0.482 & 0.322 \\
Law Student & -0.548 & -0.548 & $-0.688^{* *}$ & $-0.658^{*}$ \\
& $(0.396)$ & $(0.396)$ & $(0.304)$ & $(0.352)$ \\
Male Evaluator & 0.197 & 0.197 & -0.101 & 0.035 \\
& $(0.397)$ & $(0.397)$ & $(0.297)$ & $(0.353)$ \\
Early Trial & 0.535 & 0.535 & $0.740^{* *}$ & $0.739 * *$ \\
& $(0.350)$ & $(0.350)$ & $(0.297)$ & $(0.288)$ \\
\hline Observations & 309 & 309 & 309 & 361 \\
Trial FE & Yes & Yes & Yes & Yes \\
Trimmed Sample & Yes & No & Yes & No \\
\hline \hline
\end{tabular}

Early Trial dummy $=1$ if the trial is one of the first three trials watched by that evaluator. Standard errors are clustered at the evaluator level. ${ }^{* * *} \mathrm{p}<0.01,{ }^{* *} \mathrm{p}<0.05$, $* \mathrm{p}<0.1$

Table 7C

Overall Racial Bias in Fines

Dependent Variable: Effective Fine (log Euros)

\begin{tabular}{|c|c|c|c|c|}
\hline \multicolumn{5}{|c|}{ A: Regressions using trimmed sample } \\
\hline & $(1)$ & $(2)$ & $(3)$ & (4) \\
\hline Minority Defendant & $\begin{array}{c}1.082 * * * \\
(0.198)\end{array}$ & $\begin{array}{c}1.069 * * * \\
(0.195)\end{array}$ & $\begin{array}{c}1.061^{* * *} \\
(0.194)\end{array}$ & $\begin{array}{c}1.071^{* * *} \\
(0.196)\end{array}$ \\
\hline Law Student & $\begin{array}{c}-0.746^{* * *} \\
(0.270)\end{array}$ & $\begin{array}{c}-0.711 * * * \\
(0.264)\end{array}$ & $\begin{array}{c}-0.689 * * \\
(0.281)\end{array}$ & $\begin{array}{c}-0.695 * * \\
(0.280)\end{array}$ \\
\hline Male Evaluator & & & $\begin{array}{c}0.084 \\
(0.284)\end{array}$ & $\begin{array}{c}0.053 \\
(0.279)\end{array}$ \\
\hline Observations & 618 & 618 & 618 & 618 \\
\hline \multicolumn{5}{|c|}{ B: Regressions using untrimmed sample } \\
\hline & $(5)$ & $(6)$ & $(7)$ & $(8)$ \\
\hline Minority Defendant & $\begin{array}{c}0.461^{* *} \\
(0.200)\end{array}$ & $\begin{array}{c}0.442 * * \\
(0.198)\end{array}$ & $\begin{array}{c}0.436 * * \\
(0.198)\end{array}$ & $\begin{array}{c}0.443 * * \\
(0.199)\end{array}$ \\
\hline Law Student & $\begin{array}{c}-0.725 * * \\
(0.292)\end{array}$ & $\begin{array}{c}-0.726 * * \\
(0.288)\end{array}$ & $\begin{array}{c}-0.681^{* *} \\
(0.304)\end{array}$ & $\begin{array}{c}-0.699 * * \\
(0.303)\end{array}$ \\
\hline Male Evaluator & & & $\begin{array}{c}0.112 \\
(0.305) \\
\end{array}$ & $\begin{array}{c}0.057 \\
(0.301) \\
\end{array}$ \\
\hline Observations & 670 & 670 & 670 & 670 \\
\hline
\end{tabular}

Models in column (1) include Early Trial and Assault Case dummies. Column (2) includes Trial Fixed Effects. Models in column (3) include Trial Fixed Effects and Early Trial. Column (4) includes Trial Fixed Effects and Sequence dummies. Standard errors are clustered at the evaluator level. $* * * p<0.01,{ }^{* *} p<0.05,{ }^{*} p<0.1$ 
Table 8

Results of Sensitivity Analyses

\begin{tabular}{|c|c|c|c|c|c|c|c|c|c|c|c|}
\hline & $\begin{array}{c}\text { Whole } \\
\text { Sample } \\
(1)\end{array}$ & $\begin{array}{c}\text { First } 3 \\
\text { decisions } \\
(2) \\
\end{array}$ & $\begin{array}{c}\text { Last } 3 \\
\text { decisions } \\
(3)\end{array}$ & $\begin{array}{c}\text { Change } \\
\text { (4) }\end{array}$ & $\begin{array}{c}\text { No } \\
\text { change } \\
(5)\end{array}$ & $\begin{array}{c}\text { Drop Slow } \\
25 \% \\
(6) \\
\end{array}$ & $\begin{array}{c}\text { Drop Fast } \\
25 \% \\
(7) \\
\end{array}$ & $\begin{array}{c}\text { Males } \\
\text { (8) }\end{array}$ & $\begin{array}{c}\text { Females } \\
(9)\end{array}$ & $\begin{array}{c}\text { Law } \\
\text { Students } \\
(10)\end{array}$ & $\begin{array}{c}\text { Econ } \\
\text { Students } \\
(11)\end{array}$ \\
\hline $\begin{array}{l}\text { Racial bias in } \\
\text { conviction }\end{array}$ & $\begin{array}{c}0.120 * * * \\
(0.024)\end{array}$ & $\begin{array}{c}0.115^{* * * *} \\
(0.041)\end{array}$ & $\begin{array}{c}0.123 * * * \\
(0.033)\end{array}$ & $\begin{array}{l}0.061 * \\
(0.031)\end{array}$ & $\begin{array}{c}0.164^{* * * *} \\
(0.035)\end{array}$ & $\begin{array}{c}0.123 * * * \\
(0.029)\end{array}$ & $\begin{array}{c}0.107 * * * \\
(0.029)\end{array}$ & $\begin{array}{c}0.129 * * * \\
(0.040)\end{array}$ & $\begin{array}{c}0.115^{* * * *} \\
(0.030)\end{array}$ & $\begin{array}{c}0.146 * * * \\
(0.037)\end{array}$ & $\begin{array}{c}0.098 * * * \\
(0.033)\end{array}$ \\
\hline $\begin{array}{l}\text { In-group bias } \\
\text { in conviction }\end{array}$ & $\begin{array}{c}0.085 \\
(0.084)\end{array}$ & $\begin{array}{c}0.148 \\
(0.114)\end{array}$ & $\begin{array}{c}0.027 \\
(0.114)\end{array}$ & $\begin{array}{l}-0.016 \\
(0.072)\end{array}$ & $\begin{array}{c}0.221 \\
(0.138)\end{array}$ & $\begin{array}{l}-0.037 \\
(0.106)\end{array}$ & $\begin{array}{c}0.016 \\
(0.091)\end{array}$ & $\begin{array}{c}0.159 \\
(0.135)\end{array}$ & $\begin{array}{c}0.025 \\
(0.107)\end{array}$ & $\begin{array}{c}0.199 \\
(0.142)\end{array}$ & $\begin{array}{c}0.061 \\
(0.102)\end{array}$ \\
\hline $\begin{array}{l}\text { Racial bias in } \\
\text { prison } \\
\text { sentence }\end{array}$ & $\begin{array}{l}1.285 * * \\
(0.511)\end{array}$ & $\begin{array}{c}1.093 \\
(0.907)\end{array}$ & $\begin{array}{c}1.482 * * * \\
(0.562)\end{array}$ & $\begin{array}{c}0.859 \\
(0.530)\end{array}$ & $\begin{array}{c}1.692 * * \\
(0.837)\end{array}$ & $\begin{array}{c}1.325 * * \\
(0.655)\end{array}$ & $\begin{array}{c}0.462 \\
(0.324)\end{array}$ & $\begin{array}{l}1.830 * * \\
(0.910)\end{array}$ & $\begin{array}{c}0.722 \\
(0.446)\end{array}$ & $\begin{array}{l}1.013 * * \\
(0.480)\end{array}$ & $\begin{array}{l}1.479 * \\
(0.837)\end{array}$ \\
\hline $\begin{array}{l}\text { In-group bias } \\
\text { in prison } \\
\text { sentence } \\
\end{array}$ & $\begin{array}{c}-3.766 * * * \\
(1.240)\end{array}$ & $\begin{array}{l}-3.055^{*} \\
(1.580)\end{array}$ & $\begin{array}{c}-4.340^{* *} \\
(1.953)\end{array}$ & $\begin{array}{c}-3.946^{* *} \\
(1.591)\end{array}$ & $\begin{array}{c}-3.158^{* *} \\
(1.455)\end{array}$ & $\begin{array}{c}-4.045^{* *} \\
(1.809)\end{array}$ & $\begin{array}{c}-3.050^{* *} \\
(1.190)\end{array}$ & $\begin{array}{c}-5.894 * * * \\
(1.955)\end{array}$ & $\begin{array}{l}-2.163 \\
(1.496)\end{array}$ & $\begin{array}{c}-2.529 * * \\
(1.066)\end{array}$ & $\begin{array}{c}-4.305 * * \\
(1.706)\end{array}$ \\
\hline $\begin{array}{l}\text { Racial bias in } \\
\text { fine }\end{array}$ & $\begin{array}{c}1.071^{* * * *} \\
(0.196)\end{array}$ & $\begin{array}{c}0.999 * * * \\
(0.305)\end{array}$ & $\begin{array}{c}1.125^{* * * *} \\
(0.268)\end{array}$ & $\begin{array}{c}1.113^{* * * *} \\
(0.269)\end{array}$ & $\begin{array}{c}1.037 * * * \\
(0.285)\end{array}$ & $\begin{array}{c}1.074 * * * \\
(0.219)\end{array}$ & $\begin{array}{c}1.032 * * * \\
(0.226)\end{array}$ & $\begin{array}{c}1.076^{* * *} \\
(0.289)\end{array}$ & $\begin{array}{c}1.214^{* * * *} \\
(0.250)\end{array}$ & $\begin{array}{c}1.105^{* * * *} \\
(0.294)\end{array}$ & $\begin{array}{c}1.047 * * * \\
(0.266)\end{array}$ \\
\hline $\begin{array}{l}\text { In-group bias } \\
\text { in fine }\end{array}$ & $\begin{array}{l}-0.616 \\
(0.576)\end{array}$ & $\begin{array}{l}-0.273 \\
(0.567)\end{array}$ & $\begin{array}{l}-1.172 \\
(0.927)\end{array}$ & $\begin{array}{l}-1.101 \\
(0.791)\end{array}$ & $\begin{array}{l}-0.012 \\
(0.825)\end{array}$ & $\begin{array}{l}-0.235 \\
(0.852)\end{array}$ & $\begin{array}{l}-0.829 \\
(0.587)\end{array}$ & $\begin{array}{c}-1.740 * * * \\
(0.625)\end{array}$ & $\begin{array}{c}0.400 \\
(0.776)\end{array}$ & $\begin{array}{l}-0.942 \\
(0.826)\end{array}$ & $\begin{array}{l}-0.450 \\
(0.759)\end{array}$ \\
\hline
\end{tabular}

The column Whole Sample re-produces the results reported in Tables 4C, 4A, 6C, 6A, 7C, and 7A. Change stands for the sample of observations related to the cases where the evaluator has made at least one change after making his/her initial decisions on conviction, prison term and fine. No Change represents the cases for which the evaluator did not alter his/her initial decisions. Drop Slow includes the sample that is created after dropping the slowest $25 \%$ of the evaluators based on total time spent in decision making. Drop Fast excludes the 25\% fastest evaluators (see Figure 4). 
Table 9

Descriptive Statistics of Evaluator Characteristics (Lawyers)

\begin{tabular}{lc}
\hline \hline & Evaluator Attributes \\
\cline { 2 - 2 } Male Evaluator & 0.58 \\
& $(0.50)$ \\
\hline $\mathrm{N}$ & 36 \\
\cline { 2 - 2 } Trust in the Legal System & Evaluator Beliefs \\
& 0.28 \\
Trust in Police & $0.45)$ \\
\hline Terrorism is an Important Problem & 0.42 \\
in Belgium & $0.50)$ \\
\hline $\mathrm{N}$ & 0.75 \\
\hline Belgium is made a worse place to & $(0.44)$ \\
live by people coming to live here & 36 \\
from other countries & 0.67 \\
$\mathrm{~N}$ & $(0.48)$ \\
\hline \hline
\end{tabular}

Table 10

Descriptive Statistics of Conviction Decision, Sentence Length and Fine Imposed by Evaluators (Lawyers)

\begin{tabular}{lcc}
\hline \hline & $\begin{array}{c}\text { Minority } \\
\text { Defendant } \\
(1)\end{array}$ & $\begin{array}{c}\text { White } \\
\text { Defendant } \\
(2)\end{array}$ \\
\hline (1) Conviction Rate & $\mathbf{0 . 6 9 * *}$ & $\mathbf{0 . 5 5 * *}$ \\
$\mathbf{( 0 . 4 7 )}$ & $(\mathbf{0 . 5 0 )}$ \\
\hline (2) Initial Prison Sentence & 108 & 108 \\
\hline $\mathrm{N}$ & 11.2 & 11.1 \\
& $(6.5)$ & $(7.5)$ \\
\hline (3) Suspended Prison Sentence & 74 & 59 \\
\hline $\mathrm{N}$ & 6.2 & 6.5 \\
\hline $\mathbf{( 4 )}$ Effective Prison Sentence & $(4.2)$ & $(4.1)$ \\
\hline $\mathrm{N}$ & 74 & 59 \\
\hline (5) Initial Fine & $\mathbf{5 . 0}$ & $\mathbf{4 . 5}$ \\
$\mathrm{N}$ & $\mathbf{( 6 . 5 )}$ & $\mathbf{( 7 . 5 )}$ \\
\hline (6) Suspended Fine & 74 & 59 \\
\hline $\mathrm{N}$ & 711 & 701 \\
\hline $\mathbf{( 7 )}$ Effective Fine & $(840)$ & $(779)$ \\
\hline $\mathrm{N}$ & 74 & 59 \\
\hline \hline
\end{tabular}

significant difference at the $5 \%$ level, and $* * *$ represents difference at the $1 \%$ level or better. 
Table 11A

Lawyers

Racial Bias in Conviction Decisions

\begin{tabular}{lcccc}
\hline \hline & $(1)$ & $(2)$ & $(3)$ & $(4)$ \\
\cline { 2 - 5 } Minority Defendant & $0.139^{*}$ & $0.139^{* *}$ & $0.139^{* *}$ & $0.139^{* *}$ \\
& $(0.075)$ & $(0.061)$ & $(0.060)$ & $(0.061)$ \\
Male Evaluator & & & $-0.106^{*}$ & $-0.108^{*}$ \\
& & & $(0.061)$ & $(0.055)$ \\
Early Trial & $-0.123^{* *}$ & & -0.104 & \\
& $(0.056)$ & & $(0.063)$ & \\
Sequence 1 & & & & 0.008 \\
& & & & $(0.068)$ \\
Sequence 2 & & & & $-0.149^{* *}$ \\
& & & & $(0.061)$ \\
Assault Case & $-0.190^{* * *}$ & & & \\
& $(0.061)$ & & & 216 \\
\hline Observations & 216 & 216 & 216 & 216 \\
\hline Trial FE & No & Yes & Yes & Yes \\
\hline \hline
\end{tabular}

Early Trial dummy $=1$ if the trial is one of the first three trials watched by that evaluator. Sequence 1 and Sequence 2 are dichotomous indicators of the order in which the videos are watched (see table 1). Standard errors are clustered at the evaluator level. ${ }^{* * *} \mathrm{p}<0.01,{ }^{* *} \mathrm{p}<0.05$, ${ }^{*} \mathrm{p}<0.1$

Table 11B

Lawyers

Racial Bias in Prison Sentencing

Dependent Variable: Effective Prison Sentence (months)

\begin{tabular}{lcccc}
\hline \hline & $(1)$ & $(2)$ & $(3)$ & $(4)$ \\
\cline { 2 - 5 } Minority Defendant & 0.896 & 0.683 & 0.707 & 0.716 \\
Male Evaluator & $(0.835)$ & $(0.882)$ & $(0.890)$ & $(0.862)$ \\
& & & 2.138 & 1.840 \\
Early Trial & -1.171 & & $(1.717)$ & $(1.425)$ \\
& $(1.311)$ & & -0.298 & \\
Sequence 1 & & & & $1.379)$ \\
& & & & $(2.447)$ \\
Sequence 2 & & & & 0.202 \\
& & & & $(1.022)$ \\
Assault Case & $-5.495^{* * *}$ & & & \\
& $(0.766)$ & & & \\
\hline Observations & 118 & 118 & 118 & 118 \\
Trial FE & No & Yes & Yes & Yes \\
\hline \hline
\end{tabular}

See notes to Table $11 \mathrm{~A}$ 
Table 11C

Lawyers

Racial Bias in Fines

Dependent Variable: Effective Fine (log Euros)

\begin{tabular}{lcccc}
\hline \hline & $(1)$ & $(2)$ & $(3)$ & $(4)$ \\
\cline { 2 - 5 } Minority Defendant & $0.941^{* *}$ & $0.923^{* *}$ & $0.925^{* *}$ & $0.927^{* *}$ \\
Male Evaluator & $(0.436)$ & $(0.443)$ & $(0.430)$ & $(0.421)$ \\
& & & 0.569 & 0.431 \\
Early Trial & & & $(0.656)$ & $(0.644)$ \\
& 0.245 & & 0.167 & \\
Sequence 1 & $(0.413)$ & & $(0.457)$ & \\
& & & & 0.648 \\
Sequence 2 & & & & $(0.758)$ \\
& & & & 0.246 \\
Assault Case & & & & \\
& $-0.971^{* *}$ & & & \\
\hline Observations & $(0.409)$ & 118 & 118 & 118 \\
Trial FE & 118 & Yes & Yes & Yes \\
\hline \hline
\end{tabular}

Early Trial dummy $=1$ if the trial is one of the first three trials watched by that evaluator. Sequence 1 and Sequence 2 are dichotomous indicators of the order in which the videos are watched (see table 1 ). Standard errors are clustered at the evaluator level. ${ }^{* * *} \mathrm{p}<0.01$, ** $\mathrm{p}<0.05, * \mathrm{p}<0.1$ 
Table 12

Sensitivity Analysis for the Entire Sample of Law Students, Economics Students and Practicing Attorneys

\begin{tabular}{|c|c|c|c|c|c|c|c|}
\hline & $\begin{array}{c}\text { Whole } \\
\text { sample } \\
\text { (1) }\end{array}$ & $\begin{array}{c}\text { First } 3 \\
\text { decisions } \\
(2)\end{array}$ & $\begin{array}{c}\text { Last } 3 \\
\text { decisions } \\
(3)\end{array}$ & $\begin{array}{c}\text { Change } \\
\text { (4) }\end{array}$ & $\begin{array}{c}\text { No change } \\
\text { (5) }\end{array}$ & $\begin{array}{c}\text { Drop Slow } \\
25 \% \\
(6) \\
\end{array}$ & $\begin{array}{c}\text { Drop Fast } \\
25 \% \\
(7) \\
\end{array}$ \\
\hline \multirow[t]{2}{*}{$\begin{array}{l}\text { Overall bias in } \\
\text { conviction }\end{array}$} & $\begin{array}{c}0.121^{* * *} \\
(0.024)\end{array}$ & $\begin{array}{c}0.115^{* * *} \\
(0.041)\end{array}$ & $\begin{array}{c}0.126^{* * *} \\
(0.034)\end{array}$ & $\begin{array}{l}0.060^{*} \\
(0.031)\end{array}$ & $\begin{array}{c}0.166^{* * *} \\
(0.031)\end{array}$ & $\begin{array}{c}0.127 * * * \\
(0.029)\end{array}$ & $\begin{array}{c}0.102^{* * *} \\
(0.027)\end{array}$ \\
\hline & $\mathrm{N}=1,134$ & $\mathrm{~N}=567$ & $\mathrm{~N}=567$ & $\mathrm{~N}=4$ & $\mathrm{~N}=6$ & $\mathrm{~N}=852$ & 352 \\
\hline \multirow[t]{2}{*}{$\begin{array}{l}\text { Overall bias in } \\
\text { prison sentence }\end{array}$} & $\begin{array}{l}1.253^{* *} \\
(0.509)\end{array}$ & $\begin{array}{c}1.092 \\
(0.881)\end{array}$ & $\begin{array}{l}1.424^{* *} \\
(0.565)\end{array}$ & $\begin{array}{c}0.805 \\
(0.528)\end{array}$ & $\begin{array}{l}1.687^{* *} \\
(0.832)\end{array}$ & $\begin{array}{l}1.292^{*} \\
(0.658)\end{array}$ & $\begin{array}{c}0.433 \\
(0.328)\end{array}$ \\
\hline & $\mathrm{N}=736$ & $\mathrm{~N}=340$ & $\mathrm{~N}=396$ & $\mathrm{~N}=319$ & $\mathrm{~N}=417$ & $\mathrm{~N}=549$ & $\mathrm{~N}=577$ \\
\hline \multirow[t]{2}{*}{$\begin{array}{l}\text { Overall bias in } \\
\text { fine }\end{array}$} & $\begin{array}{c}1.059^{* * *} \\
(0.197)\end{array}$ & $\begin{array}{c}0.969^{* * *} \\
(0.305)\end{array}$ & $\begin{array}{c}1.106^{* * *} \\
(0.267)\end{array}$ & $\begin{array}{c}1.079 * * * \\
(0.273)\end{array}$ & $\begin{array}{c}1.030 * * * \\
(0.285)\end{array}$ & $\begin{array}{c}1.074^{* * *} \\
(0.221)\end{array}$ & $\begin{array}{c}1.015^{* * *} \\
(0.228)\end{array}$ \\
\hline & $\mathrm{N}=736$ & $\mathrm{~N}=340$ & $\mathrm{~N}=396$ & $\mathrm{~N}=319$ & $\mathrm{~N}=417$ & $\mathrm{~N}=549$ & $\mathrm{~N}=577$ \\
\hline
\end{tabular}

Change stands for the sample of observations related to the cases where the evaluator has made at least one change after making his/her initial decisions on conviction, prison term and fine. No Change represents the cases for which the evaluator did not alter his/her initial decisions. Drop Slow includes the sample that is created after dropping the slowest $25 \%$ of the evaluators based on total time spent in decision making. Drop Fast excludes the 25\% fastest evaluators (see Figure 4).

Table 13A

Lawyers, Prosecutors and Judges

Racial Bias in Conviction Decisions

\begin{tabular}{lcccc}
\hline \hline \multirow{3}{*}{ Minority Defendant } & $(1)$ & $(2)$ & $(3)$ & $(4)$ \\
\cline { 2 - 5 } Male Evaluator & $0.124^{* *}$ & $0.103^{* *}$ & $0.103^{* *}$ & $0.103^{* *}$ \\
& $(0.061)$ & $(0.050)$ & $(0.050)$ & $(0.050)$ \\
Early Trial & & & -0.063 & -0.055 \\
& -0.079 & & $(0.053)$ & $(0.052)$ \\
Sequence 1 & $(0.049)$ & & -0.056 & \\
& & & & $-0.052)$ \\
Sequence 2 & & & & $(0.067)$ \\
& & & & -0.093 \\
Assault Case & $-0.198^{* * *}$ & & & \\
& $(0.051)$ & & & \\
\hline Observations & 288 & 288 & 288 & 288 \\
Trial FE & No & Yes & Yes & Yes \\
\hline \hline
\end{tabular}

Early Trial dummy $=1$ if the trial is one of the first three trials watched by that evaluator. Regressions include lawyer, prosecutor, and age dummies. Sequence 1 and Sequence 2 are dichotomous indicators of the order in which the videos are watched (see table 1 ). Standard errors are clustered at the evaluator level. ${ }^{* * *} \mathrm{p}<0.01,{ }^{* *} \mathrm{p}<0.05,{ }^{*} \mathrm{p}<0.1$ 
Table 13B

Lawyers, Prosecutors and Judges

Racial Bias in Prison Sentencing

Dependent Variable: Effective Prison Sentence (months)

\begin{tabular}{lcccc}
\hline \hline & $(1)$ & $(2)$ & $(3)$ & $(4)$ \\
\cline { 2 - 5 } Minority Defendant & 0.754 & 0.508 & 0.524 & 0.525 \\
Male Evaluator & $(0.763)$ & $(0.764)$ & $(0.780)$ & $(0.733)$ \\
& & & 1.861 & 1.701 \\
Early Trial & -0.845 & & $(1.671)$ & $(1.487)$ \\
& $(1.057)$ & & -0.292 & \\
Sequence 1 & & $(1.040)$ & \\
& & & 0.838 \\
Sequence 2 & & & $(1.952)$ \\
& $-5.438^{* * *}$ & & & 0.233 \\
Assault Case & $(0.813)$ & & & \\
& 160 & 160 & 160 & $1600)$ \\
\hline Observations & No & Yes & Yes & Yes \\
Trial FE & & & & \\
\hline \hline
\end{tabular}

Early Trial dummy = 1 if the trial is one of the first three trials watched by that evaluator. Regressions include lawyer, prosecutor, and age dummies. Sequence 1 and Sequence 2 are dichotomous indicators of the order in which the videos are watched (see table 1 ). Standard errors are clustered at the evaluator level. ${ }^{* * *} \mathrm{p}<0.01,{ }^{* *} \mathrm{p}<0.05,{ }^{*} \mathrm{p}<0.1$

Table 13C

Lawyers, Prosecutors and Judges

Racial Bias in Fines

Dependent Variable: Effective Fine (log Euros)

\begin{tabular}{lcccc}
\hline \hline & $(1)$ & $(2)$ & $(3)$ & $(4)$ \\
\cline { 2 - 5 } Minority Defendant & $0.836^{* *}$ & $0.844^{* *}$ & $0.840^{* *}$ & $0.860^{* *}$ \\
Male Evaluator & $(0.352)$ & $(0.354)$ & $(0.346)$ & $(0.347)$ \\
& & & 0.407 & 0.389 \\
Early Trial & 0.202 & & $(0.547)$ & $(0.528)$ \\
& $(0.319)$ & & 0.104 & \\
Sequence 1 & & & & $0.353)$ \\
& & & & $(0.622)$ \\
Sequence 2 & & & & -0.172 \\
& & & & $(0.697)$ \\
Assault Case & $-1.072^{* * *}$ & & 160 & 160 \\
& $(0.326)$ & & Yes & Yes \\
\hline Observations & 160 & 160 & & \\
Trial FE & No & Yes & & \\
\hline \hline
\end{tabular}

See notes to Table 13B 


\section{References}

Abrams, David S, Marianne Bertrand and Sendhil Mullainathan. 2012. "Do Judges Vary in Their Treatment of Race?" The Journal of Legal Studies, 41:2, 347-383

Alesina, Alberto and Eliana La Ferrara. 2014. "A Test of Racial Bias in Capital Sentencing." The American Economic Review, 104:11, 3397-3433

Agan, Amanda, Matthew Freedman and Emily Owens.2018. "Is Your Lawyer a Lemon?Incentives and Selection in the Public Provision of Criminal Defense" NBER Working Paper No. 24579.

Anderson, James M and Paul Heaton. 2012. "How Much Difference Does the Lawyer Make? The Effect of Defense Counsel on Murder Case Outcomes." Yale Law Journal, 122:154, 154217

Angrist, Joshua, Eric Bettinger and Michael Kremer. 2006. "Long-Term Educational Consequences of Secondary School Vouchers: Evidence from Administrative Records in Colombia." The American Economic Review, 96:3, 847-862

Anwar, Shamena, Patrick Bayer and Randi Hjalmarsson. 2012. "The Impact of Jury Race in Criminal Trials." The Quarterly Journal of Economics, 127:2, 1017-1055

Argys, Laura M and H Naci Mocan. 2004. "Who Shall Live and Who Shall Die? An Analysis of Prisoners on Death Row in the United States." The Journal of Legal Studies, 33:2, 255-282

Bertrand, Marianne, and Sendhil Mullainathan. 2004. "Are Emily and Greg More Employable Than Lakisha and Jamal? A Field Experiment on Labor Market Discrimination." American Economic Review, 94 (4): 991-1013.

Boylan, Richard T. 2012. "The Effect of Punishment Severity on Plea Bargaining." The Journal of Law and Economics, 55:3, 565-591

Chen, Daniel, Yosh Halberstam and Alan Yu. 2018 "Covering: Mutable Characteristics and Perceptions of Voice in the U.S. Supreme Court," Toulouse Schhol of Economics Working Paper.

Chen, Yan and Sherry Xin Li. 2009. "Group Identity and Social Preferences." American Economic Review, 99:1, 431-457.

Correll, Joshua, Bernadette Park, Charles Judd and Bernd Wittenbrink. 2002. "The police officer's dilemma: Using ethnicity to disambiguate potentially threatening individuals." Journal of Personality and Social Psychology, 83:6, 1314-1329

Correll, Joshua, Bernadette Park, Charles Judd, Bernd Wittenbrink, Melody Sadler and Tracie Keesee. 2007. "Across the thin blue line: Police officers and racial bias in the decision to shoot." Journal of Personality and Social Psychology, 92:6, 1006-1023.

Depew, Briggs, Ozkan Eren and Naci Mocan. 2017. "Judges, Juveniles and In-group Bias." The Journal of Law and Economics, 60:2, 209-239

Eren, Ozkan and Naci Mocan. 2018. "Emotional Judges and Unlucky Juveniles." American Economic Journal: Applied Economics, 10:3, 171-205

Gazal-Ayal, Oren and Raanan Sulitzeanu-Kenan. 2010. "Let My People Go: Ethnic In-Group Bias in Judicial Decisions-Evidence from a Randomized Natural Experiment." Journal of Empirical Legal Studies, 7:3, 403-428

Glaeser, Edward L and Bruce Sacerdote. 2003. "Sentencing in Homicide Cases and the Role of Vengeance." The Journal of Legal Studies, 32:2, 363-382

Goette, Lorenz, David Huffman and Stephan Meier. 2006. "The Impact of Group Membership on Cooperation and Norm Enforcement: Evidence using Random Assignment to Real Social Groups." American Economic Review, 96:2, 212-216

Grossman, Guy, Oren Gazal-Ayal, Samuel Pimentel and jeremy Weinstein, 2016. "Descriptive Representation and Judicial Outcomes in Multiethnic Societies." American Journal of Political Science. 60: 1, pp. 44-69.

Hoffman, Florian and Philip Oreopoulos. 2009. "A Professor Like Me: Influence of Professor Gender on University Achievement." Journal of Human Resources. 44: 479-494. 
Jones, Angela, Amanda Bergold, Marlee Kind Dillon and Steven Penrod. 2017. "Comapring the Effectiveness of Henderson Instructions and Expert Testimony: Which Safeguard Improves Jurors' Evaluations of Eyewitness Evidence?" Journal of Experimental Criminology, 13, 29-52.

Kennedy, Peter E. 1981. "Estimation with Correctly Interpreted Dummy varaibles in Semilogarithmic Equations." American Economic Review. p. 801

List, John and Michael Price.2009. " The role of social connections in charitable fundraising: Evidence from a natural field experiment." Journal of Economic Behavior and Organization, 69:2, 160-169

Lusher, Lester, Doug Campbell and Scott Carrell. 2015. "TAs like me: Racial Intercations between Graduate Teachnig Assistants and Undergraduates." NBER Working Paper, No: 21568.

Maeder, Eveltn, Annik Mossieere and Liann Cheung. 2012. "Candian Mock Juror Attitudes and Decisions in Domestic Violence Cases involving Asisna and White Interracial and Intraracial Couples." Journal of Interpersonal Violence. 28:4, 667-684.

Mendoza, Saaid A, Sean P Lane and David M Amodio. 2014. "For Members Only: Ingroup Punishment of Fairness Norm Violations in the Ultimatum Game." Social Psychological and Personality Science, 5:6, 662-670

Mercado, Cynthia Calkins, Brian Bornstein and Robert Schopp. 2006. "Decision-Making about Volitional Imapirment in Sexually Violent Predators." Law and Human Behavior. 3), 587602.

Mossiere, Annik, Evelyn Maeder and Emil Pica. 2018."Racial Composition of Couples in Battered Spouse Syndrome Cases: A Look at Juror Perceptions and Decisions." Journal of Interpersonal Violence. 33:18, 2867-2890.

Mustard, David B. 2001. "Racial, Ethnic, and Gender Disparities in Sentencing: Evidence From the US Federal Courts." Journal of Law and Economics, 44:1, 285-314.

Omi, Michael and Howard Winant, 1994. Racial Formation in the United States. New York: Routledge.

Parsons, C. A., J. Sulaeman, M. C. Yates, and D. S. Hamermesh (2011). Strike Three: Discrimination, Incentives, and Evaluation. American Economic Review 101(4), 1410-35.

Price, Joe and Justin Wolfers (2010). Racial Discrimination among NBA Referees. Quarterly Journal of Economics 125(4), 1859-1887.

Rehavi, M Marit and Sonja B Starr. 2014. "Racial Disparity in Federal Criminal Sentences." Journal of Political Economy, 122:6, 1320-1354

Sadowski, W., \& Stanney, K.M. (2002). Presence in virtual environments. In K. M. Stanney (Eds.). Handbook of virtual environments: Design, implementation and applications (pp. 791-806). Mahwah : IEA

Schulman, Kevin A., Jesse A. Berlin, William Harless, Jon F. Kerner, Shyrl Sistrunk, Bernard J. Gersh, D. Phil, Ross Dubé, Christopher K. Taleghani, Jennifer E. Burke, Sankey Williams, John M. Eisenberg, William Ayeand José J. Escarce. 1999, "The Effect of Race and Sex on Physicians' Recommendations for Cardiac Catheterization." New England Journal of Medicine, 340, 618-626.

Shayo, Moses and Asaf Zussman. 2011. "Judicial Ingroup Bias in the Shadow of Terrorism." The Quarterly Journal of Economics, 126:3, 1447-1484.

Shayo, Moses and Asaf Zussman. 2017. "Conflict and the Persistence of Ethnic Bias." American Economic Journal: Applied Economics, 9:4, 137-65.

Slater, M., \& Wilbur, S. 1997. A Framework for Immersive Virtual Environments (FIVE): Speculations on the Role of Presence in Virtual Environments. Presence : Teleoperators and Virtual Environments, 6(6), 603-616.

Yariv, Leeat, Ben Gillen and Erik Snowberg, "Experimenting with Measurement Error: Techniques with Applications to the Caltech Cohort Study," Forthcoming in Journal of Political Economy. 


\section{Appendix 1}

\section{$\underline{\text { The Design and Organization of the VR experiment }}$}

\section{Design of the experiment}

We were granted permission by the district attorney of Limburg (Belgium) to use actual criminal cases as well as actual prosecutors and an actual court room.

\subsection{Selection of cases}

We had an initial discussion with two Belgian prosecutors about the case types which could be suitable for this research purpose. The criteria that were discussed with the prosecutors during the selection process of the case types were:

- the range of the potential sentences allowed by the penal code for a given case type (e.g. we are less interested in cases where the discretionary powers of the judge are limited);

- the complexity of the general case type (e.g. no medical liability cases in which one has to study numerous medical documents to understand the nature of the case)

Burglaries and assaults fit these criteria. Thus, we asked the prosecutors who specialized in either burglaries or assault to each select seven actual cases from the archive (or the docket) so that we could review them. We asked them to consider cases in which the defendant pleaded not guilty in order to avoid clear cut outcomes. After elaborate discussions with the prosecutors on the content of each of these cases, we kept three burglary and three assault case files that were suited for the purpose of this research.

We did not change any actual facts of the cases. The names of the actual victims, however, have been changed to guarantee anonymity of the real cases. We do not use names for the defendants because the names need to fit for both the white and non-white defendant. For the burglaries we changed the location of the facts as well. Given that the actual defendants were in some cases older than our actor-defendants, we changed the age to make it more realistic. Otherwise, no substantive changes were made to the content of the cases.

\subsection{Selection of the court room}

We decided to organize the shooting of all the videos in one court room (keeping it constant over all videos). We reviewed three court rooms in the main court building in Hasselt (Belgium) and decided to use a small court room (which is better for purposes of the 360 degree camera). This court room is in fact also being used for burglaries and assault cases.

\subsection{Selection of prosecutors, lawyers and the judge}

The district attorney informed all prosecutors of the region of Limburg that we were looking for two prosecutors to participate in the experiment. Two prosecutors experienced in (among others) burglary and assault cases and with camera experience volunteered to participate in the experiment.

We also contacted a number of law firms with experience in criminal cases to participate in the experiment. We had five actual criminal lawyers that were eager to participate and after an interview we selected three lawyers (two female and one male) with actual experience in both burglary and assault cases. The lawyers were given the case files one week before the shooting of the videos and we asked them to prepare it similar to an actual court hearing. The lawyers did not talk to the prosecutors before the shooting, in order to keep the courtroom interactions as realistic as possible. 
Given the nature of proceedings in criminal cases in Belgium, we also needed a judge. In Belgium the judge is in control of the court hearing although his actual role is limited. The judge first asks the defendant if he understands the charges being made against him/her. The judge then allows the prosecutor to start with his pleading. Once the prosecutor is finished his presentation, the defense attorney can launch their pleading. At the end of the hearing, the judge sets the time frame for his final decision (normally four weeks after the hearing) and he could potentially ask some questions to the defendant. Our set up with the VR headsets does not allow for the evaluators to interrogate the defendant. It is, however, rather common in Belgian criminal proceedings for the judge not to ask questions. For the sake of realism in our videos, we needed an actual judge to control the flow of proceedings. Therefore, we selected a retired judge from the region of Hasselt to be in control of the cases like he would normally do. He was in fact sitting behind the 360 camera and participants could only hear his voice. This way the setting remained realistic and participants still viewed the cases from the perspective of the judge.

\subsection{Selection of defendants}

We needed three white defendants (each would participate in two cases) and three non-white defendants (each would participate in two cases) for our six cases. We decided to select actors that lived outside of the region where the evaluators are likely to reside (in order to avoid to be actors being recognized). We gave the actor-defendants wardrobe instructions so that the clothing of the pairs of actors was similar.

\subsection{Selection of equipment and the shooting}

We made use of a static 360 camera (OZO) to shoot the cases. The camera was positioned before the bench of the judge and was on the same height as the judge. This way the participants in the experiment observed the court room from the exact same angle as the actual judge. We hired a professional cameraman and a sound technician to make sure that the technical quality was optimal. Given that we shot the cases with a 360 camera, only the actors could be in the actual court room. The technicians were set up in a nearby courtroom where they could watch the camera footage on a monitor.

For each video we shot at least three full takes to make sure that there was a high quality take. After the video-shooting of a given case was completed, the video of the second defendant was shot in the empty courtroom. The production team replaced the former actor-defendant (in the first video) with the latter actor-defendant to generate identical VR videos in which only the defendants differed.
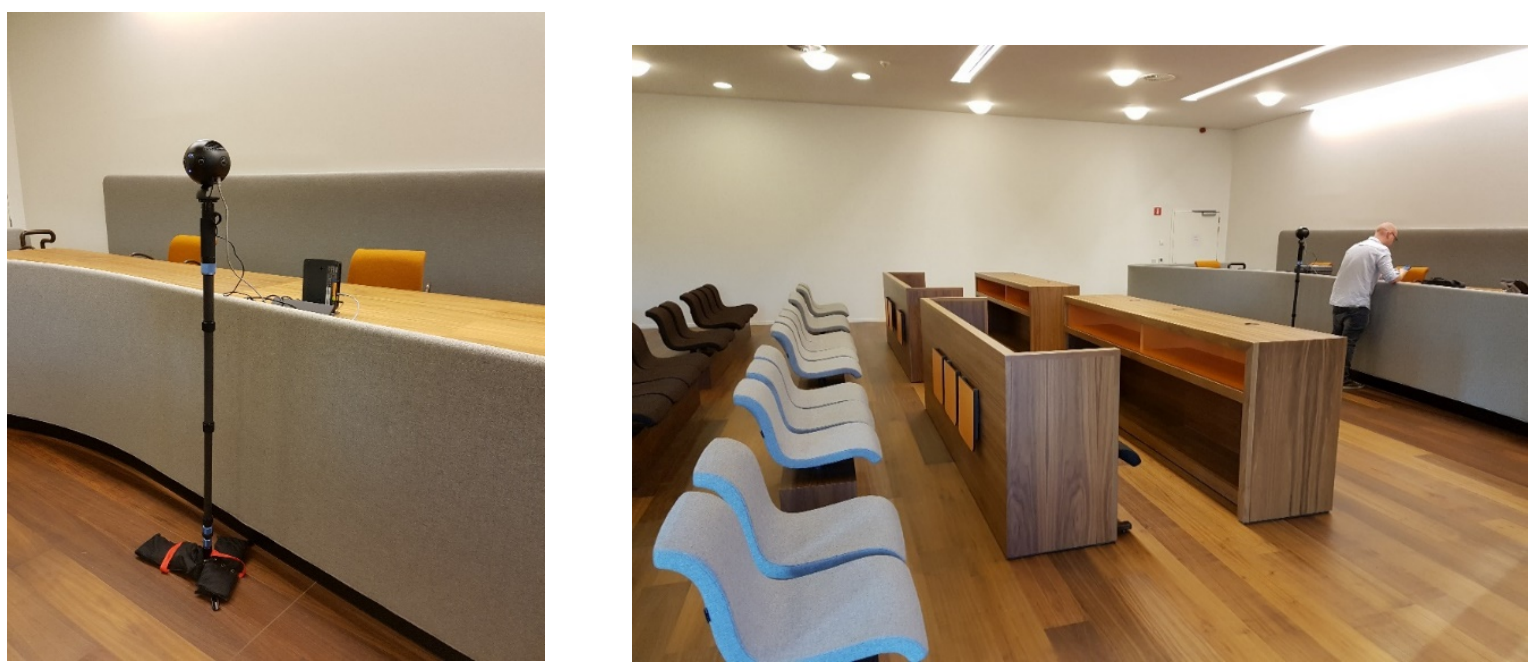


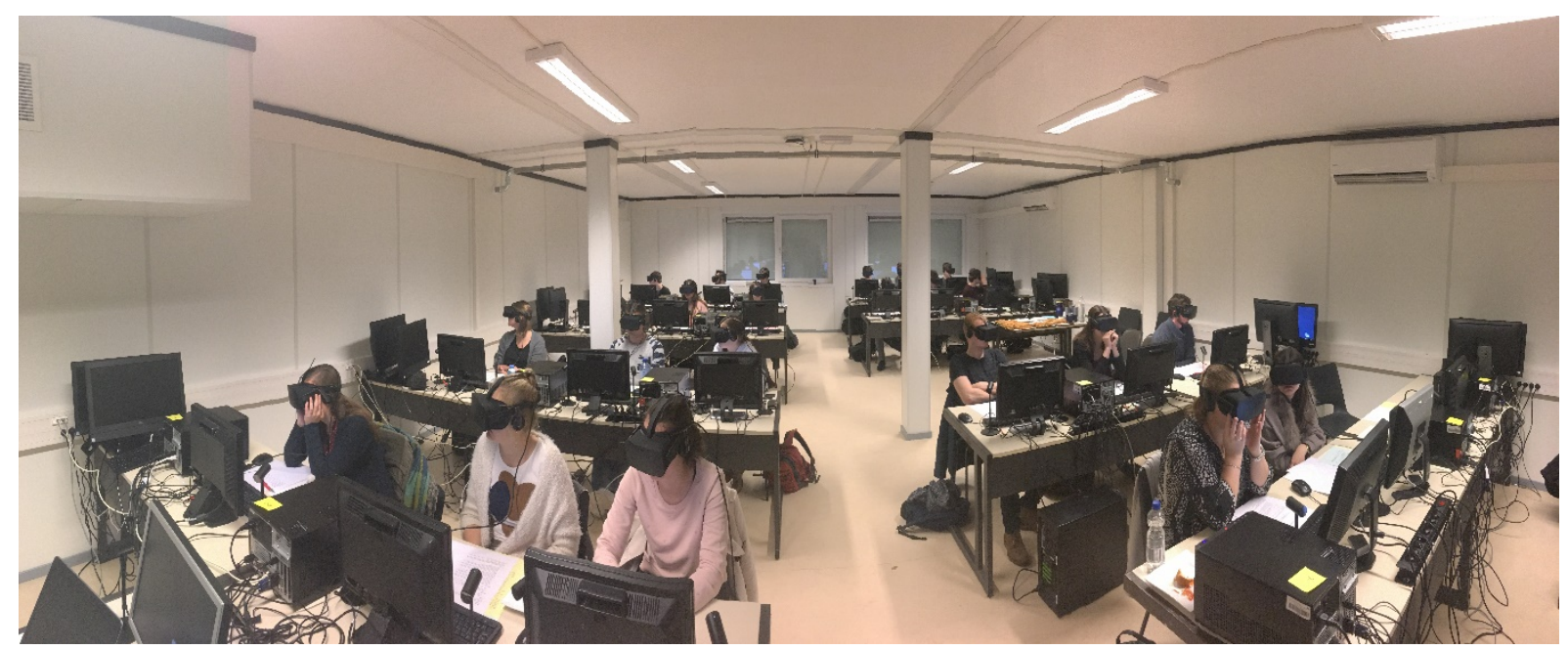

\section{Organization of the experiment}

\subsection{Description of the equipment}

We made use of 25 similar computers with powerful graphic cards. We tested various virtual reality headsets and decided to use the latest Oculus Rift headsets for the participants to wear during the experiment.

\subsection{Description of the students}

For the experiment we involved 153 students from the faculties of Economics and Law of Hasselt University. The Economics students were a mixture of bachelor and masters students who were enrolled in the Policy Evaluation course. The Economics group consisted of in total 86 students. They were randomly subdivided into four groups (given that we only had 25 headsets) to take the experiment. The economics students all took the experiment on the same day (November 21, 2017) and we made sure there was no interaction between the four groups of students. To avoid interaction between the groups, we put them in separate rooms and let them watch a movie (or follow a different course) while one of the other groups was taking the experiment. They were also instructed not to inform each other via mail or phone.

The law students are master students enrolled in Hasselt. They participated in the experiment as part of a course on Research Methods. There were 67 Masters' level law students enrolled in this course and they all took the experiment on November 22, 2017. They were randomly divided into three groups and again we made sure they could not interact with the other groups as long as the experiment was ongoing for one of the groups.

Participants were told that they would participate in an experiment which was an exercise in the adjudication and sentencing. We organized a random lottery (with 20 movie tickets) for students that participated in both the experiment and the follow up survey.

\subsection{Description of the lawyer participants}

In early July 2018 we randomly contacted lawyers via email and phone. We obtained lawyers' contact information from the website of the Limburg bar Association and only selected the ones listed under the category 'criminal law'. We contacted a little over 250 lawyers of which 36 decided to participate in the experiment in July 2018. The lawyers received the same information as the student participants and the flow of the proceedings was identical. The only difference is that the lawyers took the experiment individually during a 10-day period and they were instructed not to talk to anyone about the experiment. 


\subsection{Description of the case folders and the sequence of the cases}

For each of the cases we made a case folder that contained the relevant information. We used a summary of the actual case folders from the cases, and changed the actual names, dates and places to make sure that no one could identify the actual defendant and victims. We also changed the ages of the defendants on the case folders so that they would match our actordefendants. We produced six different cases (three burglaries and three assault) with two versions of each case (one with a white defendant and one with a non-white defendant). This means that in total we had 12 videos for our experiment and each defendant acted in two videos. We made six sets with different sequences of the videos and combinations in order to make sure that each participant would only see each defendant once.

\subsection{Description of the anonymity and the website}

The participants are granted anonymity during the experiment and in the follow-up survey (see Section 3 of the Appendix). Upon entering the computer lab, students had to randomly pick a three digit number from a bowl. After picking the number, the students could randomly pick one of the 25 computers in the lab. Before they could start with the experiment they had to type in the three digit number in a custom made online tool.

For the purpose of the experiment we developed a website that would guide the participants through the experiment. The website contained clear instructions for participants on what to do (when to put on the headsets, when to take of the headsets, when to read a case folder, etc.). The website also communicated with the headset so that the videos would play automatically in the correct order. The experiment took 2 hours, with a five minute break after watching three videos.

Participants first had to read the case folder of a certain case. The folders were color coded to avoid confusion. After reading the case folder students could click on a button to start the video. They had 30 seconds to put on the headsets. After watching the video they could take off the headset and click on the button to go to the deliberation phase.

\subsection{Description of assignment of sentences}

After watching each case video, the students were faced with the choice to either acquit or convict the defendant. The picture below shows the screen students were shown during the deliberation phase.

\section{UHasselt}

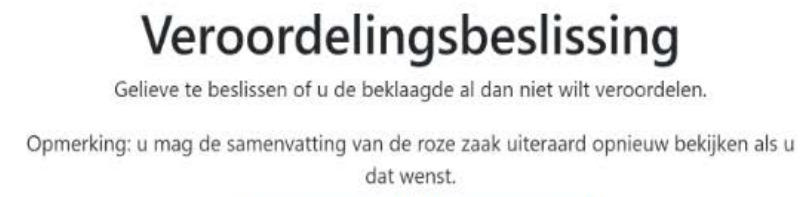

Veroordelen

Vrijspreken

(Translation: Conviction decision: Please indicate whether you want to convict or acquit the defendant. Note: You can read the case folder again if you want. Buttons: Convict; Acquit) 
If the evaluators acquitted the defendant, they would automatically proceed to the next case folder and they were instructed to read the next case folder. If they convicted the defendant they would go to the next screen to assign the sentences (which could be a prison sentence, a fine or a combination of both, depending on the circumstances of the case). For each case the evaluators could assign a sentence that was in accordance with the range prescribed by the penal code (for instance, a prison sentence between 12 months and 60 months). The Belgian criminal code also allows for the suspension of sentences (both for prison sentence and for fine). So the evaluators also had the option to assign a certain sentence and then suspend (part of) the sentence. For example, they could assign a prison sentence of 12 months and suspend 4 months of this sentence. This would mean that the defendant would go to prison for only 8 months, and the other 4 months were suspended. Similar to the actual judge, the participants had the choice of suspending (part of) the prison sentence and/or the fine. Both the law and econ students were given a small lecture (by the same lecturer) on the assignment of sentences before they participated in the experiment. If the penal code prescribes that the actual judge in a certain type of crime has to assign both a prison sentence and a fine or either one of them, we made sure the participants were faced with the same option. See the picture below.

We also made sure the students could not type in values for the postponed sentences that were higher than the total sentences. We also made sure that students could not go outside of the range prescribed by the penal code. The information on the sentence range allowed by the penal code was on the case folders (see the case folders at the end of the annex for the ranges of the sentences for each case).

After making the decision on acquittal or conviction and assigning the sentences for each of the six cases, the students were presented an overview of all their conviction decisions and sentences. They were than informed that they could make changes to their answers. We registered both the initial answers of the students as well as their changed answers.

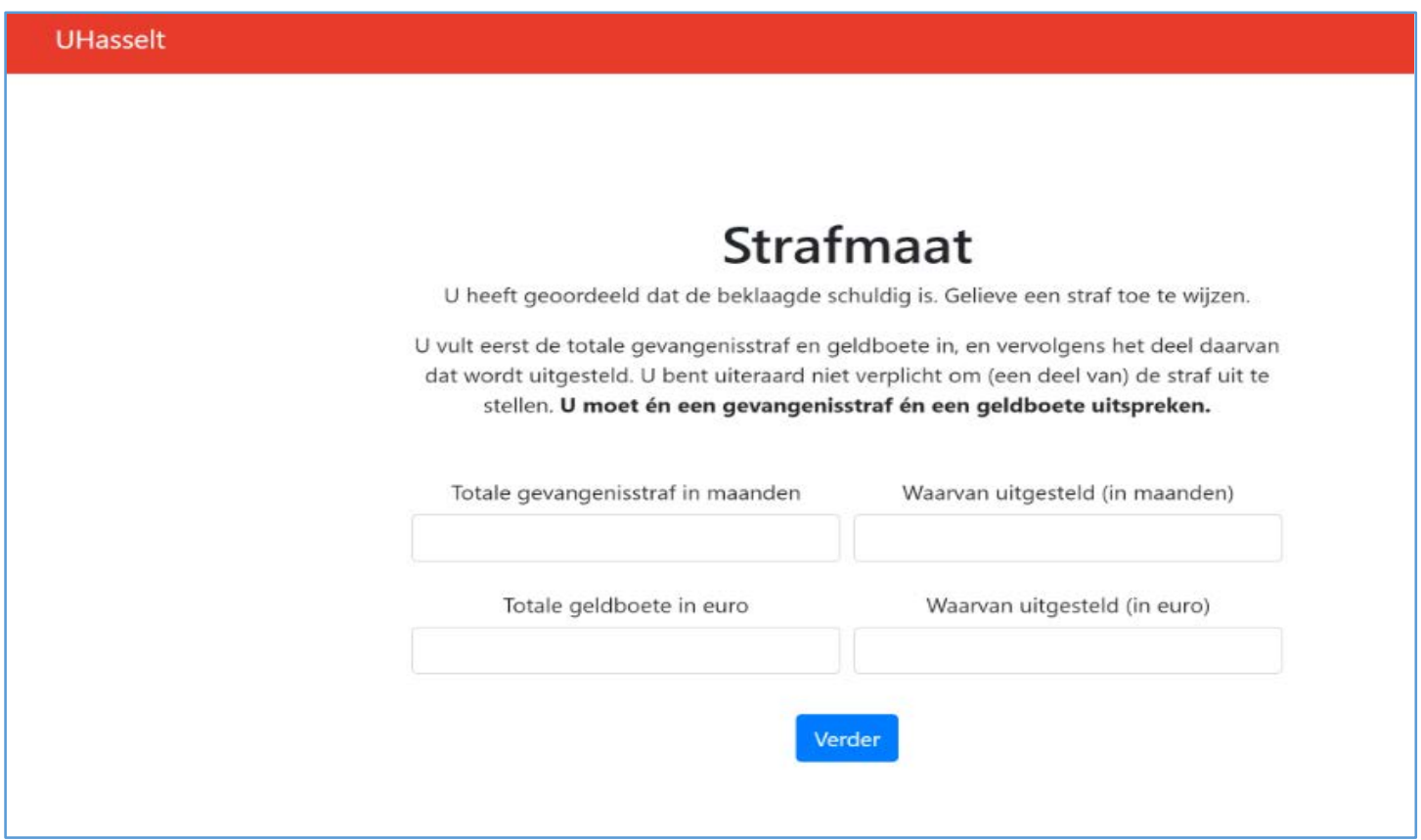

(Translation of text: You have decided that the defendant is guilty. Please assign a sentence. You first have to fill in the total prison sentence and fine, and next you fill in the part of the sentence that is suspended. You can of course not suspend (part of) the sentence. You have to fill in a prison sentence and a fine. Translation of boxes: Total prison sentence in months; postponed prison sentence (in months); Total fine in euro; postponed fine (in euro)) 


\section{Overzicht veroordelingsbeslissingen}

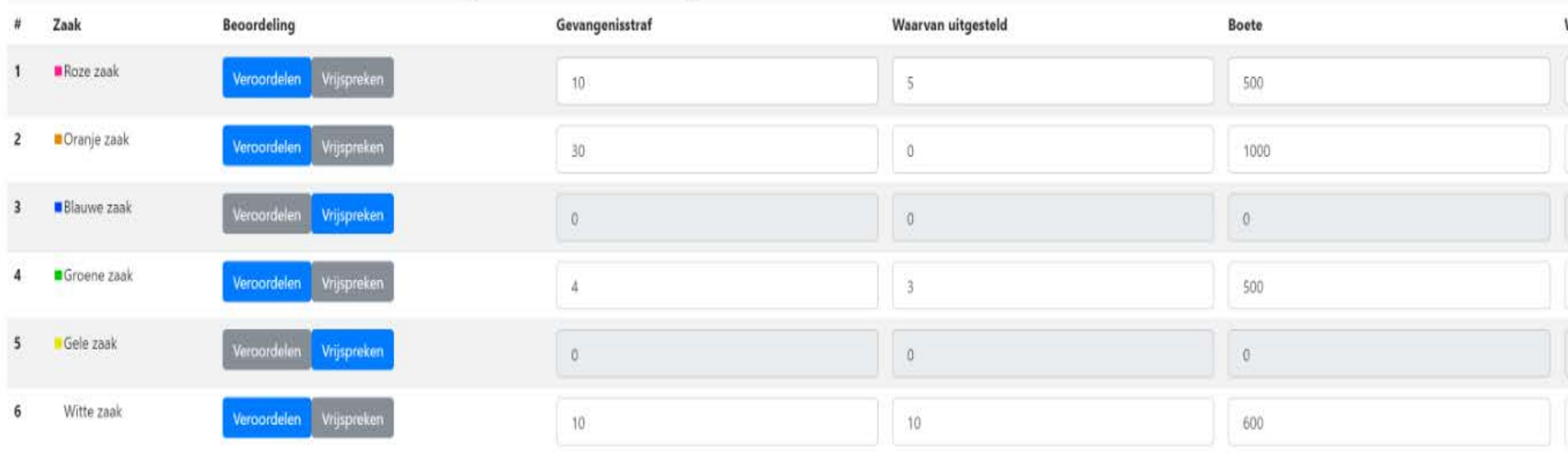

(Translation: Overview conviction decision; \# Case; Decision ; Prison sentence; Postponed prison sentence; Fine; Postponed fine)

\subsection{Description of the testing}

Two weeks prior to the experiment, we had an extensive testing phase. We tested the entire experiment with two groups of respectively 8 and 15 participants (who had no connections to the university). They tested both the functionality and the user friendliness of the online website and the headsets. This lead to the inclusion of a 1 minute instruction video on how to use the headsets in the beginning of the actual experiment. The participants also tested the clarity and terminology of the case folders which lead to minor changes in the wording.

\section{The Follow-up survey}

\subsection{Drafting and testing the survey}

We decided to organize a follow up survey for the participants. For the questions of the survey we made use of questions from the European Social Survey rounds 5 and 8. The survey contained groups of questions on the following topics: personal characteristics of the respondent, crime and migration, institutions, income and human values. We tested the survey on a group of 15 participants to make sure the questions were clear and the total duration of the survey took no more than 12 minutes. The survey was programmed in Qualtrics and was available via an online link. In the beginning of the survey the participants had to fill in the same three digit number in the experiment, this way we were able to match their answers and guarantee their anonymity.

\subsection{Organization of the survey}

We conducted the survey nine days to two weeks after the experiment during a lecture in the respective courses of the economics and law students. All students were informed to bring their laptops to fill in the survey. We send an email to students who were not in class with the link so that they could also fill in the survey. In total 153 of the 165 students that participated in the experiment filled in the survey. These 153 students constitute the sample used in the paper.

For the lawyer participants we registered the survey immediately after the experiment. Race questions were not included in the survey given to lawyers because all lawyers were white. 


\section{Testing the photos of defendants: descent}

To make sure that the defendants that we used in the videos could be clearly identified as white or non-white, we organized a separate experiment with a group of 89 students from Hasselt University. These students were different than the ones who participated in the virtual reality experiment and they were from the first bachelor's year (freshmen). The students saw 7 pictures of males and had to indicate for each picture if they believed the person was of: (a) WesternEuropean descent, (b) Middle Eastern or North African descent or (c) Asian descent. In the beginning of the experiment we explained to the students which type of countries we were thinking of. For Western-European we had Belgium, Netherlands, Germany and France in mind. For Middle-Eastern or North African we had Turkey, Morocco, Syria and Iraq in mind (they have the biggest communities in Belgium). For Asian descent we had China, Japan and South Korea in mind.

The pictures of our actor-defendants were projected on a large screen in the front an auditorium and each student had a separate voting box to indicate their responses. They were not allowed to discuss their answers with each other and had to respond within 30 seconds (all of them responded much faster). We added in a picture of a male that did not appear as a defendant in our videos.

The results from this photo experiment showed that the appearance of our defendants was very clear: there was almost no confusion as to whether our defendant stemmed from Western-European descent or Middle Eastern or North African descent. For three of our defendants all students correctly perceived their descent. For the other defendants either 86 or 87 of the 89 students gave the correct answer about the ancestry of the actor-defendants. This shows that there is little to no doubt as to the descent of our defendants.

We used a different group of 89 students who were enrolled in a freshman Microeconomics course of Business Engineering degree at Hasselt University to test whether the students can correctly identify the race of the actors used in the experiment. These 89 students have not participated in the experiment and presumably have no knowledge of the experiment. The students were in an auditorium and a large screen in the auditorium displayed defendants' pictures one at a time. Under each picture there were options to choose from regarding the racial/ethnic heritage of the person in the picture. The options were: Western European descent, Middle Eastern or North African descent, and Asian descent. Students were told that examples of Western European descent would be countries such as Belgium, Netherlands, Germany and France; Middle Eastern and North African descent would include such countries as Turkey, Morocco, Syria and Iraq, and examples of Asian descent would include countries such as China, Japan and South Korea. Each student had a hand-held device to enter their choices within 30 seconds after each picture was shown. The students were not allowed to talk to each other during this process. In addition to the six defendants in our trials, we added the picture of a young Chinese man for the students to evaluate.

The results showed almost unanimous consensus regarding the racial/ethnic heritage of the individuals in the pictures; and their heritage was identified correctly. Specifically, 97 percent of the students correctly guessed that the first minority defendant was of Middle Eastern/North African descent. All students who participated in this exercise guessed correctly the heritage of the second and third minority defendants. The students guessed with 98 percent accuracy that the first and the second White defendants were of Western European origin (Belgian), and they guessed with 100 percent accuracy that the third white defendant-actor had in fact Western European descent. Also, all students correctly identified the Chinese person as someone of Asian descent. 
Overall the minority defendant-actors have been identified as being a minority with almost 99 percent accuracy, and white defendants are identified correctly as being of Western European descent with 98.5 percent accuracy.

\section{Case descriptions}

\subsection{Burglary 1}

\section{Charge}

Burglary, to the detriment of Frederik Smits and Bram Rogiers (victims). The following goods have been taken: a vehicle BMW 320cd, 100,00 EUR cash, a men's watch with a value of 50,00 EUR and spare keys of the BMW 320.

$\underline{\text { Defendant }}$

- 20 years old

- Unmarried

- Unemployed

\section{Criminal record of the defendant}

- $\quad$ Refusal drug test and driving without driver’s license: fine 2,400 EUR, 3 months driving ban.

- Driving without insurance and without driver's license, with vehicle that does not meet technical requirements of vehicles (motor vehicle inspection) and is not registered: fine of 2,400 EUR, 3 months driving ban.

- Burglary: 3-month prison sentence.

- Burglary by breaking, climbing in, or false keys: 8-month prison sentence.

Police report summary

- Victim Frederik Smits reported a burglary with breaking in his house.

- The forensics investigation for trace evidence in the house does not yield any results with the DNA and fingerprint databank.

- The burglar has gained access by ramming down a wooden door.

- 2 days after the burglary the victim informs the police that a friend has found the missing BMW.

- Forensics conducts an investigation of trace evidence on the car, and finds a fingerprint and DNA on exterior door.

- $\quad$ The fingerprint turns out to be the defendant's.

- House search (with consent defendant) at defendant's does not yield results (stolen goods not found).

- During interrogation the defendant denies having something to do with these facts, and does not know how his fingerprint ended up on the car. He does not know the victim.

- Victim says that he does know the defendant, however, the defendant has never been in his car with him.

Sentence range allowed by the penal code

- In case of conviction the defendant can be sentenced with a prison sentence from 1 month till 60 months and a fine between 156 EUR and 6,000 EUR. 


\subsection{Burglary 2}

\section{Charge}

Burglary, to the detriment of John Peeters and Elke Deferm (victims). The following goods have been taken: a music installation of Bose, a golden watch from Ferrari, parfum of Mugler and Burburry, a HP laptop and 1,000 EUR cash.

$\underline{\text { Defendant }}$

- 22 years old

- Unmarried

- Unemployed

Criminal record of the defendant

- Threatening to attack persons: 3-month prison sentence (suspended) and a fine of 600 EUR (suspended).

- Document fraud: 100 hours of community service.

- Indecent exposure: 2-month prison sentence (suspended).

\section{Police report summary}

- Victim John Peeters reported a burglary with breaking in his house.

- The forensics investigation includes taking trace evidence in the house and on an outside window. The DNA on the outside of the window matches with the DNA of the defendant.

- The defendant denies the facts and has no explanation why his DNA is on the window. He also claims to be physically not capable of breaking into the house due to a broken toe and a malfunctioning knee.

- The defendant admits to have been in the area of the break-in frequently at the time because he had a relationship with someone in the same area.

Sentence range allowed by the penal code

- In case of conviction the defendant can be sentenced with a prison sentence from 1 month till 60 months and a fine between 156 EUR and 6,000 EUR.

\subsection{Burglary 3}

\section{Charge}

Burglary, to the detriment of Tom Bamps (victim). The following goods have been taken: 2 HP laptops, 1 Apple tablet, 1 Rolex watch, 2 golden necklaces and 2,500 EUR cash.

\section{Defendant}

- 23 years old

- Unmarried

- Unemployed

\section{Criminal record of the defendant}

- No criminal record 


\section{Police report summary}

- Victim Tom Bamps reported a burglary with breaking in his house. The victim came home from a night out and finds that the alarm system is not turned on. Upon entering the house he noticed that there had been a burglary. The neighbor indicates she noticed a black Volkwagen Passat standing in front of the house in the evening but she did not notice the number plate.

- $\quad$ The victim claims to have turned on the alarm system before he left the house. The alarm system appears to be working and there is no sign that the alarm system has been tampered with.

- The burglar(s) gained access through a small window in the back of the house that was not protected by the alarm system.

- The alarm system was only installed in the week prior to the break-in. The victim states that one of the technicians was asking a lot of questions on their social activities in the coming weeks. The victim saw him in their street a few days before the burglary.

- The forensic investigation turns up one finger print on the outside of the window that was used by the burglar(s) to gain access to the house.

- Both technicians that installed the alarm system are interrogated. One of them has an alibi for the night of the burglary. The second technician was fired from the company the day before the burglary under suspicion of stealing material from the company.

- The technician denies the allegations of breaking in. He states to have no financial problems and that his parents would support him if he had financial problems.

- The technician owns a black Volkswagen Passat (same model as seen in front of the house the night of the burglary). He claims not to have been in the street at the time of the facts.

- The fingerprint found on the window matches the fingerprint of the technician. He claims that the fingerprint was there because he installed the alarm system the week before the burglary.

Sentence range allowed by the penal code

- In case of conviction the defendant can be sentenced with a prison sentence from 1 month till 60 months and a fine between 208 EUR and 8,000 EUR.

\subsection{Assault 1}

Charge

Intentional assault of partner.

Defendant

- 25 years old

- Unmarried

- Unemployed

\section{Criminal record of the defendant}

- No criminal record

\section{Police report summary}

- $\quad$ Victim and defendant have a relationship for five years and have a 3-yeor old son together. 
- There was an argument between the victim and the defendant, because he was not allowed to take the son to a family gathering.

- The victim tried to film the argument with her smartphone and the defendant grabbed the smartphone and smashed it. The victim states that the defendant than grabbed her and threw her on the table and on the ground. The defendant says she lost her balance and fell but that he was not behaving violently.

- The victim says she managed to get upstairs and call the police with another cell phone.

- The police see no apparent injuries on the victim. The police also see no signs on the table of a fight.

- The victim goes to the hospital on the same day and the medical record shows that she has pain in the neck, nausea and a tingling feeling in both her arms. The defendant claims that she had these complaints for an entire year and it has nothing to do with the argument.

- The victim claims that he has been aggressive before and hit her on multiple occasions in front of their son. The police was called to the house a year ago, but no police report was filed.

- The victim and the defendant decide to live in the same house for financial reasons. Once they sell the house, they will each go their own way.

Sentence range allowed by the penal code

In case of conviction the defendant can be sentenced with a prison sentence from 4 months till 24 months and a fine between 300 EUR and 1,200 EUR.

\subsection{Assault 2}

Charge

Intentional assault of partner.

Defendant

- 24 years old

- Married

- Employed

\section{Criminal record of the defendant}

- $\quad$ No criminal record

\section{Police report summary}

- Victim calls the police and claims that the husband has locked her in the house.

- Police enter the house through a window.

- Victim says that she and her husband have been problems for 6 months.

- Victim claims that her husband destroyed her clothes three weeks ago and strangled her in front of their 2 year old son. She shows the police pictures of her injured neck but she did not file it.

- Victim claims that her husband hit her and locked her in the house.

- The defendant claims that he did not hit his wife, and that she has a key so that she could have left the house. He claims to have never hit his wife and that she destroyed her own clothes three weeks ago. 
- The defendants sister is interrogated and claims that the victim lived with her for a while because of the problems in her marriage. The sister claims that she could not believe that her own brother would use violence and states that the victim was aggressive herself.

Sentence range allowed by the penal code

In case of conviction the defendant can be sentenced with a prison sentence from 3 months till 24 months and a fine between 208 EUR and 1,600 EUR.

\subsection{Assault 3}

\section{Charge}

Intentional assault of partner.

Defendant

- 23 years old- Unmarried - Employed

Criminal record of the defendant

- Driving under influence: loss of driver's license for a month and 1,100 EUR fine.

- Driving under influence: loss of driver's license for 4 months.

- Document fraud: 7 months prison sentence (suspended) and fine (962.5 EUR).

- Online fraud: 6 months prison sentence and fine (600 EUR).

\section{Police report summary}

- Police are called to the house for a domestic dispute. The police have been at the house before for domestic disturbances while both partners are drunk.

- Police find a broken glass on the kitchen sink and hairs of the victim on the stairs.

- The victim goes to the doctor to document the injuries and provides the police with previous reports of injuries which she claims have been caused by the defendant.

- The argument started the previous day during a night out at a bar, when the defendant claimed that the victim was hanging around other men. The defendant left irritated and his partner stayed there. She did not come home that night, but only around noon the next day. The victim claimed to spent the night at a friend's place, while the defendant claims that she spent the night with another man. When she arrived at home, the couple started to have the argument.

- The victim claims that the defendant pulled her by her hairs throughout the house. After that she claims he pushed her down the stairs. The defendant denies to have hit her. He claims that she fell from the stairs herself (without him pushing her) and that he did aggressively tried to help her up by pulling her hair.

- Both of them admit to drink too much. The defendant claims that the victim has a real problem.

- The DA's office has tried mediation in this case to avoid it coming to court, but the mediation was not successful.

- The couple is back together at the moment of the trial.

Sentence range allowed by the penal code

In case of conviction the defendant can be sentenced with a prison sentence from 1 month till 12 months and a fine between 156 EUR and 600 EUR. 
Appendix 2

Table A2-1

In-group Bias in Conviction Decisions Models with Evaluator Fixed Effects

\begin{tabular}{lccc}
\hline \hline & $(1)$ & $(2)$ & $(3)$ \\
\cline { 2 - 4 } Minority Defendant & $0.105^{* * *}$ & $0.103^{* * *}$ & $0.110^{* * *}$ \\
Minority Defendant & $(0.028)$ & $(0.029)$ & $(0.026)$ \\
x Minority Evaluator & $(0.074$ & 0.070 & 0.089 \\
Early Trial & $-0.118^{* * *}$ & $(0.102)$ & $(0.087)$ \\
& $(0.029)$ & $(0.028)$ & $(0.030)$ \\
Assault Case & & $-0.105^{* * *}$ & \\
Observations & 918 & $(0.029)$ & \\
Number of & 153 & 918 & 918 \\
Evaluators & & 153 & 153 \\
Evaluator FE & Yes & Yes & Yes \\
Trial FE & No & No & Yes \\
\hline \hline
\end{tabular}

Early Trial dummy $=1$ if the trial is one of the first three trials watched by that evaluator. Standard errors are clustered at the evaluator level. ${ }^{* * *} \mathrm{p}<0.01, * *$ $\mathrm{p}<0.05, * \mathrm{p}<0.1$

Table A2-2

Overall Racial Bias in Conviction Decisions Models with Evaluator Fixed Effects

\begin{tabular}{|c|c|c|c|}
\hline & $(1)$ & (2) & (3) \\
\hline Minority Defendant & $\begin{array}{c}0.113 * * * \\
(0.027)\end{array}$ & $\begin{array}{c}0.111^{* * *} \\
(0.028)\end{array}$ & $\begin{array}{c}0.120 * * * \\
(0.025)\end{array}$ \\
\hline Early Trial & $\begin{array}{c}-0.117^{* * * *} \\
(0.029)\end{array}$ & $\begin{array}{c}-0.127 * * * \\
(0.028)\end{array}$ & $\begin{array}{c}-0.101 * * * \\
(0.030)\end{array}$ \\
\hline Assault Case & & $\begin{array}{c}-0.105^{* * *} \\
(0.029)\end{array}$ & \\
\hline Observations & 918 & 918 & 918 \\
\hline Number of Evaluators & 153 & 153 & 153 \\
\hline Evaluator FE & Yes & Yes & Yes \\
\hline Trial FE & No & No & Yes \\
\hline
\end{tabular}


Appendix 2

Table A2-3

In-group Bias in Prison Sentencing-

Models with Evaluator Fixed Effects

\begin{tabular}{|c|c|c|c|}
\hline \multicolumn{4}{|c|}{ A: Regressions using trimmed sample } \\
\hline & $(1)$ & $(2)$ & (3) \\
\hline Minority Defendant & $\begin{array}{c}1.345^{* * *} \\
(0.452)\end{array}$ & $\begin{array}{c}1.340 * * * \\
(0.440)\end{array}$ & $\begin{array}{c}1.417 * * * \\
(0.445)\end{array}$ \\
\hline $\begin{array}{l}\text { Minority Defendant } \\
\text { x Minority Evaluator }\end{array}$ & $\begin{array}{l}-3.129 * * * \\
(1.185)\end{array}$ & $\begin{array}{c}-3.109 * * * \\
(1.143)\end{array}$ & $\begin{array}{c}-3.203 * * * \\
(1.123)\end{array}$ \\
\hline Early Trial & $\begin{array}{c}-1.341^{* * *} \\
(0.409)\end{array}$ & $\begin{array}{c}-1.566 * * * \\
(0.358)\end{array}$ & $\begin{array}{c}-1.327 * * * \\
(0.414)\end{array}$ \\
\hline Observations & 618 & 618 & 618 \\
\hline Number of Evaluators & 152 & 152 & 152 \\
\hline Evaluator FE & Yes & Yes & Yes \\
\hline Trial FE & No & No & Yes \\
\hline \multicolumn{4}{|c|}{ B: Regressions using untrimmed sample } \\
\hline & $(1)$ & $(2)$ & $(3)$ \\
\hline Minority Defendant & $\begin{array}{l}0.797^{*} \\
(0.407)\end{array}$ & $\begin{array}{l}0.870 * * \\
(0.406)\end{array}$ & $\begin{array}{l}0.992 * * \\
(0.404)\end{array}$ \\
\hline $\begin{array}{l}\text { Minority Defendant } \\
\text { x Minority Evaluator }\end{array}$ & $\begin{array}{l}-3.146 * * * \\
(1.033)\end{array}$ & $\begin{array}{l}-3.167 * * * \\
(1.051)\end{array}$ & $\begin{array}{c}-3.118 * * * \\
(1.010)\end{array}$ \\
\hline Early Trial & $\begin{array}{c}-1.150 * * * \\
(0.363)\end{array}$ & $\begin{array}{c}-1.417 * * * \\
(0.322)\end{array}$ & $\begin{array}{c}-1.241^{* * *} \\
(0.380)\end{array}$ \\
\hline Observations & 670 & 670 & 670 \\
\hline Number of Evaluators & 152 & 152 & 152 \\
\hline Evaluator FE & Yes & Yes & Yes \\
\hline Trial FE & No & No & Yes \\
\hline
\end{tabular}

Models in column (1) include Evaluator Fixed Effects. Models in column (2) include Evaluator Fixed Effects and Assault Case. Models in column (3) include Evaluator Fixed Effects and Trial Fixed Effects. Standard errors are clustered at the evaluator level. ${ }^{* * *} \mathrm{p}<0.01,{ }^{* *} \mathrm{p}<0.05,{ }^{*} \mathrm{p}<0.1$ 


\section{Appendix 2}

Table A2-4

Overall Racial Bias in Prison SentencingModels with Evaluator Fixed Effects

\begin{tabular}{lccc}
\hline \hline \multicolumn{4}{c}{ A: Regressions using trimmed sample } \\
\cline { 2 - 4 } Minority Defendant & $(1)$ & $(2)$ & $(3)$ \\
\cline { 2 - 4 } & $\left(0.036^{* *}\right.$ & $1.034^{* *}$ & $1.102^{* * *}$ \\
Early Trial & $-1.346^{* * *}$ & $(0.416)$ & $(0.418)$ \\
& $(0.412)$ & $\left(0.361^{* * *}\right.$ & $-1.349^{* * *}$ \\
\hline Observations & 618 & 618 & $(0.422)$ \\
Number of Evaluators & 152 & 152 & 618 \\
Evaluator FE & Yes & Yes & Yes \\
\hline \multicolumn{4}{c}{ B: Regressions using untrimmed sample } \\
\hline \multirow{4}{*}{ Minority Defendant } & $(1)$ & $(2)$ & $(3)$ \\
\cline { 2 - 4 } & 0.457 & 0.528 & $0.660^{*}$ \\
Early Trial & $(0.384)$ & $(0.384)$ & $(0.379)$ \\
& $-1.162^{* * *}$ & $-1.428^{* * *}$ & $-1.274 * * *$ \\
Observations & $(0.366)$ & $(0.327)$ & $(0.387)$ \\
Number of Evaluators & 670 & 670 & 670 \\
Evaluator FE & 152 & 152 & 152 \\
\hline \hline
\end{tabular}

Models in column (1) include Evaluator Fixed Effects. Models in column (2) include Evaluator Fixed Effects and Assault Case. Models in column (3) include Evaluator Fixed Effects and Trial Fixed Effects. Standard errors are clustered at the evaluator level. *** $\mathrm{p}<0.01$, ** $\mathrm{p}<0.05$, ${ }^{*} \mathrm{p}<0.1$ 
Appendix 2

Table A2-5

In-group Bias in Fines-

Models with Evaluator Fixed Effects

\begin{tabular}{lccc}
\hline \hline \multicolumn{4}{c}{ A: Regressions using trimmed sample } \\
\cline { 2 - 4 } Minority Defendant & $(1)$ & $(2)$ & $(3)$ \\
Minority Defendant & $(0.219)$ & $(0.218)$ & $(0.210)$ \\
x Minority Evaluator & -0.872 & -0.870 & -0.788 \\
& $(0.576)$ & $(0.581)$ & $(0.609)$ \\
Early Trial & $1.054^{* * *}$ & $1.035^{* * *}$ & $0.686^{* * *}$ \\
& $(0.245)$ & $(0.244)$ & $(0.253)$ \\
\hline Observations & 618 & 618 & 618 \\
Number of Evaluators & 152 & 152 & 152 \\
Evaluator FE & Yes & Yes & Yes \\
Trial FE & No & No & Yes \\
\hline \multicolumn{4}{c}{ B: Regressions using untrimmed sample } \\
\hline \multirow{4}{*}{ Minority Defendant } & $(1)$ & $(2)$ & $(3)$ \\
\cline { 2 - 4 } Minority Defendant & $0.623^{* * *}$ & $0.629^{* * *}$ & $0.610^{* * *}$ \\
X Minority Evaluator & $(0.212)$ & $(0.211)$ & $(0.208)$ \\
Early Trial & -0.878 & -0.880 & -0.828 \\
& $(0.606)$ & $(0.613)$ & $(0.632)$ \\
Observations & $0.986^{* * *}$ & $0.964^{* * *}$ & $0.672^{* * *}$ \\
Number of Evaluators & $(0.237)$ & $(0.236)$ & $(0.244)$ \\
Evaluator FE & 670 & 670 & 670 \\
Trial FE & 152 & 152 & 152 \\
\hline \hline
\end{tabular}

Models in column (1) include Evaluator Fixed Effects. Models in column (2) include Evaluator Fixed Effects and Assault Case. Models in column (3) include Evaluator Fixed Effects and Trial Fixed Effects. Standard errors are clustered at the evaluator level. ${ }^{* * *} \mathrm{p}<0.01,{ }^{* *} \mathrm{p}<0.05,{ }^{*} \mathrm{p}<0.1$ 
Appendix 2

Table A2-6

Overall Racial Bias in Fines-

Models with Evaluator Fixed Effects

\begin{tabular}{lccc}
\hline \hline \multicolumn{4}{c}{ A: Regressions using trimmed sample } \\
\hline \multirow{4}{*}{ Minority Defendant } & $(1)$ & $(2)$ & $(3)$ \\
\cline { 2 - 4 } & $0.951^{* * *}$ & $0.951^{* * *}$ & $0.954^{* * *}$ \\
Early Trial & $(0.206)$ & $(0.205)$ & $(0.199)$ \\
& $1.052^{* * *}$ & $1.034^{* * *}$ & $0.681^{* * *}$ \\
& $(0.244)$ & $(0.244)$ & $(0.253)$ \\
\hline Observations & 618 & 618 & 618 \\
Number of Evaluators & 152 & 152 & 152 \\
Evaluator FE & Yes & Yes & Yes \\
\hline \multicolumn{4}{c}{ B: Regressions using untrimmed sample } \\
\hline \multirow{4}{*}{ Minority Defendant } & $(1)$ & $(2)$ & $(3)$ \\
\cline { 2 - 4 } Early Trial & $0.529^{* * *}$ & $0.534^{* * *}$ & $0.522^{* * *}$ \\
& $(0.201)$ & $(0.200)$ & $(0.198)$ \\
\hline Observations & $0.982^{* * *}$ & $0.961^{* * *}$ & $0.663^{* * *}$ \\
Number of Evaluators & $(0.236)$ & $(0.236)$ & $(0.244)$ \\
Evaluator FE & 670 & 670 & 670 \\
\hline \hline
\end{tabular}

Models in column (1) include Evaluator Fixed Effects. Models in column (2) include Evaluator Fixed Effects and Assault Case. Models in column (3) include Evaluator Fixed Effects and Trial Fixed Effects. Standard errors are clustered at the evaluator level. ${ }^{* * *} \mathrm{p}<0.01,{ }^{* *} \mathrm{p}<0.05,{ }^{*} \mathrm{p}<0.1$ 
Appendix 2

Table A2-7

In-group Bias in Prison Sentencing

Dependent Variable: Effective Prison Sentence (months)

Defendants who are Found Not Guilty are included in the Sample with Prison Sentence $=0$

\begin{tabular}{lcccc}
\hline \hline & $(1)$ & $(2)$ & $(3)$ & $(4)$ \\
\cline { 2 - 5 } Minority Defendant & $1.057^{* *}$ & $1.097^{* * *}$ & $1.097^{* * *}$ & $1.097^{* * *}$ \\
& $(0.408)$ & $(0.389)$ & $(0.393)$ & $(0.390)$ \\
Minority Evaluator & 1.022 & 0.993 & 1.031 & 1.052 \\
Minority Defendant & $(0.938)$ & $(0.912)$ & $(0.890)$ & $(0.900)$ \\
X Minority Evaluator & $-2.424^{* *}$ & $-2.366^{* *}$ & $-2.315^{* *}$ & $-2.366^{* *}$ \\
Law Student & $(0.989)$ & $(0.918)$ & $(0.928)$ & $(0.919)$ \\
& -0.544 & -0.544 & -0.263 & -0.268 \\
Observations & $(0.463)$ & $(0.464)$ & $(0.484)$ & $(0.480)$ \\
Trial FE & 918 & 918 & 918 & 918 \\
\hline \hline
\end{tabular}

Effective Prison Sentence is equal to initial prison sentence minus suspended sentence. Acquittals are coded as a zero effective prison sentence. Models in column (1) include Early Trial and Assault Case dummies. Models in column (2) include Trial Fixed Effects. Models in column (3) include Trial Fixed Effects, Male Evaluator and Early Trial. Models in column (4) include Trial Fixed Effects, Male Evaluator and Sequence dummies. Standard errors are clustered at the evaluator level. ${ }^{* * *} \mathrm{p}<0.01,{ }^{* *} \mathrm{p}<0.05,{ }^{*} \mathrm{p}<0.1$

Table A2-8

Overall Racial Bias in Prison Sentencing

Dependent Variable: Effective Prison Sentence (months)

Defendants who are Found Not Guilty are included in the Sample with Prison Sentence $=0$

\begin{tabular}{lcccc}
\hline \hline & $(1)$ & $(2)$ & $(3)$ & $(4)$ \\
\cline { 2 - 5 } Minority Defendant & $0.788^{* *}$ & $0.836^{* *}$ & $0.842^{* *}$ & $0.836^{* *}$ \\
& $(0.380)$ & $(0.358)$ & $(0.360)$ & $(0.358)$ \\
Law Student & -0.527 & -0.527 & -0.250 & -0.255 \\
& $(0.457)$ & $(0.458)$ & $(0.477)$ & $(0.474)$ \\
Male Evaluator & & & $0.905^{*}$ & $0.865^{*}$ \\
& & & $(0.496)$ & $(0.518)$ \\
\hline Observations & 918 & 918 & 918 & 918 \\
\hline \hline
\end{tabular}

Effective Prison Sentence is equal to initial prison sentence minus suspended sentence. Acquittals are codes as having received zero effective prison sentence. Models in column (1) include Early Trial and Assault Case dummies. Acquittals are coded as a zero effective prison sentence. Models in column (2) include Trial Fixed Effects. Models in column (3) include Trial Fixed Effects and Early Trial. Models in column (4) include Trial Fixed Effects and Sequence dummies. Standard errors are clustered at the evaluator level. *** $\mathrm{p}<0.01, * * \mathrm{p}<0.05, * \mathrm{p}<0.1$ 


\section{Appendix 2}

Table A2-9

In-group Bias in Fines

Dependent Variable: Effective Fine (log Euros)

Defendants who are Found Not Guilty are included in the Sample with Fine (log Euros) $=0$

\begin{tabular}{lcccc}
\hline \hline \multirow{3}{*}{ Minority Defendant } & $(1)$ & $(2)$ & $(3)$ & $(4)$ \\
\cline { 2 - 5 } & $0.771^{* * *}$ & $0.790^{* * *}$ & $0.790^{* * *}$ & $0.790^{* * *}$ \\
Minority Evaluator & $(0.190)$ & $(0.188)$ & $(0.189)$ & $(0.189)$ \\
Minority Defendant & 0.675 & 0.643 & 0.626 & 0.630 \\
X Minority Evaluator & $(0.595)$ & $(0.580)$ & $(0.583)$ & $(0.595)$ \\
Law Student & $(0.661)$ & -0.157 & -0.160 & -0.157 \\
& $-0.417^{*}$ & $-0.417^{*}$ & $-0.501^{*}$ & $(0.619)$ \\
Observations & $(0.251)$ & $(0.251)$ & $(0.269)$ & $(0.269)$ \\
Trial FE & 918 & 918 & 918 & 918 \\
\hline \hline
\end{tabular}

Effective Fine is equal to initial fine minus suspended fine. Acquittals are codes as having received one Euro of effective fine (log effective fine=0). Models in column (1) include Early Trial and Assault Case dummies. Acquittals are coded as a zero effective fine. Models in column (2) include Trial Fixed Effects. Models in column (3) include Trial Fixed Effects, Male Evaluator and Early Trial. Models in column (4) include Trial Fixed Effects, Male Evaluator and Sequence dummies. Standard errors are clustered at the evaluator level. ${ }^{* * *} \mathrm{p}<0.01,{ }^{* *} \mathrm{p}<0.05,{ }^{*} \mathrm{p}<0.1$

Table A2-10

Overall Racial Bias in Fines

Dependent Variable: Effective Fine (log Euros)

Defendants who are Found Not Guilty are included in the Sample with Fine (log Euros) $=0$

\begin{tabular}{lcccc}
\hline \hline \multirow{3}{*}{ Minority Defendant } & $(1)$ & $(2)$ & $(3)$ & $(4)$ \\
\cline { 2 - 5 } & $0.746^{* * *}$ & $0.772^{* * *}$ & $0.772^{* * *}$ & $0.772^{* * *}$ \\
Law Student & $(0.183)$ & $(0.179)$ & $(0.179)$ & $(0.179)$ \\
& $-0.469^{*}$ & $-0.469^{*}$ & $-0.556^{* *}$ & $-0.566^{* *}$ \\
Male Evaluator & $(0.243)$ & $(0.244)$ & $(0.258)$ & $(0.259)$ \\
& & & -0.285 & -0.325 \\
& & & $(0.258)$ & $(0.256)$ \\
\hline Observations & 918 & 918 & 918 & 918 \\
\hline \hline
\end{tabular}

See notes to Table A2-9. 